\title{
Insulin-induced endothelial cell proliferation and viability in stretched murine skin and cell culture
}

Carl D. Shrader Jr.

West Virginia University

Follow this and additional works at: https://researchrepository.wvu.edu/etd

\section{Recommended Citation}

Shrader, Carl D. Jr., "Insulin-induced endothelial cell proliferation and viability in stretched murine skin and cell culture" (2007). Graduate Theses, Dissertations, and Problem Reports. 2584.

https://researchrepository.wvu.edu/etd/2584

This Dissertation is protected by copyright and/or related rights. It has been brought to you by the The Research Repository @ WVU with permission from the rights-holder(s). You are free to use this Dissertation in any way that is permitted by the copyright and related rights legislation that applies to your use. For other uses you must obtain permission from the rights-holder(s) directly, unless additional rights are indicated by a Creative Commons license in the record and/ or on the work itself. This Dissertation has been accepted for inclusion in WVU Graduate Theses, Dissertations, and Problem Reports collection by an authorized administrator of The Research Repository @ WVU.

For more information, please contact researchrepository@mail.wvu.edu. 
Insulin-induced Endothelial Cell Proliferation and Viability in Stretched Murine Skin and Cell Culture

Carl D. Shrader Jr.

Dissertation submitted to the School of Medicine at West Virginia University

in partial fulfillment of the requirements

for the degree of

Doctor of Philosophy

in

Anatomy

Frank D. Reilly, Ph.D., Chair

Eugene V. Cilento, Ph.D.

Holly G. Ressetar, Ph.D.

Jia Luo, Ph.D.

Richard D. Dey, Ph.D.

Department of Neurobiology and Anatomy

Morgantown, West Virginia

2007

Keywords: insulin, viability, endothelial cell, proliferation, survival, acute stretch, skin, PI3-K, Akt, VEGF, PCNA, wound healing 


\section{ABSTRACT \\ Insulin-induced Endothelial Cell Proliferation and Viability in Stretched Murine Skin and Cell Culture}

\section{Carl D. Shrader Jr.}

We developed a novel in vivo model utilizing acute stretch to investigate endothelial cell (EC) proliferation as a marker of vascular growth in healing SKH1 mouse skin. We also used human umbilical vein endothelial cells (HUVECs) as an in vitro model system to validate postulated tissue insulin-mediated signal transduction pathway(s) using paradigms that would prove lethal in the animal model.

Dorsal distally based flaps of skin were stretched for 3 min using linear (skin hook) plus hemispherical load cycling (inflated subcutaneous silicone catheter). Unstretched, wounded skin along the back and sternum served as postoperative controls. Laser Doppler flowmetry demonstrated a three-fold increase in flap perfusion at postoperative day 7. A stretch-induced six-fold increase in EC mitogenesis accompanied enhancements in blood flow and extracorporal wound healing over the sternum. Western blots revealed upregulation / activation of insulin and mitogenic signaling intermediates in stretched skin. Activated insulin and insulin growth factor receptors (pIR/pIGFR), protein kinase B (Akt, pAkt), vascular endothelial growth factor (VEGF) and vascular endothelial growth factor receptor 2 (flk-1) were among the identified stretch-responsive intermediates. These results indicated the benefits of acute stretch are mediated through enhanced vascularity as evidenced by EC mitogenesis and up-regulation / activation of insulin and key angiogenic effectors in dorsal distally based skin flaps. 


\section{DEDICATION}

This dissertation is dedicated to the memory of my grandfather, Thomas Harrison Shrader. He was always there through good and bad, no matter how great or small. It was his support and guidance that taught me the importance of passion in all that one does. In his words, it is our passion, perseverance and faith that will allow us to become successful. Today, I can only reminisce of his words and the times we shared. As I conclude this portion of my life and embark on a new adventure, I find myself uneasy with what lies ahead as it is the first major event of my life in the absence of granddad's counsel. However, he taught me to believe in the following: when you come to the edge of all that you are and know, you must believe one of two things; there will be earth to stand on, or you will be given wings to fly - unknown author. 
Colorimetric analyses (MTT based) demonstrated that insulin enhances proliferation and viability of HUVECs. Western blot analysis revealed insulin induces the up-regulation and activation of mitogenic signaling intermediates in ECs. Activated insulin and insulin growth factor receptors (pIR / pIGFR), protein kinase $B\left(\mathrm{pAkt}_{308}, \mathrm{pAkt}_{473}\right)$ and vascular endothelial growth factor (VEGF) were the insulin-responsive intermediates in HUVECs. The beneficial effects of insulin were abrogated by the inhibition of IR / IGFR or phosphoinositide kinase-3 (PI3$\mathrm{K})$, indicating that insulin-induced EC proliferation and viability are mediated through pIR / pIGFR and PI3-K effectors.

Together the data from in vivo and in vitro studies provide new knowledge about the beneficial effects of insulin on vascularization and tissue viability, providing a mechanistic link to enhanced wound healing in acutely stretched skin. 


\section{PREFACE}

This dissertation will begin with a review of the literature that constitutes the scientific foundation on which this research was based. The studies that constitute the dissertation work will then be presented in manuscript form, followed by a general unified discussion of the findings. 


\section{ACKNOWLEDGEMENTS}

I would like to express my sincerest and deepest appreciation to my advisor and mentor, Dr. Frank D. Reilly. Dr. Reilly has always been available for guidance and support both professionally and personally. His unrelenting commitment to my success will never be surmounted. When others questioned my potential, he stood beside me. Together, we have experienced change that significantly altered our professional experiences. In the face of these changes, he taught me to take the high road, even in the wake of significant adversity. I could have never developed into the person I am today without his instruction. I can genuinely say he is my academic father. In addition, I would like to express my gratitude to the members of my research advisory committee: Dr. Eugene V. Cilento for his friendship and support, in spite of our differing political views. This research would not be possible without Dr. Cilento's financial contribution (WVU College of Engineering and Mineral Resources; account \#: DA310880010 fund \#: 11100124); Dr. Holly G. Ressetar for all of her expert advice and help with immunohistochemical techniques. She always had time to talk and a smile to share; Dr. Jia Luo for his significant contribution in the development of the cellular and molecular experiments, as well as, donating lab space for performing the research; and Dr. Richard D. Dey for providing solid feedback on experimental design that enabled this project to be successful. Dr. Dey also allocated funds that made this research possible (WVU Department of Neurobiology and Anatomy; account \#: DA491030020 fund \#: 12301430). 
Special thanks to Dr. Jun Liu and the members of his laboratory for their contribution to the in vitro assays presented in this dissertation. Sincerest gratitude to Dr. Greg Konat - he worked as hard as any committee member to assure a strong, successful research dissertation. I would also like to thank Mrs. Pat Turner in the Department of Pathology for her friendship and technical assistance throughout my histochemical analyses. My extended appreciation to Mrs. Janice Shaw (a.k.a. Mama J) for being there when I just needed a mom. I would also like to recognize the contributions of my closest friends and allies, Mr. Cary Johnson, Mr. Jeffrey Altemas, Mr. Robert Bolyard, Mr. Joshua Barker, Mr. Brent Lally, Dr. Penny Klickhachorn, and Mrs. Claire Noel for their support and encouragement - you were always there for me.

I would like to recognize the faculty and staff in the Department of Neurobiology and Anatomy. Many of you represent and embody that which is great in this world. To Lois Corbin, Roberta Gasper and Debra Buchanan thanks for all the hugs and words of encouragement at those necessary moments. May God bless each of you and your future undertakings.

Lastly, and most importantly, I am grateful and thankful for all opportunities God has given me. This would not be possible without his blessing. I ask God to direct my future endeavors and place me where I can make the greatest contribution. Accept my talents, great or small, Choose thou the path for me, Where I shall labor joyously, In service Lord, for thee - from one of my favorite hymns: "Teach Me Thy Truth". 


\section{TABLE OF CONTENTS}

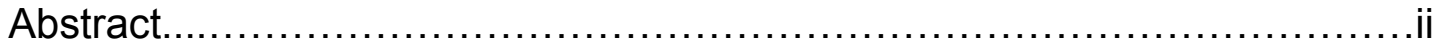

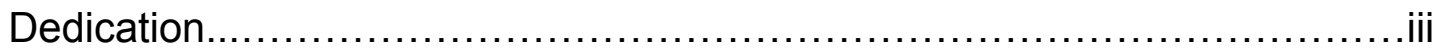

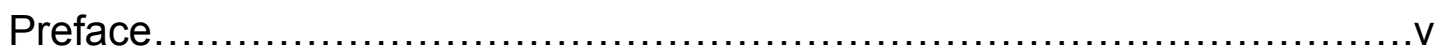

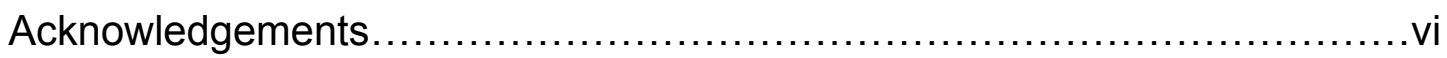

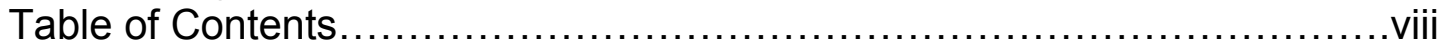

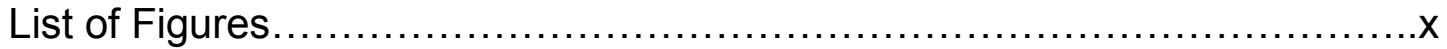

Glossary of Abbreviations .....................................................

I. Literature Review

1. Skin .......................................................................

A. Physiological Contribution: General Consideration.................... 1

B. Histological Architecture ............................................

C. Mechanism of Repair: General Consideration........................ 5

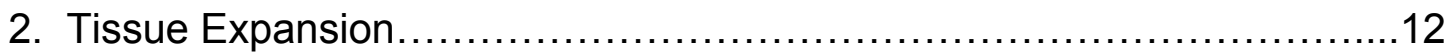

A. Chronic vs. Acute: General Consideration.............................12

1. Architectural Changes and Benefits in Dermal Tissue..............14

a. Wound Closure and Scar Formation..............................14

B. Effects of Expansion on Wound Repair and Endothelium..............15

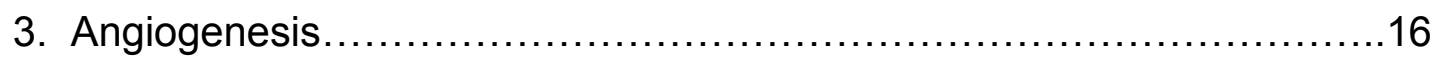

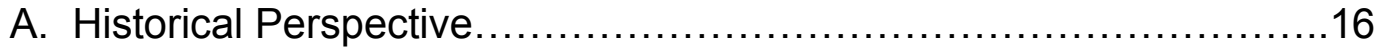

B. Regulatory Factors: General Consideration........................18

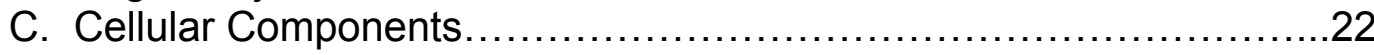

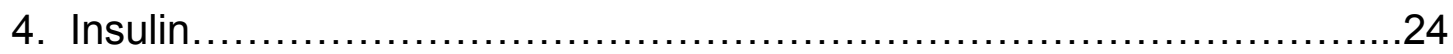

A. Sources: Circulating vs. Tissue Derived.............................24

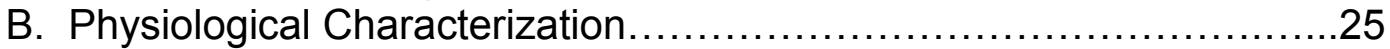

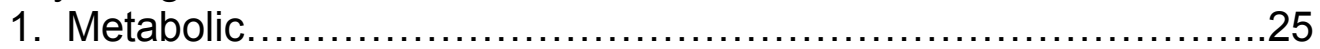

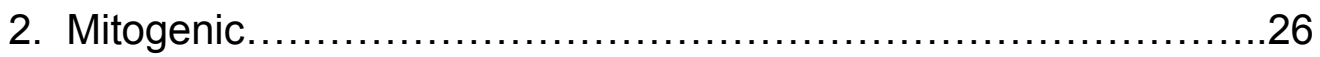

C. Signaling Pathways: Mitogenic and Survival........................27

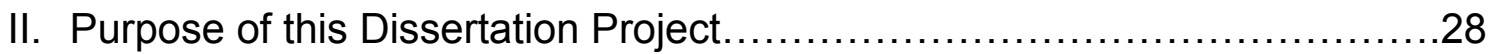

III. Study I: Acute Stretch Promotes Endothelial Cell Proliferation in

Wounded Healing Mouse Skin........................................30

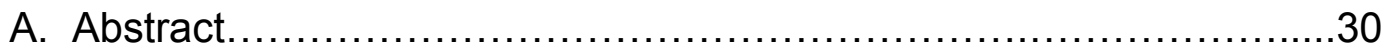

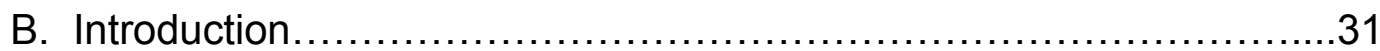

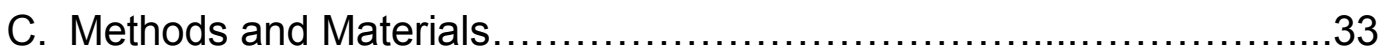

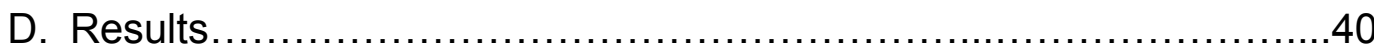

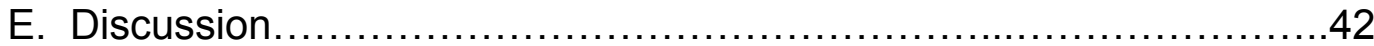

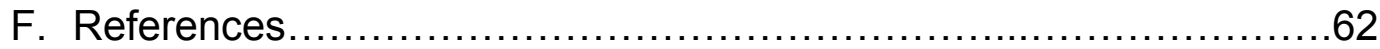


IV. Study II: Insulin Induces Enhanced Proliferation and Viability in Human Umbilical Vein Endothelial Cells (HUVECs). 69

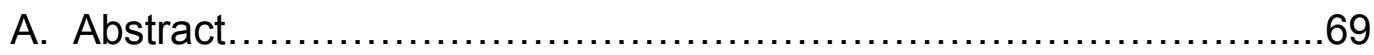

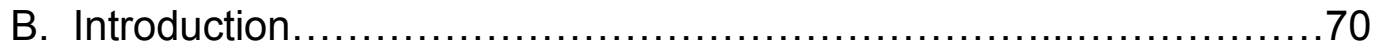

C. Methods and Materials .............................................. 72

D. Results and Discussion..............................................

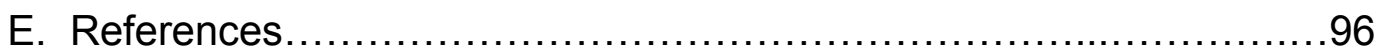

V. General Discussion...................................................103

VI. References for Literature Review and General Discussion................111

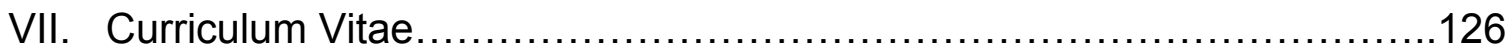




\section{LIST OF FIGURES}

\section{LITERATURE REVIEW}

Figure 1. Insulin signal transduction promoting metabolism, mitogenesis and cell survival

\section{Study I}

Figure 1. Temporal changes in total flap perfusion at postoperative days $2,5,7,10$ and 15 .

Figure 2. Extracorporeal wound length at post-operative times $6 \mathrm{~h}, 1 \mathrm{~d}, 2 \mathrm{~d}, 5 \mathrm{~d}$ and $7 \mathrm{~d}$.

Figure 3. Post-operative expression and endothelial immunolabeling of PCNA.

Figure 4. Post-operative expression of insulin and pIR/pIGFR, as well as immunolabeling of pIR/pIGFR on proliferating endothelium.

Figure 5. Post-operative expression of VEGF and flk-1 $\quad$. $\ldots \ldots \ldots \ldots 7$

Figure 6. Post-operative expression of Akt and pAkt.................59

Figure 7. The temporal relationship of protein expression in stretched, wounded flaps

\section{Study II}

Figure 1. Proposed insulin-mediated intracellular signaling pathways that stimulate endothelial cell proliferation and viability.

Figure 2. Colorimetric analyses revealed dose-dependent enhanced proliferation of HUVECs in response to exogenous insulin under ideal culture conditions ( $25 \%$ serum).

Figure 3. Densitometry of Western blots revealed activation of IR / IGFR in response to exogenous insulin under ideal culture conditions ( $25 \%$ serum). 
Figure 4. Densitometry of Western blots revealed activation of Akt in response to exogenous insulin under ideal culture conditions (25\% serum)

Figure 5. Densitometry of Western blots revealed up-regulation of VEGF in response to exogenous insulin under ideal culture conditions ( $25 \%$ serum).

Figure 6. Colorimetric analyses revealed dose-dependent enhanced viability of HUVECs in response to exogenous insulin under non-ideal culture conditions (12.5\% serum).

Figure 7. Densitometry of Western blots revealed activation of IR / IGFR in response to exogenous insulin under non-ideal culture conditions ( $12.5 \%$ serum)

Figure 8. Densitometry of Western blots revealed activation of Akt in response to exogenous insulin under non-ideal culture conditions ( $12.5 \%$ serum $)$. 


\section{GLOSSARY OF ABBREVIATIONS}

Akt

Protein kinase B

ALP Alkaline phosphotase

ANOVA Analysis of variance

bFGF Basic fibroblast growth factor

BSA Bovine serum albumin

CAM Chorioallantoic membrane

DAB Diaminobenzidine

DII4 Delta-like ligand 4

D3PPI D3-phosophorylated phosphoinositides

EC Endothelial cells

ECL Enhanced chemiluminescence

ECM Extracellular matrix

eNOS Endothelial-derived nitric oxide synthase

flk-1 Vascular endothelial growth factor receptor 2

GSK $3 \quad$ Glycogen synthase kinase 3

HNMPA Hydroxy-2-naphthalenylmethyl-phosphonic acid

HRP Horse radish peroxidase

HUVECs Human umbilical vein endothelial cells

ICAM Intracellular cell adhesion molecule

IGF Insulin growth factor

IR / IGFR Insulin receptor / insulin growth factor receptor

LY 294002 Phosphoinositide kinase-3 blocker 


\begin{tabular}{|c|c|}
\hline VEGF & Vascular endothelial growth factor \\
\hline MAP-K & Mitogen activated protein kinase \\
\hline MCDB & Molecular, cellular, and developmental biology culture medium \\
\hline MMP & Matrix metalloproteinases \\
\hline MTT & Methyl-thiazolyl tetrazolium salt \\
\hline NGS & Normal goat serum \\
\hline NO & Nitric oxide \\
\hline pAkt & Phosphorylated protein kinase B \\
\hline PBS & Phosphate buffered saline \\
\hline PCNA & Proliferating cellular nuclear antigen \\
\hline PDGF & Platelet derived growth factor \\
\hline PDK-1 & 3'-Phosphoinositide-dependent protein kinase 1 \\
\hline $\mathrm{PI} 3 \mathrm{~K}$ & Phosphoinositide kinase-3 \\
\hline pIR / pIGFR & Phosphorylated insulin receptor / insulin growth factor receptor \\
\hline PMSF & Phenylmethanesulfonyl fluoride \\
\hline RIPA & Radioimmunoprecipitation assay \\
\hline SDS & Sodium Dodecyl Sulfate \\
\hline SEM & Standard error of the mean \\
\hline TBS & Tris buffered saline \\
\hline TPBS & Tris / phosphate buffered saline \\
\hline VCAM & Vascular cell adhesion molecule \\
\hline
\end{tabular}




\section{LITERATURE REVIEW}

\section{Skin}

\section{A. Physiological Contribution: General Considerations}

The skin and all appendages make up the integumentary system. Skin is the largest organ, constituting up to $20 \%$ of total body mass. The skin of all animals has two common functions: it enables the organism to live in a specific environment and it maintains that organism in communication with its environment, sustaining the homeostasis of the organism (Montagna, 1971). All other functions of the cutaneous system are secondary to these two functions. These two functions are maintained by the following: the barrier action of skin, immunological responses to antigen information, body temperature regulation, sensory input, endocrine function, and excretion. Skin also aids in locomotion and allows individual recognition. Therefore, skin not only acts as a barrier and a means to communication with the outside world, but is dynamically involved in defense mechanisms.

\section{B. Histological Architecture}

The skin and it's derivatives constitute a complex organ. This organ is composed of numerous cell types within two main layers: the epidermis and dermis. The epidermis, ectodermally derived, is composed of stratified, keratinized squamous epithelium. The dermis, a mesoderm derivative, is dense connective tissue that provides strength and support to skin. A third layer, the hypodermis, contains variable amounts of adipose tissue, microvessels, and innervation. Epithelial skin appendages consist of hair follicles and hair, glands, 
and nails. Skin is characterized as thick (hairless; i.e. palms and soles) and thin. This nomenclature is based solely on the thickness of the epidermis.

There are five main layers of the epidermis: stratum basale, stratum spinosum, stratum granulosum, stratum lucidum, and stratum corneum. The stratum basale is the layer closest to dermis and is the source of mitotic cells that generate the other layers of the epidermis. The stratum spinosum contain cells that are "prickly" as a result of cytoplasmic processes that attach to adjacent cells by desmosomes. The stratum granulosum, making up the most superficial layer of the nonkeratinized portion of the epidermis, contains numerous keratohyalin granules. The stratum lucidum layer, a subdivision of the stratum corneum, is found only in thick skin. Keritinization is well advanced in this layer. Cells in the stratum corneum lose their nucleus and organelles and become filled almost entirely with keratin. This layer varies the most in thickness.

There are four cell types found in the epidermis: keratinocytes, melanocytes, Langerhans' cells, and Merkel's cells. Keratinocytes are the predominant cell type in each layer and contain numerous ribosomes that synthesize keratin. Melanocytes are derived from neural crest cells and migrate to the epidermis. They are spread throughout the stratum basale and are often referred to as dendritic cells because they have extensions between keratinocytes in the stratum spinosum. These cells function to produce melanin to protect the integument against ultraviolet radiation. Langerhans' cells are dendritic appearing cells that are antigen presenting cells of the epidermis. Their nuclei stain heavily with hematoxylin and the cytoplasm remains clear. These 
cells are often involved in delayed-type hypersensitivity reactions (e.g. contact allergic dermatitis). Merkel's cells are sensory cells located in the stratum basale and are most abundant where sensory perception is most acute (e.g. fingertips). The nucleus is lobed and the cytoplasm is denser than that of melanocytes and Langerhan's cells.

Hemidesmosomes connect the epidermis to the dermis by attaching intermediate filaments of the cytoskeleton to the basal lamina beneath the stratum basale. The dermis is composed of two layers: a papillary layer and the reticular layer. The papillary dermis is composed of loose connective tissue and is the most superficial dermal layer. It is in this layer where nerve endings and blood vessels are concentrated and serve the epidermis. The microvasculature generally takes the form of small loops coming up from the deeper layer that contains larger muscular arteries, each supplying a local area of skin. The luminal size of the blood vessels in these loops is controlled by neurogenic signals, myogenic mechanisms, and local factors (e.g., prostacyclin and NO). Also, flow can be altered through anatomical shunting (glomus body regulation) and physiological shunting of blood into existing vessels. At any given time the skin can receive up to $25 \%$ of the cardiac output (Feldschuh, 1977). However, normally it receives only $\sim 3 \%$ due to low metabolic demands during resting conditions.

Collagen type I and III and elastic fibers make-up an irregular network in this layer. The reticular dermis lies deep to the papillary dermis and is considerably thicker and less cellular. Collagen type I predominantly and elastin 
are not randomly organized and form lines (Langer's lines) that maintain skin tension. Layers of adipose tissue and smooth muscle cells may be seen below the reticular dermis and make-up the hypodermis. The smooth muscle cells that form the arrector pili muscle (attached to hair follicles) and the striated muscle cells of the panniculus carnosus muscle are found in this layer.

The skin is supplied with various sensory perception and motor nerve terminals to blood vessels, arrector pili muscles, and sweat glands. Free nerve endings are the commonest type, and are primarily found in the stratum granulosum and perform nociception. Encapsulated nerve endings of mechanoreceptors consist of Pacinian (sense pressure and displacement), Ruffini's (sense displacement of collagen), and Meissner's (sense light touch) corpuscles. Pacinian corpuscles are large and ovoid and are located in the deep dermis and hypodermis especially at joints. Ruffini's corpuscles are the simplest mechanoreceptor. They have an elongated, fusiform shape and respond to the displacement of adjacent collagen fibers. Meissner's corpuscles appear as tapered cylinders and are located in the papillary layer of the lips, palmar and volar surfaces.

There are predominantly two types of glands in skin: sebaceous and sweat. Sebaceous glands coat the hair and skin with sebum. Sweat glands consist of two types: eccrine and apocrine. Eccrine sweat glands are not associated with hair follicles and are ubiquitous. Apocrine glands are located at the axilla, areola, nipple of the mammary gland, and around the anus and external genitalia. 
There are important differences to note in the comparative anatomy between mouse and human skin (Sakai et al., 2003). Mice have a thinner stratum corneum and no stratum lucidum (Montagna, 1971). The thin skin of mice contains a flattened papillary dermis with rete ridges that are scarcely discernable (Montagna, 1971). Also, murine skin has less elastic connective tissue. There is no thermoregulatory response as sweat glands are only located on foot pads (Montagna, 1971).

Scientists have long been searching for animal models representing the biological properties of skin that impact human health and disease (Montagna, 1971). It is important to note, no one animal exists that can serve as an experimental model for human skin (Montagna, 1971). Traditionally, porcine skin has been regarded as representative model, but it's modulus of elasticity is much higher than in humans. This suggests that it may in fact be a poor model for studying the beneficial effects of mechanical stretch (Bartel and Mustoe, 1989). In contrast, the dorsal distally based skin of our SKH1 nude hairless mouse has an elastic modulus of $9.85(1.02) \mathrm{N} / \mathrm{mm}^{2}$ that approximates the human face (Hochberg et al., 1994). It permits blood flow measurements using in vivo microscopy and laser Doppler flowmetry without subjecting the animal to hair removal (Sakai et al., 2003). This is important because removal induces reactive hyperemia in response to shaving of the animal.

C. Mechanism of Repair: General Considerations

Healing is the culmination of a complex cascade of cellular events that generates resurfacing, reconstitution, and restoration of the tensile strength of 
injured skin (Gordon, 2002; Roesel et al., 1995). Healing is a process explained in three classic phases: inflammation, proliferation, and maturation. During the inflammatory phase, a clot forms and inflammatory cells debride injured tissue. Epithelialization, fibroplasia, and angiogenesis occur during the proliferative phase (Bhushan et al., 2002; Bielenberg et al., 1998). The wound begins contracture as granulation tissue forms. Lastly, during the maturation phase, tight cross-links form between collagen itself and protein molecules. This increases the tensile strength of the scar.

Many aspects of wound healing have yet to be elucidated. The inflammatory phase occurs in tandem with injury, generating vascular and cellular responses to injury. An incision made through the full thickness of skin causes a disruption of the microvasculature and immediate hemorrhage. Following incision of the skin, a 5- to 10-minute period of vasoconstriction ensues, mediated by epinephrine, norepinephrine, prostaglandins, serotonin, and thromboxane. Vasoconstriction temporarily blanches the wounded skin and functions to reduce hemorrhage immediately following injury. This aids in platelet aggregation and localizes healing factors to the wound.

Recent studies show that endothelial cells respond to exposed collagen surfaces, allowing for the attachment of platelets. This attachment occurs through adhesive glycoproteins: fibrinogen, fibronectin, thrombospondin, and von Willebrand factor. This aggregation forms a primary platelet plug and activates platelets. This triggers platelets to degranulate and release chemotactic and 
growth factors, such as platelet-derived growth factor, proteases, and vasoactive agents.

Coagulation then occurs via two different pathways. The intrinsic pathway begins with the activation of factor XII (Hageman factor) when blood is exposed to extravascular surfaces. The extrinsic coagulation pathway is activated by tissue factors found in extravascular cells in the presence of factors VII and VIla. Both mechanisms activate thrombin, leading to the conversion of fibrinogen to fibrin. This is the primary component of the wound matrix into which inflammatory cells, platelets, endothelial cells, pericytes, and plasma proteins migrate. Thrombin also facilitates migration of inflammatory cells to the site of injury by increasing vascular permeability.

Clot formation begins when platelets aggregate and the coagulation cascade ensues. It is limited to the site of injury as healthy endothelium produces prostacyclin, which inhibits clot formation. Next, plasminogen is converted to plasmin, an enzyme that performs cell lysis.

During the inflammatory phase, cellular recruitment occurs within hours of injury. Neutrophils are the predominant cell type for the first 48 hours after injury, but are not essential to healing. Their function is to cleanse the wound site of bacteria and necrotic matter. Macrophages are essential to wound healing. Macrophages phagocytose debris and bacteria and secrete collagenases and elastases, digesting injured tissue. In addition, macrophages release PDGF, an important cytokine that stimulates the chemotaxis and proliferation of fibroblasts and smooth muscle cells. Finally, macrophages secrete substances that attract 
endothelial cells to the wound and stimulate proliferation, promoting angiogenesis. T-lymphocytes migrate into the wound $\sim 72$ hours following injury (Wada et al., 1995). They secrete lymphokines such as heparin-binding epidermal growth factor and basic fibroblast growth factor (a potent stimulant of angiogenesis). Lymphocytes also play a role in cellular immunity and antibody production.

The proliferative phase promotes formation of granulation tissue. Inflammatory cells, fibroblasts, and neovascularization are imperative to it's formation (Grzeszkiewicz et al., 2001; Trabucchi et al., 1988). Pericytes punch holes in the extracellular matrix and provide a scaffold for migrating endothelial cells to form new blood vessels. This process occurs 3-5 days following injury and overlaps with the inflammatory phase.

The formation of epithelium over a denuded surface is referred to as epithelialization. This involves the migration of cells at the wound edges over a distance of less than $1 \mathrm{~mm}$, from one side of the incision to the other. Incisional wounds are epithelialized within 24-48 hours after injury. This seals the underlying wound from the environment. Cells at the wound edges undergo structural changes, allowing them to detach from their connections to other epidermal cells and to their basement membrane (Grzeszkiewicz et al., 2002). Epidermal cells secrete collagenases that break down collagen and activate plasmin. Plasmin promotes clot dissolution along the path of epithelial cell migration. Upon completion, the epidermal cell assumes its original form, and 
new desmosomal linkages to other epidermal cells and hemidesmosomal linkages to the basement membrane are restored.

The fibroblast is a critical component of granulation tissue. Fibroblasts produce collagen, elastin, fibronectin, glycosaminoglycans, and proteases. These cells increase in the wound as the number of inflammatory cells decrease. The synthesis and deposition of collagen, 3-polypeptide chains twisted into a lefthanded helix, is a critical event in the proliferative phase and to wound healing in general. Three chains of collagen aggregate by covalent bonds and twist into a right-handed superhelix, forming the basic collagen unit. A striking structural feature of collagen is that every third amino acid is glycine, a requirement for triple-helix formation. Hydroxylysine and hydroxyproline moieties enable collagen to form strong cross-links. Filaments aggregate to form fibrils. Collagen fibrils, in turn, aggregate to form collagen fibers. Approximately $80 \%$ of the collagen in normal skin is type I collagen; the remainder is mostly type III. In contrast, type III collagen is the primary component of early granulation tissue. Elastin is a structural protein with random coils that allow for stretch and recoil properties of the skin and is present in wounds in smaller amounts. It is responsible for stretch-back during skin expansion and, thereby, limits the benefits of mechanical stretch.

A rich blood supply is vital to sustain newly formed tissue. New blood vessels regress through vascular remodeling as metabolic demands decrease within the wound (Chang et al., 2002; Ko et al., 1995). Wound contraction begins almost concurrently with collagen synthesis. Contraction is the centripetal 
movement of wound edges that facilitates closure of a wound defect. This process does not seem to depend on collagen synthesis. Although the role of the peripheral nervous system in wound healing is not well delineated, recent studies have suggested that sympathetic innervation may affect wound contraction and epithelialization through unknown mechanisms.

Collagen also remodels during the maturation phase. This depends on the balance between collagen synthesis and destruction. Collagenases and matrix metalloproteinases in the wound assist in the removal of excess collagen. Inhibitors of metalloproteinases limit these collagenolytic enzymes. Type III collagen is replaced by type I collagen. Water is resorbed from the scar. These events allow collagen fibers to approximate, facilitating collagen cross-linking and ultimately decreasing scar thickness. Structural and functional changes (i.e. remodeling) continue indefinitely following wound healing.

Cytokines are released from various cell sources. They bind to cell surface receptors to stimulate responses; therefore, emerging as important mediators of wound healing events. Cytokines can reach their target cell by endocrine, paracrine, autocrine, or intracrine routes. A short list of the most important mitogenic cytokines are described below (Perona, 2006):

- Epidermal growth factor was the first cytokine described and is a potent mitogen for endothelial cells and fibroblasts. Epidermal growth factor stimulates fibronectin synthesis, angiogenesis, fibroplasia, and collagenase activity. 
- Fibroblast growth factor is a mitogen for endothelial cells, fibroblasts, keratinocytes, and myoblasts and an important stimulus for angiogenesis (Duraisamy et al., 2001). It also stimulates wound contraction and epithelialization and production of collagen, fibronectin, and proteoglycans.

- PDGF is released from the alpha granules of platelets and is responsible for the stimulation of neutrophils and macrophages and for the production of transforming growth factor-b (Franke et al., 1995; Luo and Miller, 1997). PDGF is a mitogen and chemotactic agent for fibroblasts and smooth muscle cells and stimulates angiogenesis, collagen synthesis, and collagenase. Vascular endothelial growth factor is similar to PDGF but does not bind to the same receptors. Vascular endothelial growth factor is mitogenic for endothelial cells and plays an important role in angiogenesis.

- Insulin growth factor's primary action is mediated by binding to specific IGF receptors localized on numerous cell types in many tissues. The signal is transduced by intracellular events (Baserga, 1999). IGF-1 is one of the most potent natural activators of the Akt signaling pathway, a stimulator of cell growth and multiplication and a potent inhibitor of programmed cell death (apoptosis).

- Transforming growth factor- $\beta$ is released from the alpha granules of platelets and has been shown to regulate its own production in an autocrine manner. This factor is an important stimulant for fibroblast proliferation and the production of proteoglycans, collagen, and fibrin 
(Lynch et al., 1989). The factor also promotes accumulation of the extracellular matrix and fibrosis. Transforming growth factor- $\beta$ reduces scarring and reverses glucocorticoid-induced inhibition of wound healing.

- Tumor necrosis factor- $\alpha$ is produced by macrophages and stimulates angiogenesis and synthesis of collagen and collagenase (Perona, 2006). Tumor necrosis factor-a is a mitogen for fibroblasts.

\section{Tissue Expansion}

\section{A. Chronic vs. Acute: General Considerations}

The concept of chronic tissue expansion by progressive distention of an implanted subcutaneous balloon was introduced by Newman (Neuman, 1957) in 1957 and propagated by Radovan (Radovan, 1979) since 1979. This technique currently is used clinically to obtain large amounts of high quality skin for reconstructive surgery in almost all anatomical regions except lower extremity (Sasaki, 1987). It is based on the rich 3D network of collagen and elastin that characterize skin mechanics and its natural ability to stretch in response to an applied force (Balestrini et al., 2005; Gibson, 1977; Johnson et al., 1993). Chronic tissue expansion produces real gains in cutaneous tissue (Austad et al., 1986). In the long term, the implanted balloon expander becomes encapsulated with fibrous tissue. The neovascularization induced by this process is superior to that seen in the subdermal plexus (Pasyk et al., 1982). Numerous biological events occur from stretching, resulting in biological tissue creep (tissue proliferation) that accounts for the tissue length gained (Johnson et al., 1993; Marek et al., 2005; Vander et al., 1987). The disadvantage of chronic implantation is its prolonged period of 
postoperative recovery with numerous office visits as well as pain and discomfort, increased health risks and costs.

With the introduction of acute expansion, immediate repair of moderately sized defects becomes a reality due to the skin's ability to stretch and increase skin surface area, thereby avoiding more complex and painful procedures (Greenbaum and Greenbaum, 1990; Greenbaum, 1993; Guida et al., 1993; Lam et al., 1994; Sasaki, 1987). Success is partly explained by mechanical tissue creep (constant stress relaxation) which accounts for the length gained when skin is stretched quickly under a constant load (Greenbaum, 1993; Johnson et al., 1993;

Greenbaum et al., 1990; Shapiro et al., 1996). Acute expansion offers the surgeon a less expensive technique with less morbidity potential (Machida et al., 1991; Ehlert et al., 1991). The tissue expanders used clinically are filled with sterile isotonic saline by the surgeon to tolerances determined by inspection (skin pallor) and palpation (firmness) (Ehlert and Thomas, 1991; Greenbaum, 1993; Lam et al., 1994; Shapiro et al., 1996; Siegert et al., 1993). This fill-volume is maintained for several minutes creating a tissue tension as a single load cycle to maximize creep. Then, the expander is deflated by withdrawing saline to permit tissue reperfusion for 2-3 minutes (Ehlert and Thomas, 1991; Greenbaum, 1993; Lam et al., 1994; Shapiro et al., 1996; Siegert et al., 1993). The procedure is repeated for 2 to 3 load cycles to produce additional skin for reconstruction (Gibson, 1977; Lam et al., 1994; Sasaki, 1987). The fill-volume is routinely increased by $2-10 \mathrm{ml}$ increments after each cycle, because additional initial stretch is thought to be needed to minimize tension and to maximize the total length gained. 
Unfortunately, the optimal conditions for acute expansion have only been suggested empirically for there currently are no well-characterized animal models for assessing the best conditions for using acute stretch. In the pig (Mackay et al., 1990; McGuire, 1980), acute expansion offers no immediate advantage over simple undermining of skin. However, the modulus of elasticity for this model is much higher than in human skin, suggesting that it may in fact be a poor model for studying expansion (Bartell and Mustoe, 1989). Moreover, the longer-term benefits arising from the application of acute stretch have not been explored within the pig or any other model (Siegert et al., 1993).

\section{Architectural Changes and Benefits in Dermal Tissue}

The beneficial effects of tissue expansion are considered to be immediate and secondary to the: (a) relative dehydration of tissue by displacement of fluids and glycoconjugates from the ground substance; (b) parallel re-alignment of randomly positioned collagen fibers; (c) microfragmentation of elastic fibers; and (d) elongation of tissue into the surgical field by forces produced by the expansion and relaxation of the skin (Gibson, 1977; Johnson et al., 1993; Sasaki, 1987).

a. Wound Closure and Scar Formation

In response to the cited beneficial effects of tissue expansion, wounds become more responsive to closure and tissue more closely re-approximates wound dimensions. These observations are responsible for decreased scar formation in expanded tissue.

B. Effects of Expansion on Wound Repair and Endothelium 
Clinically, a few studies have shown that expansion of skin for 10 to 15 minutes is too long for it can produce irreversible ischemia leading to progressive tissue necrosis (Lam et al., 1994). The injury caused by this rapid expansion may narrow blood vessels, occlude venous and lymphatic drainage, and produce endothelial cell disruption leading to vasospasm and microthrombosis (Sasaki, 1987). In contrast, Doppler blood flow quantification in humans, rats, and mice demonstrated rapid decreases in blood flow during intermittent expansion, with subsequent recovery to near normal levels within one minute after each cycle of stretch and relaxation (Sasaki, 1987; Zhu et al., 2003). Histological examination of the skin showed that shorter recovery periods between expansion cycles, larger volumes of inflation at each time interval, and longer durations of expansion, all produced more ischemia (Sasaki, 1987).

Others have reported initiation of the delay phenomenon as early as $24 \mathrm{~h}$ after the creation of surgical flaps (Greenbaum and Greenbaum, 1990; Susuki et al., 1986; Wechsler and Fisher, 1978). Beginning at $48 \mathrm{~h}$, there is reperfusion of areas of random circulation following surgical delay incisions and by 4-6 days neovascularization (Garcia et al., 1991; Milton, 1969; Milton, 1970). Blood flow remains elevated until day 14 ( $\mathrm{Li}$ et al., 2005; Li, 2005). Both the number and size of vessels are increased, and there is growth of new vessels from surrounding tissue 4-5 days postoperatively. However, the reasons and underlying physiological, biochemical, and cellular and molecular, mechanisms involved in reducing necrosis and promoting wound healing and longer term viability are 
unknown and need to be elucidated using well-characterized models and wellestablished conditions.

Therefore, a well-characterized model for studying acute stretch is required to develop the best conditions for the parameters associated with rapid intermittent expansion. Underlying changes in nutrient blood flow that impact flap viability and long-term survival are unknown and need to be elucidated using contemporary cellular and molecular biology. We hypothesize that rapid intermittent stretch triggers the release of endogenous factors that promote neovascularization (angiogenesis) and growth and this impacts the long-term viability of skin following elevation and closure of random flaps. The mediators are postulated to prevent irreversible ischemia and necrosis and, thereby, to promote the healing of wounded skin. We examine the identity and localization of the potential stretch-released proteins in a well-characterized model of mouse dorsal distally based flap. The information is completely lacking and is essential for successful application of acute stretch.

\section{Angiogenesis}

\section{A. Historical Perspective}

Growth of blood vessels has intrigued scientists for centuries (Dvork, 2005; Skalak, 2005). They recognized that the formation of new vessels from existing capillary beds (i.e. angiogenesis) and vascular remodeling (e.g. apoptosis) control the structure and function of the microcirculation over the lifetime of an organism (Conway et al., 2001). As early as 1794, John Hunter wrote about the development of vessels in the chick embryo. Hunter noted that 
vessels are not elongations from original ones, but are newly formed from mitogenic endothelium. Meyer, in 1853, was the first to correctly sketch the growth of new capillaries from observations in tadpole tails and sheep embryos. In 1885, Bobritzky was the first to suggest endothelial cell migration during angiogenesis. Clark (1918) noted that capillary sprouting occurred primarily in high flow vessels, while high flow capillaries tended to regress. In 1965, Branemark suggested that vessels became functional as a result of oscillatory movement of erythrocytes. This was confirmed by experiments conducted by Myrhage and Hudlicka in 1978. More recently, it has been established that the angiogenic process occurs at the venular end of pre-existing capillaries under physiological and pathological conditions (Haas, 2002). Folkman and numerous collaborators have contributed significant knowledge to endothelial cell proliferation that leads to capillary formation in response to factors in cell and tissue cultures.

Historically, many techniques have been utilized to study angiogenesis. Among these are intravital microscopy, quantitative light microscopy, electron microscopy, ${ }^{3} \mathrm{H}$-thymidine incorporation, tissue culture and chorioallantoic membrane (CAM) assays. Intravital microscopy is limited to small range of tissues, and is one of the earliest methods used to study angiogenesis. In the seventeenth century, often magnifying lenses were used for experiments. Most data referring to growth of capillaries arise from quantitative light microscopy. We used quantitative light microscopy in immunohistochemical assays of proliferating cellular nuclear antigen (PCNA), factor VIII, and IR / IGFR in 
combination with Western blot analysis and proliferation assays (Bravo et al., 1987; Denizot and Lang, 1986; Freeman et al., 1993; Gerlier et al., 1986; Hong et al., 2003; Hoyer et al., 1981; Kindblom et al., 1982; Luo et al., 1996; Mosmann, 1983; Shrader et al., 2007; Takasaki et al., 1984; Woods et al., 1991). These data generally reflect changes in number or length of capillaries per volume of tissue. Electron microscopy reveals the ultrastructure of the microvasculature. Stereological quantification of capillaries has also been achieved with this method. ${ }^{3} \mathrm{H}$-thymidine incorporation has been used in vivo and in vitro to analyze mitotic activity of endothelial cells. These experiments allowed for the detection and analysis of new capillaries. Tissue culture techniques have been used extensively to study blood vessel formation and the response of cell types to angiogenic factors. In 1974, Folkman described CAM assays to study angiogenesis. Angiogenic agents could be easily applied and evaluated through the thin membranes of the chorioallantois.

In spite of centuries of investigation, a mechanistic understanding of the components of angiogenesis is poorly understood (Frantz et al., 2005). Research has focused on endothelial cells in vitro and in vivo, with the hope of discovering the mechanism(s) that control vessel growth. For example, scientists hope to some day limit vessel growth in tumors, while stimulating vessel formation for collateral circulation in conditions where blood flow is impaired as in ischemia / reperfusion and healing.

B. Regulatory Factors: General Considerations 
Endothelial cells are very stable with turnover of about every 1000 days in capillaries. However, these cells mitose in substantially higher numbers in younger animals. For example, Schwartz and Benditt (1977) found that $13 \%$ of aortic endothelial cells were labeled in newborn rats. This number reduced to $0.2 \%$ by six months of age. Although the growth and division of endothelium are not fully understood, there are key mechanisms and events that can be described in detail. Cells can only divide and grow in the presence of nutrients. Various growth factors facilitate these processes. These factors bind to their respective receptors and stimulate cell signaling that controls cell division. Capillaries bud (i.e. vascular splitting and sprouting) from existing capillaries in response to these growth factors (i.e. angiogenesis). Endothelial cells coalesce and bind fibrin, which adds support to the vessel wall. Angiogenesis enhances blood flow to the wound and, consequently an increase in tissue healing factors. Angiogenesis ceases as the demand for new blood vessels ceases. New blood vessels disappear via programmed cell death (i.e. apoptosis).

VEGF (Vascular Endothelial Growth Factor) has been demonstrated to be a major contributor to angiogenesis, increasing the number of capillaries in a given network (Akita et al., 2004; Bermont et al., 2000; Byrne et al., 2005; Ferrara, 2002). Early in vitro studies demonstrated that bovine capillary endothelial cells proliferate and form tube structures upon stimulation by VEGF and basic fibroblast growth factor (bFGF) (Gerwins et al., 2000). Responses were more pronounced to VEGF (Goto et al., 1993). VEGF is up-regulated during exercise (Gitay-Goren et al., 1996). VEGF is also suspected to have a 
beneficial role in the treatment of vascular injuries (Ding et al., 2004; Gavin et al., 2004; Kraus et al., 2004; Lloyd et al., 2003). In vitro studies clearly demonstrate that VEGF is a potent stimulator of angiogenesis as plated endothelial cells will proliferate and migrate, eventually forming tubes that resemble capillaries (Chau et al., 2002; llan et al., 1998). VEGF triggers a massive signaling cascade in these cells (Pai et al., 2001). Binding to flk-1 initiates a tyrosine kinase signaling cascade that stimulates vessel permeability (eNOS, producting NO), proliferation / survival (bFGF), migration (ICAMs / VCAMs / MMPs) and finally differentiation into mature blood vessels (Herve et al., 2005; Hoeben et al., 2004; Miller et al., 2005; Senger et al., 2002). Mechanically, it is expressed during muscle contractions from increased wall shear stress resulting from increased blood flow to exercised areas (Ingber, 2002; Joung et al., 2006). NO is widely considered to be a major contributor to the angiogenic response because inhibition of NO significantly reduces the effects of angiogenic growth factors (Kuebler et al., 2003; Murohara and Asahara, 2002; Murthy et al., 2000). However, inhibition of NO during exercise does not inhibit angiogenesis indicating that there are other factors involved in the angiogenic response (Prior et al., 2004). DII4 (Delta-like ligand 4) is a recently discovered protein growth factor with important angiogenic properties similar to VEGF (Chai et al., 2004). DIl4 is a transmembrane ligand, from the Notch family of receptors.

The angiopoietins, Ang1 and Ang2, are required for the formation of mature blood vessels, as demonstrated by mouse knock out studies (Thurston, 2003). Ang1 and Ang2 are protein growth factors which act by binding their 
receptors, Tie-1 and Tie-2 (Thurston, 2003; Unger et al., 2005). While this is somewhat controversial, it seems that cell signals are transmitted mostly by Tie2; though, some papers show physiologic signaling via Tie-1 as well. These receptors are tyrosine kinases. Thus, they can initiate cell signaling when ligand binding causes a dimerization that initiates phosphorylation on key tyrosines.

Another major contributor to angiogenesis is matrix metalloproteinase (MMP). MMPs help degrade the proteins that keep the vessel walls intact. This proteolysis allows the endothelial cells to escape into the interstitial matrix as seen in sprouting angiogenesis. Inhibition of MMPs prevents the formation of new capillaries (Haas et al., 2000). These enzymes are tightly regulated during vessel formation. Destruction of the extracellular matrix decreases the integrity of the microvasculature (Prior et al., 2004)

One of the most important functions of fibroblast growth factor-2 (FGF2) is the promotion of endothelial cell proliferation and the physical organization of endothelial cells into tube-like structures, thus promoting angiogenesis (Takahashi et al., 2005). FGF2 is a more potent angiogenic factor than VEGF or PDGF (platelet-derived growth factor) (Detillieux et al., 2003). As well as stimulating blood vessel growth, bFGF is an important player in wound healing (Odedra et al., 1987; Piotrowicz et al., 1999; Takahashi et al., 2005). It stimulates the proliferation of fibroblasts that give rise to granulation tissue, which decreases a wound cavitation early in the wound healing process. Akt is involved in the regulation of angiogenesis and promoting cell survival (Brognard et al., 2001; Burgering et al., 1995; Cantley et al., 1999; Datta et al., 1995; 
Murthy et al., 2000; Nakatani et al., 1999; Partovian et al., 2004; Rommel et al., 1999; Zimmerman and Moelling, 1999).

All of these factors regulate the two main types of angiogenesis. Sprouting was the first identified form of angiogenesis, occuring in several wellcharacterized stages. Sprouts extend toward the source of the angiogenic stimulus. Endothelial cells migrate in tandem using adhesion molecules, the equivalent of cellular grappling hooks, called integrins. These sprouts then form loops to become capillaries at the site of angiogenesis. Sprouting occurs at a rate of several millimeters per day, and enables new vessels to grow across gaps in the vasculature. It is markedly different from splitting angiogenesis (i.e. intussusception), however, because it forms entirely new vessels as opposed to splitting from existing vessels (Burri, 2004). Intussusception was first observed in neonatal rats where the EC extends into the lumen and divides a single vessel into two.

Mechanical stimulation of angiogenesis is not well characterized (Haas, 2002; Shiu et al., 2005; Shukla et al., 2004; Von Offenberg et al., 2005). There is a significant amount of controversy regarding the role of wall shear stress in promoting angiogenesis, although current knowledge suggests that increased muscle contractions increase angiogenesis (Prior et al., 2004). New vessel growth is a complex process that relies heavily upon numerous factors.

\section{Cellular Components}

This dissertation focuses on endothelial cell proliferation as a marker of angiogenesis. Endothelial cells are the central focus of research as these cells 
are activated by numerous regulatory factors (Nakatsu et al., 2003). Activation often promotes mitogenesis. As the cells proliferate, they migrate toward angiogenic stimuli (e.g. bFGF, VEGF) (Kroll et al., 2000; Stephan and Brock, 1996). As maturation occurs, endothelium remodels and stabilizes to form a patent vessel that delivers blood flow.

The macrophage is an essential component of angiogenesis as it produces macrophage-derived angiogenic factor in response to low tissue oxygenation (Kunz-Schughart et al., 2006). This factor functions as a chemoattractant for endothelial cells. Basic fibroblast growth factor secreted by macrophages and vascular endothelial growth factor secreted by epidermal cells also trigger angiogenesis (Wiedlocha and Sorensen, 2004).

Fibroblasts function to maintain the structural integrity of the connective tissue (Kunz-Schughart et al., 2006). These cells secrete all of the precursors required for the formation of extracellular matrix. As matrix is broken down to allow for endothelial cell migration, the fibroblast must construct new matrix to stabilize newly formed vessels. Fibroblasts and smooth muscle cells have receptors for epidermal growth factor and platelet derived growth factor (Luo et al., 1997; Powers et al., 2000). Endothelial cells do not contain these receptor types and, therefore, do not respond to these angiogenic agents'.

Smooth muscle cells maintain blood vessel dimensions and vascular wall integrity against imposed loads. The thin and thick filament bundles are fastened to the sarcolemma (plasma membrane) via dense plaques or focal adhesions. Individual smooth muscle cells are fastened to one another via adherens 
junctions. Consequently, they are mechanically coupled to one another such that contraction of one cell invokes some degree of contraction in an adjoining cell. Gap junctions couple adjacent cells chemically, facilitating the spread of signals (e.g., calcium) across smooth muscle as a single-unit of contraction. Tissue containing smooth muscle cells often is stretched, so that elasticity is an important attribute of smooth muscle and contributes to stretch-back during expansion (Haas, 2002). Smooth muscle cells secrete a complex extracellular matrix containing collagen (predominantly types I and III), elastin, glycoproteins, and proteoglycans (Olsen et al., 1997). They contract or relax in many different ways, responding to activation of the autonomic nervous system ("involuntarily" control) and other cell types (vasodilators or vasoconstrictors).

Lastly, pericytes are relatively undifferentiated cells, associated with the walls of small blood vessels (Munoz-Chapuli et al., 2002). They aid in the breakdown of the basal lamina and serve as a scaffold for endothelial cells to migrate and form new vessels during neovascularization. These cells are pluripotent; that is, they are capable of differentiating into a fibroblast, smooth muscle cell, or macrophage.

\section{Insulin}

\section{A. Sources: Circulating vs. Tissue Derived}

Circulating insulin (from Latin insula, "island") is produced by beta cells in the Islets of Langerhans in the pancreas and has systemic effects. However, insulin can be tissue derived. That is, insulin can be produced by 
tissue (e.g. skin) to act locally, as well as systemically (i.e. tissue insulin or insulin 1) (Pelegrinelli et al., 2001).

\section{B. Physiological Characterization}

Typically, one thinks of insulin as a key metabolic protein, regulating the functions of the insulin-dependent tissues; for example, liver, adipose, and skeletal muscle (Bates et al., 2005; Kim et al., 2001; White et al., 1985; White et al., 1988). It facilitates glucose uptake in these organs and tissues. However, recent evidence also suggests that insulin acts as a key mitogen (Kawaguchi et al., 2001). Insulin receptors are expressed on vasculature, but their functions are not completely understood. While there is only a $40 \%$ amino acid sequence homology between insulin and insulin growth factor, both IR and IGFR respond to insulin activation and are associated with mitogenic insulin signaling (Adams et al., 2000, Baserga, 2000, Brown et al., 1997; Layton et al., 2006; Marino-Buslje et al., 1999; Oh et al., 2006; Scheidegger et al., 2000; Soos et al., 1993; Ullrich et al., 1986). Insulin potentially stimulates differentiation, growth, and survival (Dickson, 1998; Gartner et al., 1992; Hernandez-Sanchez et al., 1995;

Wertheimer et al., 2000). Insulin is required for all animal life. Its mechanism of action is almost identical in nematodes, fish, and mammals, and it is a protein that has been highly conserved throughout evolution. In humans, insulin deprivation from removal or destruction of the pancreas leads to death in days or, at most, weeks if left untreated (Beeson et al., 2003).

\section{Metabolic}


There are special proteins in cell membranes through which glucose is transported from blood into cells. These transporters are, indirectly, under insulin control in certain cell types (eg, muscle cells). Low levels, or the absence, of circulating insulin will inhibit glucose uptake in these cells (e.g. Type 1 diabetes). However, more commonly there is insulin resistance (e.g. Type 2 diabetes), blocking glucose absorption. This resistance is believed to be the result of inflammation associated with peroxynitrites and glycosylated fatty acyl proteins (Asayami et al., 1984; Fuchs et al., 1997; Taub and Oppenheim, 1994).

Activation of insulin receptors leads to intracellular mechanisms which control glucose uptake and utilization by regulating the number and activity of membrane bound proteins which transport glucose (Schumacher et al., 1993). The genes which specify these proteins have been identified and comprise the intra- and extra-membrane structure of the insulin receptor. Two types of cells are most strongly influenced by receptor activation: myocytes and adipocytes. The former are important because of their central role in movement, breathing, circulation, etc, and the latter as an alternative energy source to glucose. These cells account for about two-thirds of all cells in a typical human body.

\section{Mitogenic}

Following insulin binding to it's receptor, the receptor tyrosine kinase is activated. This, in turn, stimulates phosphorylation of insulin receptor substrates 1 and 2 (IRS 1, IRS 2) and Shc (Morris and Schmid, 2000; Tavarez-Pagan et al., 
2004). These proteins lead to multiple intracellular signaling cascades that promote cell growth and differentiation (Sundell and Knuuti, 2003). Among these are PI3-K signal transduction (Poulaki et al., 2003; Turinsky and Amrau-Abney, 1999). PI3-K has been implicated in insulin-induced gene transcription (Kobayashi et al., 2002; Xiaorui, 2004). However, the increased transcription may not be biologically significant. This dissertation focuses on insulin signaling and protein up-regulation and activation to determine if there is a central role for insulin in endothelial cell mitosis and viability that promotes angiogenesis in healing stretched skin.

C. Signaling Pathways: Mitogenic and Survival

Presented in figure 1.

Glucose Metabolism

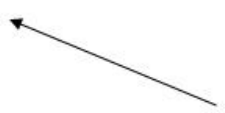

INSULIN

Glut 4 Vessicle

I-R / IGF-R

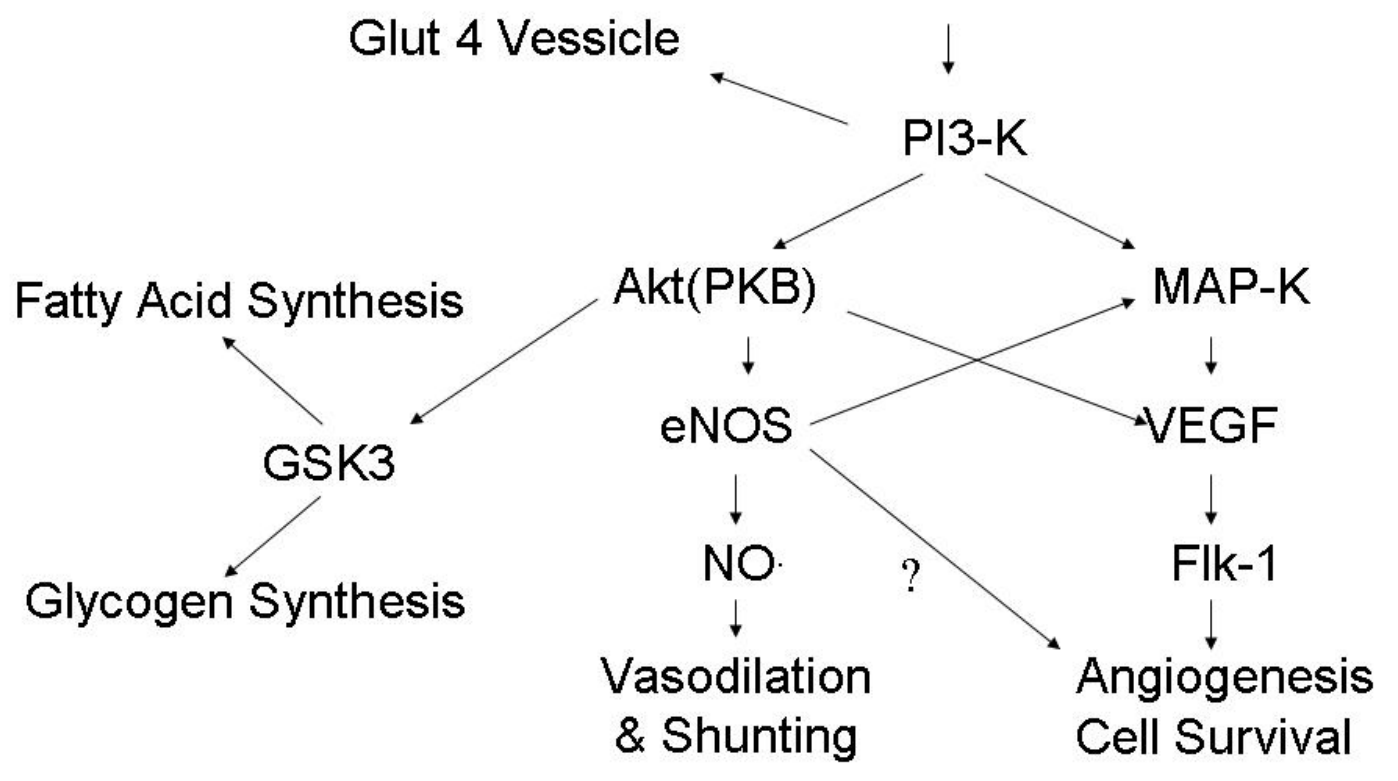

Figure 1. Insulin signal transduction promoting metabolism, mitogenesis and cell survival. 


\section{PURPOSE OF THIS DISSERTATION PROJECT}

The potential to promote wound healing is of tremendous clinical significance in injuries, e.g., lacerations, surgical incisions, reconstructive surgery, burns and peripheral vascular diseases. There is a growing body of evidence that insulin released locally in tissues (tissue insulin or insulin-1) acts as an endothelial cell mitogen. Tissue insulin is a ligand for insulin receptor (I-R) and/or insulin growth factor receptor (IGF-R). However, the molecular mechanism(s) by which insulin triggers endothelial mitosis is largely unknown. The lack of this knowledge hampers the development of rational and efficient strategies to enhance collateral vessel formation (angiogenesis) and promote wound healing.

The long-range goal of our research is to elucidate the mechanisms by which acute stretch promotes vascular growth in healing skin. Our preliminary data have shown that acute skin stretching provokes upregulation of the tissue insulin gene. The expression is coincident with improved healing and viability as seen from decreased necrosis and increased blood flow in the skin. The objective of the dissertation research is to characterize molecular mechanisms triggering endothelial cell mitogenesis in an animal model (mouse) and in primary cell culture (human). The central hypothesis is that insulin is a stretch responsive endothelial cell mitogen that enhances vascular growth and viability by activating I-R/IGF-R, and that signal transduction is mediated by phosphatidylinositol 3kinase (PI3-K) effectors protein kinase B (Akt) and vascular endothelial growth factor (VEGF). The rationale for the proposed research is that understanding of the mechanisms that promote angiogenesis will transform this stretch 
methodology into a useful clinical tool to improve healing of the skin lesions.

To test our central hypothesis and accomplish the overall objective of this research, the following specific aims are addressed within the dissertation:

1. Characterize the response of endothelial cells to acute stretch. Working Hypothesis: Endothelial cells are the major cell type that in response to stretch temporally upregulate / activate the expression of insulin, IR / IGFR, Akt, and VEGF, and proliferate.

2. Determine signal transduction pathway(s) for insulin-induced endothelial cell proliferation and survival in vitro. Working Hypothesis: Insulin signaling is mediated by I-R/IGF-R that through PI3-K activate the Akt and VEGF.

This study contributes new knowledge that will make a fundamental difference in the outcome and treatment of disorders where healing is compromised. The research will provide novel insight into unexplored mechanisms of stretchinduced mitogenic tissue insulin activity. It will enhance a promising new research focus area into the molecular mechanisms of wound healing. The new knowledge and techniques should translate into strategies that promote wound healing. Strategies include the use of gene therapy, exogenously applied insulin, or the training of physicians to utilize acute stretch, to stimulate healing in the skin. 


\title{
ACUTE STRETCH PROMOTES ENDOTHELIAL CELL PROLIFERATION IN WOUNDED HEALING MOUSE SKIN
}

\author{
Carl D. Shrader ${ }^{a}$, Holly G. Ressetar ${ }^{a}$, Jia Luo ${ }^{b}$, Eugene V. Cilento ${ }^{\mathrm{a}, \mathrm{c}}$, Frank D. \\ Reilly ${ }^{a, *}$ \\ ${ }^{a}$ Department of Neurobiology and Anatomy, School of Medicine, West Virginia \\ University, Morgantown, WV 26506-9128 \\ ${ }^{b}$ Department of Microbiology, Immunology and Cell Biology, School of Medicine, \\ West Virginia University, Morgantown, WV 26506-9177 \\ ${ }^{c}$ Department of Chemical Engineering, College of Engineering and Mineral \\ Resources, West Virginia University, Morgantown, WV 26506-6070 \\ * Corresponding author. Department of Neurobiology and Anatomy, School of \\ Medicine, West Virginia University, Morgantown,WV 26506-9128 E-mail \\ address: freilly@hsc.wvu.edu Telephone: 304-293-0607 Fax: 304-293-8159.
}

\begin{abstract}
ABSRACT
We have developed a novel in vivo model utilizing acute stretch to investigate endothelial cell proliferation as a marker of vascular growth in healing mouse skin. This study is a follow-up to ones revealing immediate stretch improves blood flow, decreases total tissue necrosis, and induces tissue insulin transcription. Dorsal distally based flaps of skin were stretched for 3 min using linear (skin hook) plus hemispherical load cycling (inflated subcutaneous silicone catheter). Unstretched, wounded skin along the back and sternum served as postoperative controls. Laser Doppler flowmetry demonstrated a three fold increase in flap perfusion at postoperative day 7. A stretch-induced six-fold increase in endothelial cell mitogenesis accompanied enhancements in blood flow and extracorporal wound healing over the sternum. Western blots revealed up-regulation / activation of insulin and mitogenic signaling intermediates in stretched skin. Activated insulin and insulin growth factor receptors (pIR/pIGFR), protein kinase B (Akt, pAkt), vascular endothelial growth factor (VEGF) and vascular endothelial growth factor receptor 2 (flk-1) were among the identified stretch-responsive intermediates. These results indicate the benefits of acute stretch are mediated through enhanced vascularity as evidenced by endothelial cell mitogenesis and up-regulation / activation of insulin and key angiogenic effectors in dorsal distally based skin flaps.
\end{abstract}




\section{INTRODUCTION}

We have reported long-term benefits and improved skin flap viability arising from the application of rapid, acute stretch in a SKH1 mouse model [43]. These benefits were demonstrated with Doppler flowmetry and by measuring necrosis along the margin of a surgically created dorsal distally based skin flap. Increases up to $50 \%$ in nutritive blood flow and decreases of $75 \%$ in tissue necrosis were observed at post-operative day 5. Despite numerous studies by others attesting to the benefits of tissue stretch, no thorough investigation into the underlying cell type(s) and molecular mechanism(s) that promote viability and improved healing have been reported [29, 35].

The microvasculature bears the enormous task of maintaining systemic homeostasis following tissue wounding. It must initiate clot formation, chemokine signaling, cellular recruitment, vasoreactivity, and immune response while maintaining normal functional and/or nutritive blood flow $[3,7,23]$. These processes are critical to survival and healing, and occur in three phases: an inflammatory phase, a proliferative phase, and a maturational phase. The endothelial cell serves a pivotal role in each phase.

Despite many advances in understanding the science of endothelium, there is a gap in knowledge of mitogenic stimuli, i.e., stretch and molecular mechanisms that trigger endothelial cell proliferation. Mitogenic activity of endothelium promotes new vascular growth as seen from existing capillary beds during angiogenesis. Angiogenesis is involved in a variety of physiological and pathological roles, and has become a central focus for many investigators $[4,8$, 
$14,21,39]$. Angiogenesis is imperative to the proliferative phase of healing as it sustains the process. Chronic unhealed wounds result if angiogenesis becomes impaired [19, 20,36].

Characterization of the cellular and molecular mechanisms underlying improved viability and healing in stretched tissue carries enormous clinical significance, warranting further investigation. Using differential display reverse transcription polymerase chain reaction (DDRT-PCR) and Northern blot analysis, we reported stretch-induced expression of tissue insulin mRNA [44]. Expression of insulin mRNA was coincident with improved healing as increased blood flow and decreased necrosis accompanied up-regulation. Despite the traditional view of insulin as a metabolic regulatory hormone, recent evidence suggests insulin can serve as a key mitogenic regulator $[2,9,22,34,40,41]$.

In the current study, we demonstrate stretch-induced gene-specific tissue insulin expression and enhanced up-regulation / activation of multiple angiogenic signaling intermediates using Western blot analysis. Immunohistochemistry revealed enhanced mitogenesis in endothelium of stretched tissue and confirmed activation of insulin receptor and insulin growth factor receptor (pIR/pIGFR). These data increase our understanding of the beneficial effects of acute stretch on skin flap viability and healing in local and remote (extracorporal) sites. 


\section{MATERIALS AND METHODS}

Animal care and anesthesia

A total of 70 outbred Crl: SKH1-hrBR albino (hairless) male mice (20-30g) of 20-42 days of age were purchased from Charles River Laboratories (Wilmington, MA). They were kept in a light and temperature regulated environment and were permitted free access to food and water while maintained on Tek fresh bedding. The mice were anesthetized intraperitoneally with Nembutal $(0.05 \mathrm{mg} / \mathrm{g}$ body weight) and $20 \mathrm{~min}$ later with ketamine $(0.03 \mathrm{mg} / \mathrm{g})$. The institutional Animal Care and Use Committee approved the project and key personnel were trained in Core Animal Welfare (protocol \#: 03-0401). NIH Publication 85-23 (revised in 1985) "Principles of laboratory animal care" was followed. The animal care facilities and program met the requirements of the Laboratory Animal Welfare Act P2-89-541, 91-579 and 94-279, NIH policies and ONM Circular A-21, the Public Health Service Act, and the American Veterinary Medical Association on euthanasia.

Treatment groups and surgical protocol

The experimental design incorporated two groups of 4-6 anesthetized mice. A dorsally based random flap measuring $30 \mathrm{~mm}$ in width by $35 \mathrm{~mm}$ in length was delineated on the animals using established methods [11, 12, 13, 43]. Skin flaps from the control group were undermined, following a cranial apex incision, without the application of acute stretch. Flaps from the experimental group were undermined and then a constant $5 \mathrm{~g}$ of linear tension plus a subcutaneous 3 min hemispherical load cycle (acute stretch) applied using a 
Foley catheter (REF 0165L 12, C.R. Bard, Inc., Covington, KY). Constant initial linear tension was accomplished by securing anesthetized mice with surgical tape to a custom built Plexiglas apparatus housing a tensiometer (Chatillon Tensiometer DGGRS-gram gauge, Greensboro, N.C.) so that movements of this instrument in relation to the flap were precisely controlled. The flap was secured to the tensiometer with a suture hook. Experimental animals, similar to control animals, received an apical incision allowing for undermining and stretching of the flap. The skin hook was attached and an initial $5 \mathrm{~g}$ of linear tissue applied. The hemispherical load cycle was achieved by inserting the inflation tube of the catheter under the flap through the cranial incision. The catheter was inflated with $6 \mathrm{ml}$ of sterile saline.

Both stretched (experimental) and unstretched (control) flaps were raised by cutting the two lateral sides. They were then re-approximated to the original donor site and closed with 5-0 nylon simple sutures. A total of 15 sutures, distributed approximately $5 \mathrm{~mm}$, were used for closure.

Flaps were excised and hemi-sected at multiple post-operative time points. One half was stored at $-80^{\circ} \mathrm{C}$ and the other half was placed in $10 \%$ neutral buffered formalin prior to paraffin embedding. After flap excision, mice were euthanized with an excess of pentobarbital.

Anterior extracorporeal skin incisions, $15 \mathrm{~mm}$ in length, were made along the sternum of both stretched, wounded and unstretched, wounded animals. Four sutures, $3 \mathrm{~mm}$ apart were used to close these surgically created wounds. 
Total wound length was measured using a micrometer between $6 \mathrm{~h}$ and postoperative day 7 .

Laser Doppler flowmetry

Blood flow measurements were repeated three times (triplicate) in each animal using a laser Doppler flowmeter Model ALF 21 (Transonic Systems, Ithaca, NY). Means of triplicate measurements \pm SEM were graphed. The measurement site was $10 \mathrm{~mm}$ from the center of the caudal flap borders, and its exact position was determined from previous studies [13, 43]. Total flap perfusion was estimated by recording blood flow before surgery (baseline) and then again at postoperative time points.

\section{Immunohistochemistry}

Skin flaps were collected, fixed in $10 \%$ neutral buffered formalin and paraffinembedded. The samples were fixed one day and processed the following day to preserve the antigenicity and morphology of the tissue. Five micrometer sections were cut and mounted on poly-lysine coated slides and air dried overnight at room temperature. Double-labeling of factor VIII (demonstrated with alkaline phosphatase - fast red chromagen) with pIR/pIGFR or proliferating cellular nuclear antigen (PCNA) (both demonstrated with DAB - brown chromagen) in vascular endothelial cells was assessed using established immunohistochemical methods [32, 33].

The basic immunostaining protocol was as follows: Flaps were processed immunohistochemically for the presence of specific proteins using an avidin-biotin method $[32,33]$. The proteins of interest (PCNA; Ventana, Tucson, 
AZ, pIR/pIGFR; Chemicon International, Temecula, CA) were double-labeled with factor VIII (Ventana, Tucson, AZ) to identify endothelial cells. Flaps were sectioned $(5 \mu \mathrm{m})$ with a microtome. Sections were washed with $3.0 \%$ bovine serum albumin (BSA) and $2 \%$ normal goat serum (NGS) in $0.10 \mathrm{M}$ phosphate buffer for $10 \mathrm{~min}$ each to block non-specific staining. Antigen retrieval was performed to remove any cross-linking damage done during fixation and processing. The samples were incubated for $30 \mathrm{~min}$ at $37^{\circ} \mathrm{C}$ with primary antibodies (PCNA and/or pIR/pIGFR) diluted at 1:50 in a solution of 3\% BSA in $0.15 \mathrm{M}$ phosphate buffer. Next, samples were washed in $1 \mathrm{X}$ tris buffered saline (TBS) and placed in horse radish peroxidase (HRP) polymer for 30 min. Sections were washed in $1 X$ TBS and DAB placed on them for 5-10 min. Slides were then placed in a running water wash for $5 \mathrm{~min}$. Double stain blocker was added for $10 \mathrm{~min}$, followed by another 5 min rinse in $1 \mathrm{X}$ TBS. A second primary antibody was added at this point (factor VIII) for 30 min, rinsed in 1X TBS for 5 minutes and placed in alkaline phosphatase (ALP) for 55 min. Samples were placed in 1 X TBS for 5 min and Fast Red was added to slides for 5-10 min. Triple labeled samples were rinsed again in 1X TBS and placed in the third antibody (PCNA), then rinsed and placed in ALP for 55 min. Finally these samples were rinsed in 1X TBS and placed in 5-bromo-4-chloro-3-indoxyphosphate / nitroblue tetrazolium chloride (BCIP/NBT) (Ventana, Tucson, AZ) substrate for 5 min. Slides were then washed well in a running water rinse for $10 \mathrm{~min}$. Hematoxylin (30-45 sec) was used as a counterstain on double labeled sections. Slides were again washed well and coverslipped as an aqueous media. Due to light sensitivity, samples were stored in a dark area for up to one week. Quantified 
antigens were labeled with $\mathrm{DAB}$ and densitometry performed using Optimas 6.2. Incubation in NGS and omission of primary antibodies served as control reactions for non-specific binding. The results of these controls were negative.

Western blot analysis

The quantitative immunoblotting protocol was similar to that used previously [27]. All analyses were repeated three times (triplicate) with new animal groups. Means of triplicate measurements \pm SEM were graphed. Time points preceding those graphed were not significant from baseline, and therefore not displayed in figures.

Flaps were placed in liquid nitrogen for $1 \mathrm{~min}$, pulverized, homogenized and lysed with ice cold RIPA buffer (150 mM NaCl, $50 \mathrm{mM}$ Tris pH 8.0, 1.0\% Polydet $\mathrm{N}-40,0.10 \%$ sodium dodecylsulfate (SDS), $0.50 \%$ sodium deoxycholic acid, 0.10 $\mathrm{mg} / \mathrm{ml}$ phenylmethylsulfonyl fluoride, $1.0 \mathrm{mM}$ sodium orthovanadate, and $3.0 \%$ aprotinin, Sigma) for $10 \mathrm{~min}$. The homogenates were centrifuged at 10,000 $\mathrm{G}$ for $10 \mathrm{~min}$, and the supernatant containing cellular proteins was collected and protein concentration determined with a Bio-Tek microplate reader. Protein samples (50 $\mu \mathrm{g} / \mathrm{lane}$ ) were loaded on 10\% SDS-polyacrylamide gels (PAGE), separated by electrophoresis and then transferred to nitrocellulose membranes. Non-specific activity was blocked by washing the membrane with $5.0 \%$ nonfat dry milk and $0.10 \%$ Tween-20 in $0.01 \mathrm{M}$ PBS (TPBS) for $1 \mathrm{~h}$ at room temperature. The membranes were incubated overnight at $4^{\circ} \mathrm{C}$ with primary antibodies against PCNA, insulin, Akt, VEGF, flk-1 (Santa Cruz Biotechnology, Santa Cruz, CA), pAkt (S473, Zymed Laboratories, San Francisco, CA) and pIR/pIGFR (Cell 
Signaling Technology, Danvers, MA). After two washes in TPBS, the membranes were incubated with a peroxidase-conjugated secondary antibody (Amersham, Piscataway, NJ ; 1:2000 in TPBS) for $1 \mathrm{~h}$. The immune complexes were detected by the enhanced chemiluminescence $(E C L)$ method (Amersham, Piscataway, NJ). As with the immunohistochemical studies, non-specific binding was assessed on immunoblots processed without the primary or secondary antibodies. The results of such controls were consistently negative.

In order to control for inter-sample variation of the total amount of protein loaded onto the gel, the membranes were stripped of antibodies directed against target proteins and re-probed with anti-tubulin $\mathrm{Ab}$ as an internal standard.

Densitometric readings of target protein contents were normalized against those of the internal standard using Optimas 6.2. The membranes were stripped by incubating in a solution containing $100 \mathrm{mM} \beta$-mercaptoethanol, $2.0 \%$ SDS, and $62.5 \mathrm{mM}$ Tris- $\mathrm{HCl}(\mathrm{pH} 6.7)$ for $30 \mathrm{~min}$ at $50^{\circ} \mathrm{C}$ or overnight at $4^{\circ} \mathrm{C}$. The membranes were then washed twice with TPBS for $15 \mathrm{~min}$. Non-specific binding was blocked with either $5.0 \%$ milk or $2.5 \%$ BSA in PBS, and the membrane was reblotted as described above. With this method, we were able to detect small differences in protein expression [28]. The relative amounts of stretch-induced protein expression in the films prepared from the immunoblots were quantified using an LKB Ultrascan XL Laser Densitometer. For detection of low abundance proteins, such as phosphorylated kinases, the homogenates were concentrated using the Microcon Centrifugal Filter Device (Millipore Inc., Billercia, MA) prior to 
electrophoresis. We have successfully employed this method to detect low levels of specific proteins.

Statistical analysis

Differences among treatment groups were tested using a one-way analysis of variance (ANOVA) and Tukey's (post hoc) test. Differences with $p$ values $\leq 0.05$ were considered statistically significant. Data are presented in figures as mean \pm standard error of the mean (SEM). 


\section{RESULTS}

Doppler flowmetry demonstrated that all flaps were adequately perfused.

Total estimated perfusion at the flap base was significantly higher $(\leq 0.05)$ at postoperative day 7 (Fig. 1) in acutely stretched wounded skin. This increase was accompanied by a significant reduction $(p \leq 0.05)$ in wound length along the sternum between post-operative days 1 (1d) and day 5 (5d) (Fig. 2). These findings were consistence with those reported previously where marginal tissue necrosis along the cut edge of stretched flaps with elevated blood flow was significantly decreased at post-operative day 5 [43].

PCNA antigen (brown chromagen) was isolated on factor VIII (red chromagen) positive endothelial cells of wounded skin (identified by arrows in Fig. 3A). Quantification of brown chromagen as a percentage (\%) of the total cross-sectional area of a blood vessel's lining revealed significant stretchenhanced labeling ( $p \leq 0.05)$. This increase in expression was confirmed by Western blots that were stripped of PCNA antigen and re-blotted with tubulin as an internal standard (Fig. 3B).

Insulin expression was significantly elevated $(p \leq 0.05)$ at $1 \mathrm{~d}$ and optimal at 2d (Fig. 4A), while pIR/pIGFR activity peaked at 1d (Fig 4B) in stretched flaps. Triple-immunolabeling of tissue sections with pIR / pIGFR (brown chromagen), factor VIII (red chromagen) and PCNA (blue-grey chromagen) confirmed the presence of pIR/pIGFR on proliferating endothelium (Fig $4 \mathrm{C}$ left and middle panels with arrows indicating pIR / pIGFR positive endothelial cells). Quantification of brown chromagen as a percentage of the total cross-sectional 
area of a blood vessel's lining demonstrated significant pIR / pIGFR activation ( $p$ $\leq 0.05$ ) on post-operative day 1 (Fig. $4 \mathrm{C}$ right panel).

Acute stretching significantly upregulated $(p \leq 0.05)$ expression of VEGF, VEGF receptor 2 (flk-1) (Fig. 5), and Akt (Fig 6). It also activated (pAkt) Akt above the levels provoked by wounding alone (Fig 6). Protein levels for upregulated / activated angiogenic factors correlated positively with the timing of insulin and PCNA expression in stretched, wounded flaps (Fig. 7). 


\section{DISCUSSION}

One of the major challenges that currently faces microvascular research is vital knowledge of mechanisms that promote vascular growth. Recent data demonstrate the importance of mechanical-chemical signaling that is transmitted throughout the endothelial cell and through extracellular matrix (ECM) adhesions on the surface of endothelium $[6,10,15,16,37]$. Most of these experimental models have elucidated mechanisms of endothelial cell migration and tubulogenesis as physiologically relevant models to study angiogenesis [16, 25].

We have recently developed a novel in vivo approach utilizing acute mechanical stretch to investigate endothelial cell proliferation as a marker of vascular growth in healing mouse skin $[1,5,31]$. This model has the following features: (1) the modulus of elasticity in the animal approximates the skin of the human face, (2) flowmetry demonstrates surgically created flaps are well perfused, (3) mechanical manipulation (acute stretch) drastically improves flap viability as assessed by decreases up to $75 \%$ in marginal tissue necrosis, (4) wounding alone (unstretched skin) enhances proliferation and protein kinase B expression, and (5) the dorsal distally based skin flap is a reliable model for studying wound closure.

Mechanical stimulation enhances local flap perfusion and remote extracorporeal wound healing that is coincident with endothelial cell proliferation

Acute stretching of a surgically created skin flap in our SKH1 hairless mouse model improves viability and healing. As previously reported, increases 
of up to $50 \%$ in blood flow and decreases of $75 \%$ in tissue necrosis were detected at post-operative day 5 [43]. After careful consideration of these results and a review of the literature, we chose to look at post-operative day 6 and beyond to determine the optimal time point for maximal increases in flap perfusion. We discovered mechanical stimulation using acute stretch results in a maximal 3-fold increase in flap perfusion at post-operative day 7 . This observation was coincident with improved flap viability and healing.

Our laboratory became interested in the effects, if any, of acute stretch beyond the local area of application. This was accomplished by creating an unstretched wound on the animal in a location remote (extracorporal) to the stretched dorsal flap. Extracorporeal wounding of skin overlying the sternum exhibited a significant improvement in healing with complete remission prior to that seen in unstretched, wounded animals. This finding provided evidence that there are beneficial systemic effects of acute stretch beyond the localized site of application.

The next major challenge was determining the mechanism of stretchresponsive increases in flap perfusion. We hypothesized stretch-induced temporal increases in blood flow, optimal at post-operative day 7 , were a result of new vascular growth (arteriogenesis and angiogenesis). Endothelial cell proliferation was selected as a marker for these experiments [1, 5, 31]. Immunolabeling of endothelium specific factor VIII with proliferating cellular nuclear antigen (PCNA) was performed. These double-labeled immunohistochemical preparations revealed a 6-fold increase in endothelial cell 
proliferation at post-operative day 6 in acutely stretched skin. The results were confirmed by Western blot analysis of PCNA. These data support our hypothesis that acute stretch enhances endothelial cell mitogenesis by promoting increased vascularity in healing wounded skin.

Mechanical stretch enhances up-regulation and activation of tissue insulin and angiogenic factors

Although advantages of skin stretching have been demonstrated both clinically and experimentally, the cellular and molecular mechanisms underlying these benefits are unknown $[33,35,38]$. We have previously reported the upregulation of tissue insulin mRNA in stretched skin [44]. It was unclear if this increased transcription was biologically significant. We hypothesized that acute stretch-induced endothelial cell proliferation was tissue insulin mediated through phosphoinositide-3 kinase (PI3-K) effectors, i.e., protein kinase B (Akt) and vascular endothelial growth factor (VEGF).

Using Western blot analysis, we confirmed the up-regulation of tissue insulin in response to acute stretch. Stretch also promoted activation of insulin receptor (pIR) and insulin growth factor receptor (pIGFR). Despite only a 40\% homology in insulin and insulin growth factor, both receptor types respond to insulin activation and are associated with mitogenic insulin signaling [24, 30]. Our preliminary studies (unpublished observation) demonstrated that stretch does not alter endothelial expression of these receptors $(p \geq 0.05)$. However, stretch did significantly impact the activation of IR / IGFR. Immunolabeling with 
factor VIII and PCNA confirmed the presence and activation of these receptors on proliferating endothelium. The relatively large increases in receptor activity in immunolabeled tissue sections compared to Western blots indicate that endothelial cells are the predominant cell type expressing the activated insulin receptors. These data demonstrate that tissue insulin and its receptors are stretch-responsive and are located on mitotic endothelial cells. Moreover, these results support recent evidence demonstrating insulin's role as a key mitogenic regulator and indicate a biologically significant role for insulin in the observed benefits of acute stretch $[9,22,26,34,40,41]$.

Angiogenesis has been shown to be mediated through PI3-K and downstream effectors Akt and VEGF $[6,10,15,17,18,42]$. We demonstrated that acute stretch up-regulates VEGF, VEGF receptor 2 (flk-1), and Akt, while enhancing activation (pAkt) of Akt. Therefore, acute stretch, unlike wounding alone, works through both VEGF and Akt. This could be the result of acute stretch-induced mechanical-chemical signaling that is transmitted throughout the endothelial cell and through extracellular matrix (ECM) adhesions $[6,10,15,16$, 37]. These results are coincident with the up-regulation of tissue insulin and receptor activation. These intracellular signaling events may serve as the link between stretch-induced insulin release and endothelial cell proliferation.

Mechanical induction of protein expression and activation provides temporal support for insulin-mediated endothelial cell proliferation 
We hypothesized that acute stretch-induced endothelial cell proliferation is tissue insulin mediated through PI3-K effectors, i.e., Akt (pAkt) and VEGF. The temporal relationships among proteins up-regulated / activated by acute stretch provides further evidence that insulin activates it's receptors (pIR/pIGFR) and stimulates endothelial cell proliferation (indicated by PCNA) through PI3-K by Akt (pAkt), VEGF and flk-1 signaling in our in vivo mouse model.

\section{Conclusions}

We have presented a novel in vivo approach to study the benefits of a mechanical stimulus (i.e., acute stretch). Although acute stretch plays a significant role in regulating endothelial cell proliferation and up-regulation / activation of insulin and key angiogenic factors, the exact mechanism that results in angiogenesis remains elusive. The Western blot data presented here are representative of all cell types found in murine skin. Future in vitro studies will focus on confluent endothelial cell (EC) monolayers. This will allow for a conclusive characterization of the implicated angiogenic pathway(s) in ECs using blockade studies that are lethal in our in vivo model.

It is important to note that our observations of improved viability, as assessed by increased blood flow and decreased necrosis, can be attributed to several variables working individually or in conjunction. Among these are increased vascular density, vasodilation, and physiological shunting. Consequences of interactions among these variables remain unclear. However, temporal observations of a steady increase in blood flow, becoming optimal at post-operative day 7 and regressing by day 10 , are indicative of vascular 
remodeling and support a potential role for arteriogenesis and angiogenesis in the initial stages of this process.

Finally, these experiments demonstrate that acute stretch enhances the up-regulation / activation of proteins (e.g. PCNA, pAkt) that respond to wounding alone. Therefore, we conclude that tissue stretch not only promotes upregulation / activation, but enhances underlying angiogenic mechanisms that are wound-responsive. Interestingly, we did not demonstrate increases in perfusion from wounding alone in unstretched (control) flaps (Fig. 1). This is attributed to vascular growth-related blood flow being below the detection sensitivity of the laser Doppler flowmeter [43].

Although the exact mechanism(s) underlying stretch-responsive angiogenesis has yet to be determined, this study provides the framework for future in vitro studies that will explicate the underlying signaling cascade(s). 
Fig. 1. Temporal changes in total flap perfusion at post-operative days 2, 5, 7 , 10 and 15 . Estimated total perfusion $(\%)=$ blood flow as a percentage of that measured at the flap base prior to surgery. $1=$ significant $(\leq 0.05)$ from unstretched, wounded skin. 


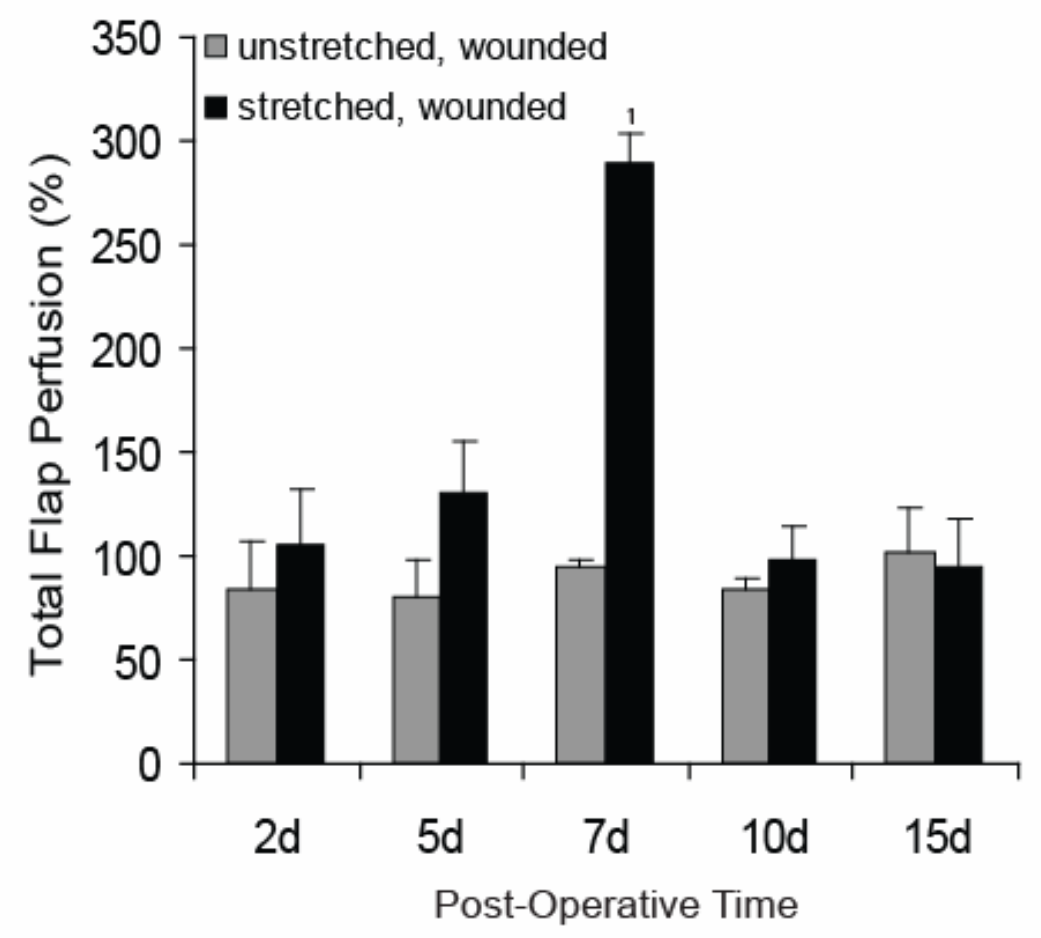


Fig. 2. Extracorporeal wound length at post-operative times $6 \mathrm{~h}, 1 \mathrm{~d}, 2 \mathrm{~d}, 5 \mathrm{~d}$ and $7 d$. $1=$ significant $(p \leq 0.05)$ from unstretched, wounded skin at indicated postoperative times. 


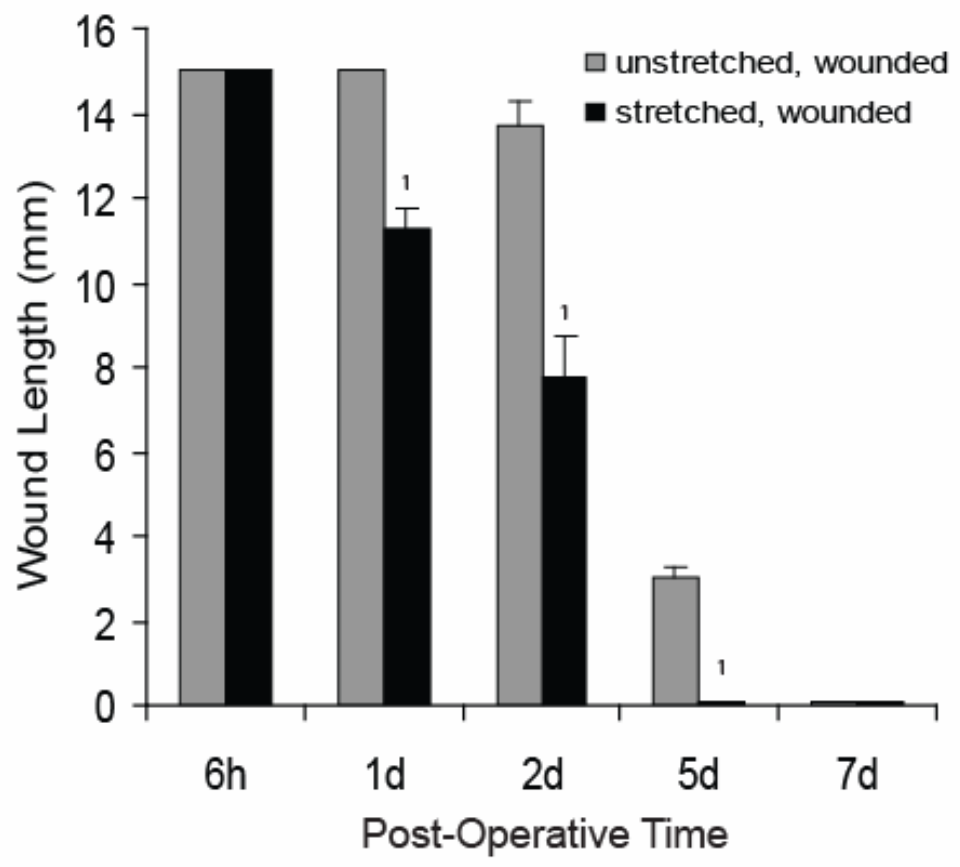


Fig. 3. Post-operative expression and endothelial immunolabeling of PCNA. A. Left and middle panels. PCNA antigen (brown chromagen) is located on endothelium (factor VIII antigen - red chromagen) of wounded skin (identified by arrows). Right panel. Quantification of PCNA reveals significant stretch enhanced labeling in endothelium. PCNA Level $(\%)=$ the total cross-sectional area of a blood vessel's endothelium that stains for PCNA (brown chromagen). 1 $=$ significant $(p \leq 0.05)$ from unstretched, wounded skin. B. Western blot of PCNA with the corresponding quantification of expressed protein. Tubulin served as an internal standard. $1=$ significant $(p \leq 0.05)$ from unstretched, wounded baseline at $12 \mathrm{~h} .2$ = significant $(p \leq 0.05)$ from unstretched, wounded skin at indicated post-operative times. Time points preceding those represented on Western blots were not significant from baseline, and therefore not displayed in figures. 


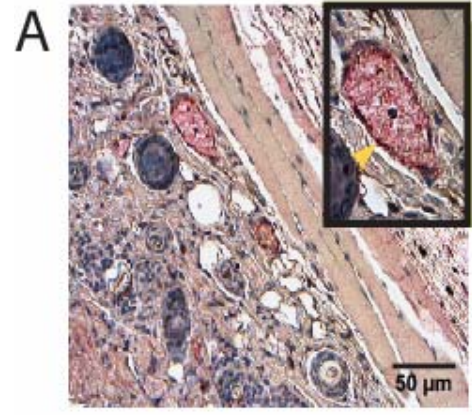

$6 \mathrm{~d}$ unstretched, wounded

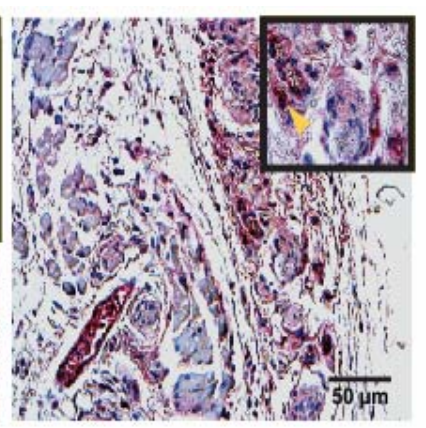

$6 \mathrm{~d}$ stretched, wounded

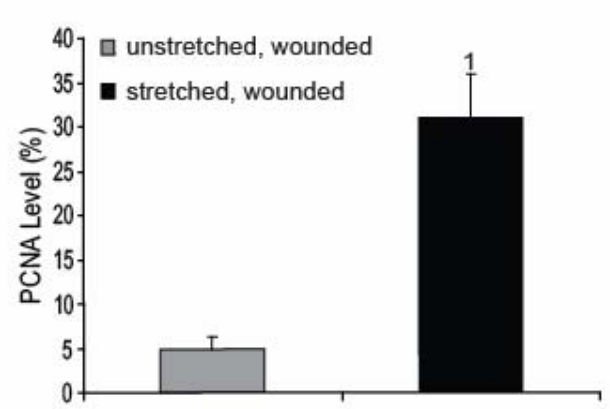

Post-Operative Day 6

B $\quad 3.07$ unstretched, wounded
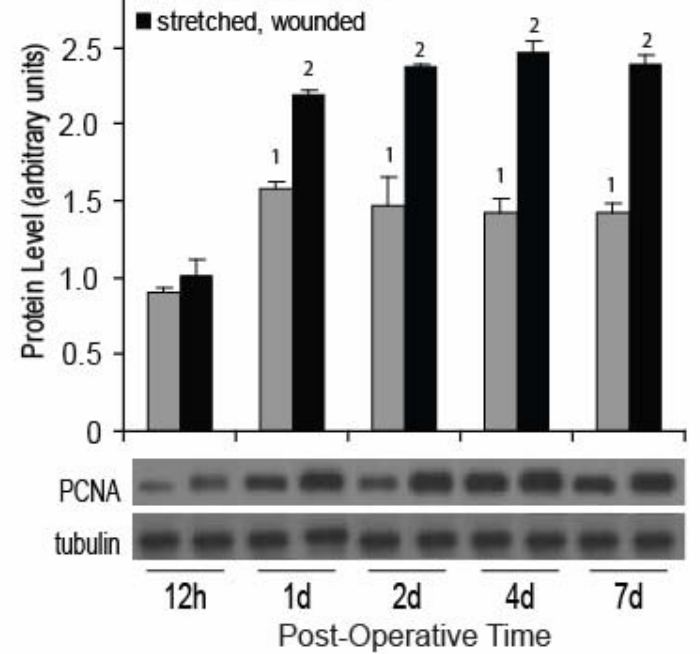
Fig. 4. Post-operative expression of insulin and pIR/pIGFR, as well as immunolabeling of pIR/pIGFR on proliferating endothelium. A. Western blot of tissue insulin with the corresponding quantification of expressed protein. Tubulin served as an internal standard. $1=$ significant $(p \leq 0.05)$ from unstretched, wounded baseline at $3 \mathrm{~h} .2=$ significant $(p \leq 0.05)$ from unstretched, wounded skin at indicated post-operative times. B. Western blot of pIR / pIGFR with quantification of expressed protein. Tubulin served as an internal standard. $1=$ significant $(p \leq 0.05)$ from unstretched, wounded skin at indicated post-operative times. C. Left and middle panels. pIR / pIGFR, factor VIII and PCNA triplelabeled sections. Arrows indicate pIR / pIGFR positive endothelial cells. [pIR / pIGFR (brown chromagen); factor VIII (red chromagen); PCNA (blue-grey chromagen)]. Right panel. Quantification of activated receptor levels on endothelium at post-operative day 1 . pIR / pIGFR Level $(\%)=$ the total crosssectional area of a blood vessel's endothelium that stains for pIR / pIGFR (brown chromagen). $1=$ significant $(p \leq 0.05)$ from unstretched, wounded skin. Time points preceding those represented on Western blots were not significant from baseline, and therefore not displayed in figures. 

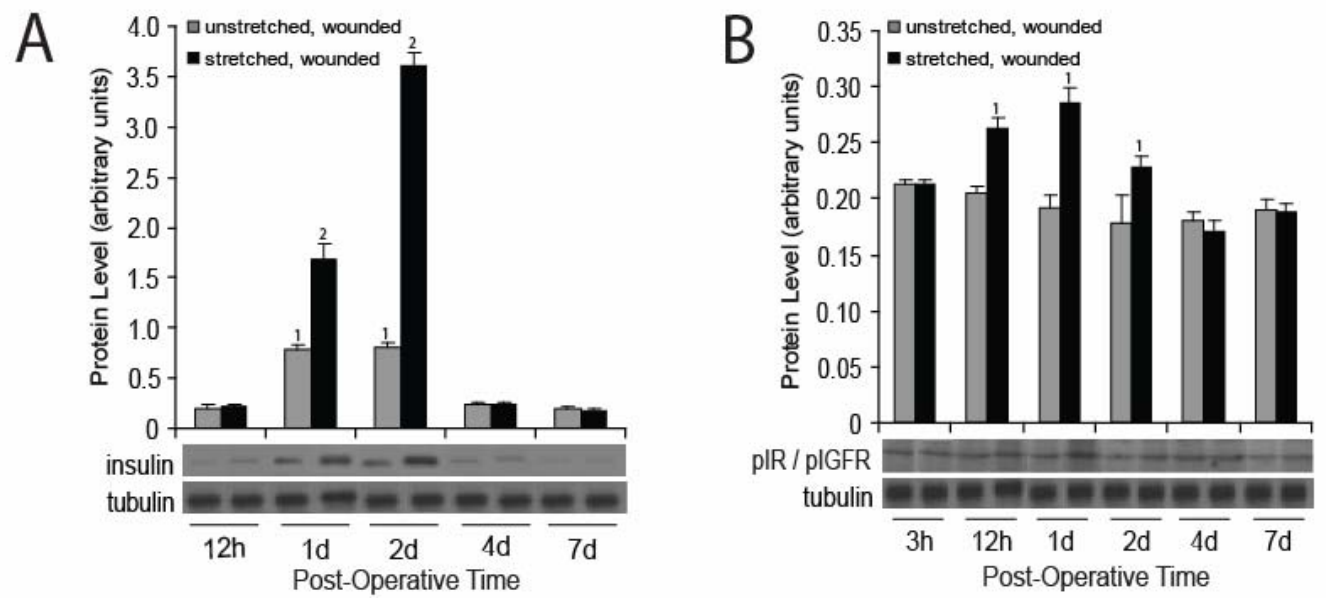

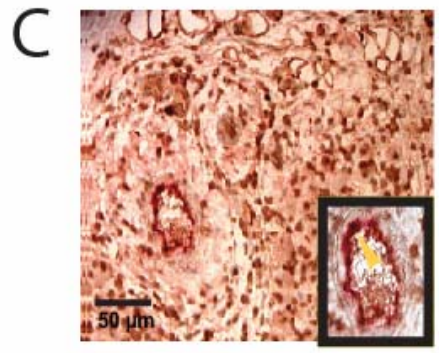

1d unstretched, wounded

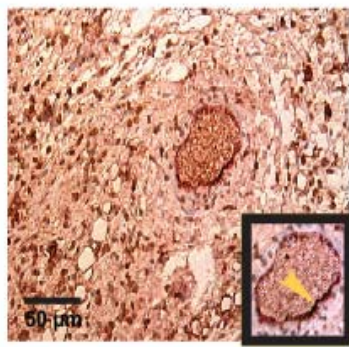

1d stretched, wounded

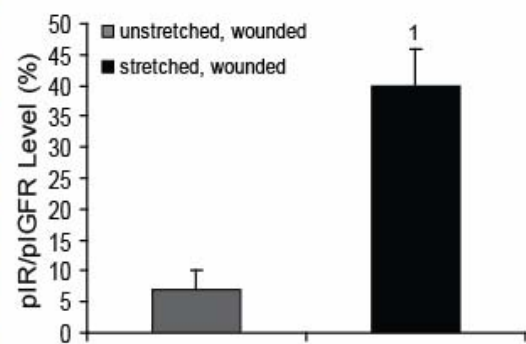

Post-Operative Day 1 
Fig. 5. Post-operative expression of VEGF and flk-1. A. Western blot of VEGF with the corresponding quantification of expressed protein. Tubulin served as an internal standard. $1=$ significant $(p \leq 0.05)$ from unstretched, wounded skin at indicated post-operative times. B. Western blot of flk-1 with the corresponding quantification of expressed protein. Tubulin served as an internal standard. $1=$ significant $(p \leq 0.05)$ from unstretched, wounded skin at indicated post-operative times. Time points preceding those represented on Western blots were not significant from baseline, and therefore not displayed in figures. 

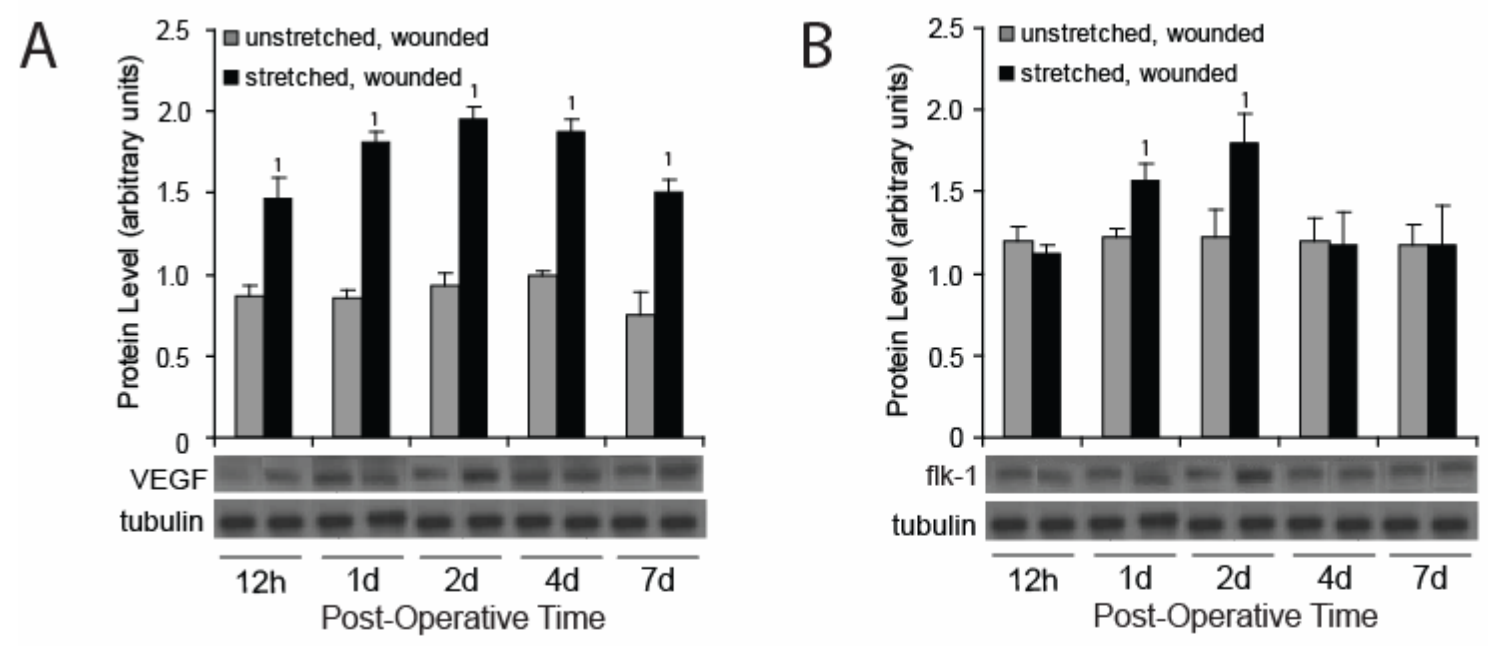
Fig. 6. Post-operative expression of Akt and pAkt._ A. Western blot of Akt with the corresponding quantification of expressed protein. Tubulin served as an internal standard. $1=$ significant $(p \leq 0.05)$ from unstretched, wounded skin at indicated post-operative times. B. Western blot of pAkt with the corresponding quantification of expressed protein. Tubulin served as an internal standard. $1=$ significant $(p \leq 0.05)$ from unstretched, wounded baseline at $3 \mathrm{~h} .2=$ significant $(p \leq 0.05)$ from unstretched, wounded skin at indicated post-operative times.

Time points preceding those represented on Western blots were not significant from baseline, and therefore not displayed in figures. 
A

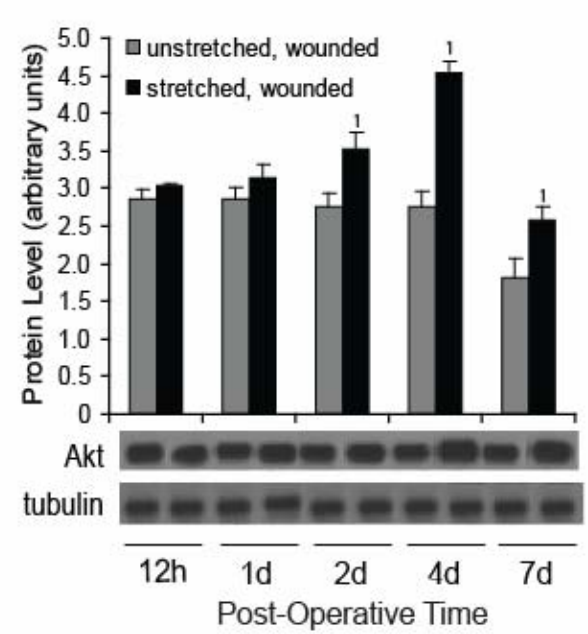

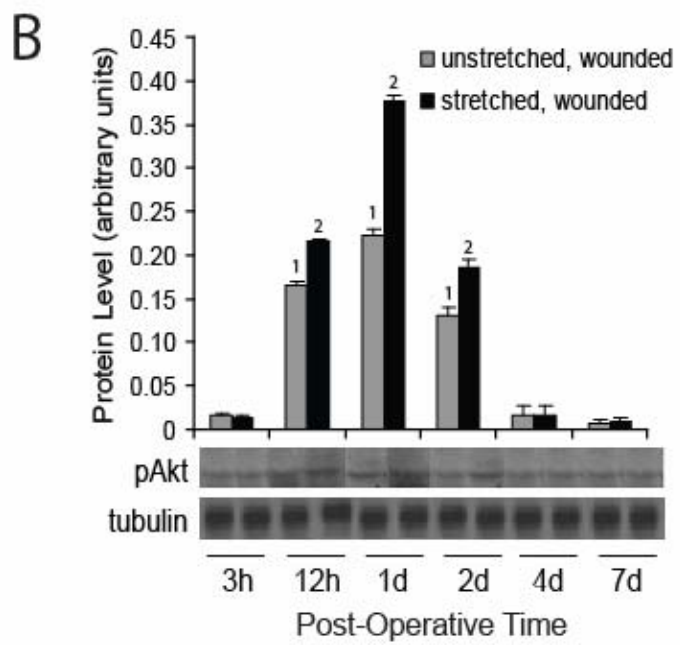


Fig. 7. The temporal relationship of protein expression in stretched, wounded flaps. Peak responses for pAkt, pIR/pIGFR, and PCNA appear small, because baseline values used for normalization were substantially elevated in Western blots. 


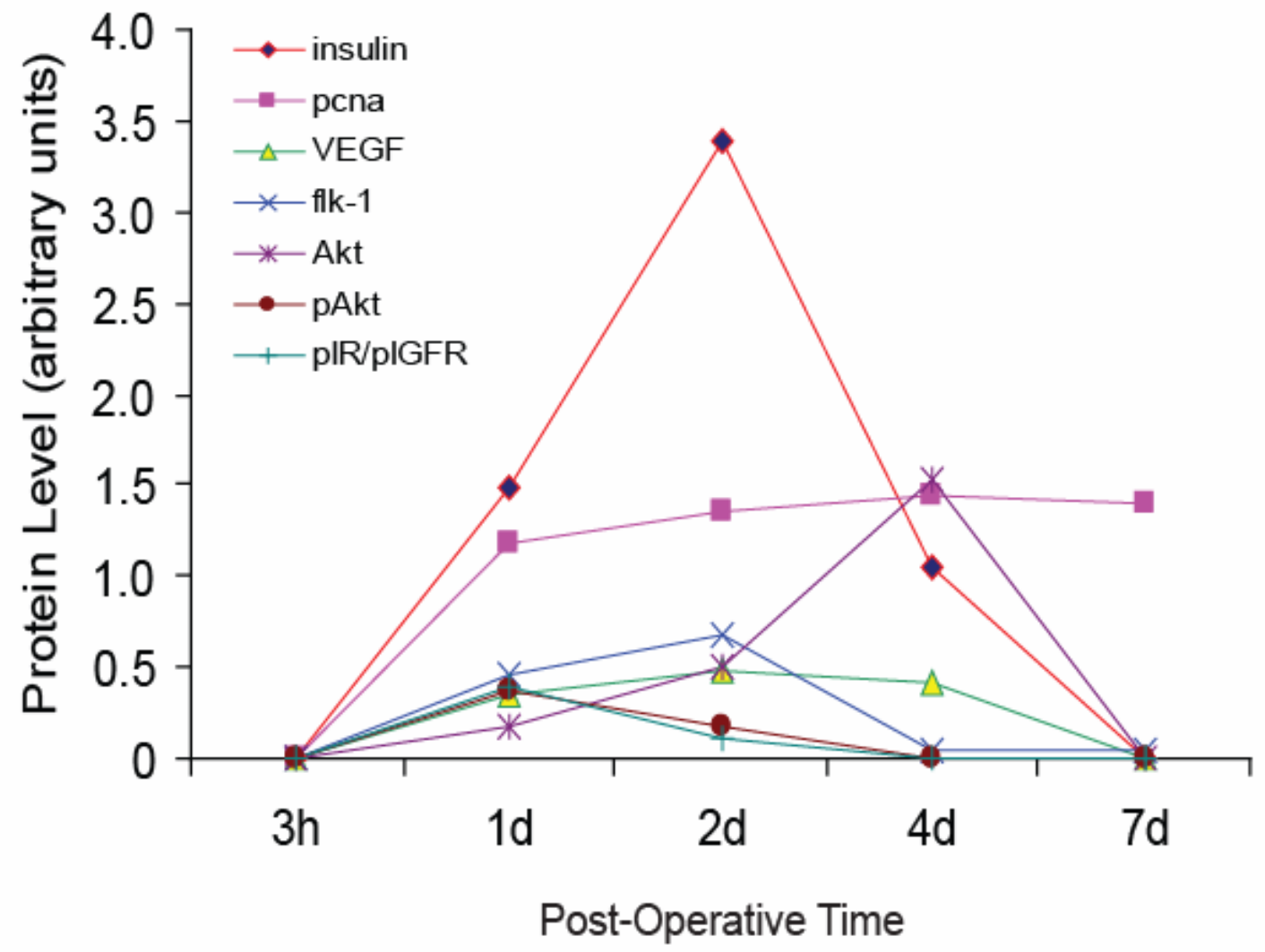




\section{REFERENCES}

1. Badr I, Brown MD, Egginton S, Hudlicka O, Milkiewicz M, Verhaeg J (2003)

Differences in local environment determine the site of physiological angiogenesis in rat skeletal muscle. Exp Physiol 88:565-568.

2. Beeson M, Sajan MP, Dizon M, Grebenev D, Gomez-Daspet J, Miura A, Kanoh Y, Powe J, Bandyopadhyay G, Standaert ML, Farese RV (2003) Activation of protein kinase C-zeta by insulin and phosphatidylinositol-3,4,5(PO4)3 is defective in muscle in type 2 diabetes and impaired glucose tolerance: amelioration by rosiglitazone and exercise. Diabetes 52:1926-1934.

3. Brewster L, Brey EM, Addis M, Xue L, Husak V, Ellinger J, Haudenschild CC, Greisler HP (2006) Improving endothelial healing with novel chimeric mitogens. Am J Surg 192:589-593.

4. Brey EM, Uriel S, Greisler HP, Mclntire LV (2005) Therapeutic neovascularization: contributions from bioengineering. Tissue Eng 11:567-584.

5. Brown MD, Kent J, Kelsall CJ, Milkiewicz M, Hudlicka O (2003) Remodeling in the microcirculation of rat skeletal muscle during chronic ischemia. Microcirculation 10:179-191.

6. Chau CH, Chen KY, Deng HT, Kim KJ, Hosoya K, Terasaki T, Shih HM, Ann DK (2002) Coordinating Etk/Bmx activation and VEGF upregulation to promote cell survival and proliferation. Oncogene 21:8817-8829. 
7. Davis GE, Saunders WB (2006) Molecular balance of capillary tube formation versus regression in wound repair: role of matrix metalloproteinases and their inhibitors. J Investig Dermatol Symp Proc 11:44-56.

8. Folkman J (2003) Fundamental concepts of the angiogenic process. Curr Mol Med 3:643-651.

9. Gordon SR (2002) Microfilament disruption in a noncycling organized tissue, the corneal endothelium, initiates mitosis. Exp Cell Res 272:127-134.

10. Haas TL (2002) Molecular control of capillary growth in skeletal muscle. Can J Appl Physiol 27:491-515.

11. Hochberg J, Raman M, Cilento E, Kemp K, Barrett M, Thomas R, Reilly F (1994) Development and evaluation of an in vivo mouse model for studying myocutaneous flap microcirculation and viability before and after suturing or stapling. Int J Microcirc Clin Exp 14:67-72.

12. Hochberg J, Beasley M, Jennings T, Zhu X, Boo S, Cilento EV, Reilly FD (1998) Effects of Hold Time, Cycling, and Catheter Fill-Volume on the Reported Benefits of Rapid Intraoperative Tissue Expansion Over Simple Undermining. Plastic Surgical Forum286-289.

13. Hochberg J, Zhu X, Beasley M, Cilento E, Reilly F (2000) The Best Estimates of Total Perfusion are From the Base of Myocutaneous Flaps. In: Plastic Surgical Forum 452. 
14. Hudlicka O (1998) Is physiological angiogenesis in skeletal muscle regulated by changes in microcirculation? Microcirculation 5:5-23.

15. Ingber DE (2002) Mechanical signaling and the cellular response to extracellular matrix in angiogenesis and cardiovascular physiology. Circ Res 91:877-887.

16. Joung IS, Iwamoto MN, Shiu YT, Quam CT (2006) Cyclic strain modulates tubulogenesis of endothelial cells in a 3D tissue culture model. Microvasc Res 71:1-11.

17. Kanda S, Mochizuki Y, Kanetake H (2003) Stromal cell-derived factor-1alpha induces tube-like structure formation of endothelial cells through phosphoinositide 3-kinase. J Biol Chem 278:257-262.

18. Kawaguchi M, Koshimura K, Sohmiya M, Murakami Y, Gonda T, Kato Y (2001) Effect of insulin on nitric oxide synthase-like immunostaining of arteries in various organs in Zucker diabetic fatty rats. Eur J Endocrinol 145:343-349.

19. Kawamura A, Horie T, Tsuda I, Abe Y, Yamada M, Egawa H, lida J, Sakata H, Onodera K, Tamaki T, Furui H, Kukita K, Meguro J, Yonekawa M, Tanaka S (2006) Clinical study of therapeutic angiogenesis by autologous peripheral blood stem cell (PBSC) transplantation in 92 patients with critically ischemic limbs. $\mathrm{J}$ Artif Organs 9:226-233.

20. Kelkar BR (2003) Induced angiogenesis for limb ischemia. Clin Orthop Relat Res234-240. 
21. Kim KE, Cho CH, Kim HZ, Baluk P, McDonald DM, Koh GY (2006) In Vivo Actions of Angiopoietins on Quiescent and Remodeling Blood and Lymphatic Vessels in Mouse Airways and Skin. Arterioscler Thromb Vasc Biol.

22. Kobayashi T, Kamata K (2002) Short-term insulin treatment and aortic expressions of IGF-1 receptor and VEGF mRNA in diabetic rats. Am J Physiol Heart Circ Physiol 283:H1761-H1768.

23. Laing AJ, Dillon JP, Condon ET, Street JT, Wang JH, McGuinness AJ, Redmond HP (2007) Mobilization of endothelial precursor cells: systemic vascular response to musculoskeletal trauma. J Orthop Res 25:44-50.

24. Layton CJ, Becker S, Osborne NN (2006) The effect of insulin and glucose levels on retinal glial cell activation and pigment epithelium-derived fibroblast growth factor-2. Mol Vis 12:43-54.

25. Li S, Huang NF, Hsu S (2005) Mechanotransduction in endothelial cell migration. J Cell Biochem 96:1110-1126.

26. Linn T, Erb D, Schneider D, Kidszun A, Elcin AE, Bretzel RG, Elcin YM (2003) Polymers for induction of revascularization in the rat fascial flap: application of vascular endothelial growth factor and pancreatic islet cells. Cell Transplant 12:769-778.

27. Luo J, Miller MW (1996) Ethanol inhibits basic fibroblast growth factormediated proliferation of C6 astrocytoma cells. J Neurochem 67:1448-1456. 
28. Luo J, Lang JA, Miller MW (1998) Transforming growth factor beta1 regulates the expression of cyclooxygenase in cultured cortical astrocytes and neurons. J Neurochem 71:526-534.

29. Machida BK, Liu-Shindo M, Sasaki GH, Rice DH, Chandrasoma P (1991) Immediate versus chronic tissue expansion. Ann Plast Surg 26:227-231.

30. Marino-Buslje C, Martin-Martinez M, Mizuguchi K, Siddle K, Blundell TL (1999) The insulin receptor: from protein sequence to structure. Biochem Soc Trans 27:715-726.

31. Milkiewicz M, Brown MD, Egginton S, Hudlicka O (2001) Association between shear stress, angiogenesis, and VEGF in skeletal muscles in vivo. Microcirculation 8:229-241.

32. Munoz-Chapuli R, Gonzalez-Iriarte M, Carmona R, Atencia G, Macias D, Perez-Pomares JM (2002) Cellular precursors of the coronary arteries. Tex Heart Inst J 29:243-249.

33. Neuman CA (1957) The Expansion of an Area of Skin by Progressive Distension of Subcutaneous Balloon. Plastic Reconstructive Surgery124-130.

34. Pelegrinelli FF, Thirone AC, Gasparetti AL, Araujo EP, Velloso LA, Saad MJ (2001) Early steps of insulin action in the skin of intact rats. J Invest Dermatol 117:971-976. 
35. Sasaki GH (1987) Intraoperative sustained limited expansion (ISLE) as an immediate reconstructive technique. Clin Plast Surg 14:563-573.

36. Schramm JC, Dinh T, Veves A (2006) Microvascular changes in the diabetic foot. Int J Low Extrem Wounds 5:149-159.

37. Shiu YT, Weiss JA, Hoying JB, Iwamoto MN, Joung IS, Quam CT (2005) The role of mechanical stresses in angiogenesis. Crit Rev Biomed Eng 33:431-510.

38. Siegert R, Weerda H, Hoffmann S, Mohadjer C (1993) Clinical and experimental evaluation of intermittent intraoperative short-term expansion. Plast Reconstr Surg 92:248-254.

39. Sieminski AL, Gooch KJ (2000) Biomaterial-microvasculature interactions. Biomaterials 21:2232-2241.

40. Sundell J, Knuuti J (2003) Insulin and myocardial blood flow. Cardiovasc Res 57:312-319.

41. Wertheimer E, Trebicz M, Eldar T, Gartsbein M, Nofeh-Moses S, Tennenbaum T (2000) Differential roles of insulin receptor and insulin-like growth factor-1 receptor in differentiation of murine skin keratinocytes. J Invest Dermatol 115:24-29.

42. Xiaorui Y (2004) Involvement of Insulin/Phosphoinositide 3-Kinase/Akt Signal pathway in 17-estradiol-mediated neuroprotection. J Biol Chem279. 
43. Zhu X, Hall D, Ridenour G, Boo S, Jennings T, Hochberg J, Cilento E, Reilly F (2003) A mouse model for studying rapic intraoperative methods of skin closure and wound healing. Med Sci Monit 9:109-115.

44. Zhu Y, Luo J, Barker J, Hochberg J, Cilento E, Reilly F (2002) Identification of genes induced by rapid intraoperative tissue expansion in mouse skin. Arch Dermatol Res 293:560-568. 


\section{INSULIN INDUCES ENHANCED PROLIFERATION AND VIABILITY OF HUMAN UMBILICAL VEIN ENDOTHELIAL CELLS (HUVECs)}

Carl D. Shrader ${ }^{a}$, Kelly M. Bailey ${ }^{b}$, Gregory W. Konat ${ }^{a}$, Eugene V. Cilento ${ }^{a, c}$, Frank D. Reilly ${ }^{a}{ }^{*}$

${ }^{a}$ Department of Neurobiology and Anatomy, School of Medicine, West Virginia University, Morgantown, WV 26506-9128

${ }^{\mathrm{b}}$ Department of Physiology and Pharmacology, Cancer Cell Biology, School of Medicine, West Virginia University, Morgantown, WV 26506-9177

${ }^{c}$ Department of Chemical Engineering, College of Engineering and Mineral Resources, West Virginia University, Morgantown, WV 26506-6070

* Corresponding author. Department of Neurobiology and Anatomy, School of Medicine, West Virginia University, Morgantown,WV 26506-9128 E-mail address: freilly@hsc.wvu.edu Telephone: 304-293-0607 Fax: 304-293-8159.

\section{ABSTRACT}

Endothelial cell proliferation and viability plays an important role in both health and disease. The multiple mechanical and chemical signals that regulate these processes are largely unknown. This investigation is a follow-up to our previous in vivo studies revealing that rapid stretch increases tissue insulin in murine skin flaps, coincident with the up-regulation of key angiogenic effectors and enhanced vascularization. In the present study, we used human umbilical vein endothelial cells (HUVECs) as an in vitro model system to determine the role of insulin in endothelial cell proliferation and survival. Colorimetric analyses (MTT based) demonstrated that insulin enhances proliferation and viability of HUVECs. Western blot analysis revealed insulin induces the up-regulation and activation of mitogenic signaling intermediates in endothelial cells. Activated insulin and insulin growth factor receptors (pIR / pIGFR), protein kinase $B$ $\left(\mathrm{pAkt}_{308}, \mathrm{pAkt}_{473}\right)$ and vascular endothelial growth factor (VEGF) were the insulinresponsive intermediates. The beneficial effects of insulin were abrogated by the inhibition of IR / IGFR or phosphoinositide-3 kinase (PI3-K), indicating that insulin-induced endothelial cell proliferation and viability are mediated through $\mathrm{pIR} / \mathrm{pIGFR}$ and PI3-K effectors. These data provide new knowledge of the beneficial effects of insulin on vascularization and tissue viability, providing a mechanistic link to the enhancement of healing in acutely stretched skin. 


\section{INTRODUCTION}

Endothelial cells $(E C)$ regulate the interaction between blood and tissue. ECs respond to various stimuli to maintain blood homeostasis and act as a selective barrier (e.g. filter) that regulates cell growth and metabolism, helps maintain the extracellular matrix, and modulates blood flow (Brewster et al., 2006; Davis and Saunders, 2006; Laing et al., 2007). All of these processes are critical to survival (Kawamura et al., 2006; Kelkar, 2003; Schramm et al., 2006). Moreover, ECs are of particular interest because of their involvement in many distinct and unrelated diseases. There has been an extensive effort by scientists to understand the mechanisms that are tightly controlled by local factors (e.g. growth factors), alterations in the extracellular matrix, and changes in mechanical force (i.e. blood flow, rapid stretch, muscle strain overload) (Badr et al., 2003; Brey et al., 2005; Brown et al., 2003; Folkman, 2003; Hudlicka, 1998; Milkiewicz et al., 2001; Sieminski and Gooch, 2000). In spite of numerous investigations, a mechanistic understanding has not evolved (Hudlicka, 1998; Shrader et al., 2007).

Our previous work implicated tissue insulin in rapid stretch-enhanced EC mitogenesis and vascularity in dorsal distally based skin flaps (Shrader et al., 2007). Our findings agreed with those reporting a role for insulin as a key mitogenic regulator, potentially involved in improving vascularization (Beeson et al., 2003; Gordon et al., 2002; He et al., 2006; Jiang et al., 2003; Kobayashi and Kamata, 2002; Pelegrinelli et al., 2001; Sundell and Knuuti, 2003; Wertheimer et al., 2000). While there is only a $40 \%$ amino acid sequence homology between 
insulin and insulin growth factor, both IR and IGFR respond to insulin activation and are associated with mitogenic insulin signaling (Layton et al., 2006; MarinoBuslje et al., 1999; Ullrich et al., 1986). However, these investigations do not directly link tissue insulin to EC activation, and the exact mechanism of enhanced proliferation and vascularity remains elusive. Moreover, the Western blot data in our in vivo research represent the numerous cell types found in murine skin (Shrader et al., 2007). In vitro analysis was warranted to focus solely on ECs. This allowed for a conclusive characterization of the implicated pathway(s) using paradigms that would prove lethal in an in vivo model.

In this study, we directly examined the effects of insulin on EC proliferation and viability, and characterized the intracellular intermediates involved in these processes. Cell cultures provide an environment free from a diverse variety of mediators that are released from wounded, stretched skin that may serve as potent EC mitogens. Using human umbilical vein endothelial cells (HUVECs), we demonstrated that insulin impacts intracellular signaling, significantly altering proliferation and viability by activating PI3-K effectors Akt and VEGF. 


\section{MATERIALS AND METHODS}

Materials

Reagents and other supplies were obtained from the following commercial sources: Cell proliferation kit (MTT) from Roche Diagnostics (Germany); HNMPA (hydroxy-2-naphthalenylmethyl-phosphonic acid) and tyrphostin 23 from BIOMOL International (Plymouth Meeting, PA); LY 294002 from Chemicon International (Temecula, CA); Antibodies against pAkt (Ser 473), pAkt (Thr 308), VEGF, pIR / pIGFR from Santa Cruz Biotechnology, Inc (Santa Cruz, CA); Bovine insulin from Sigma Aldrich (St. Louis, MO).

Cell culture

Primary cultured endothelial cells from the human umbilical vein (HUVECs) were isolated as previously described (Ashton et al., 1999; Beardsley et al., 2004) from consenting healthy, full-term patients according to approved institutional guidelines. Purity was assessed by morphology and immunocytochemistry of CD31. HUVECs were grown in medium MCDB 131 containing $1 \%$ pen/strep, $1 \%$ L-glutamine, $20 \%$ heat-inactivated newborn calf serum, $5 \%$ heat-inactivated human serum and endothelial cell growth supplement for proliferation assays and Western blot analysis. This growth medium ( $25 \%$ serum) was diluted 2 -fold and 4 -fold with serum free medium for viability analysis. Cells were starved for one hour in serum free medium prior to any pharmacological treatment.

Proliferation and viability assay 
Cellular proliferation and viability were determined using a MTT analysis kit. Two thousand HUVECs were plated per well in 96 well microplates for $24 \mathrm{~h}-$ $72 \mathrm{~h}$ and grew in $100 \mu \mathrm{L}$ of culture medium. Cells were plated in three different concentrations of culture serum ( $25 \%$ serum, $12.5 \%$ serum, $\& 6.25 \%$ serum). They were treated with insulin $(0.5 \mu \mathrm{M}, 1.0 \mu \mathrm{M}, 1.5 \mu \mathrm{M})$, PI3-K blocker LY 294002, IR blocker HNMPA, IR / IGFR blocker tyrphostin 23, and insulin in combination with each blocker. Each treatment was repeated in four individual culture wells and replicated three times on new 96-well microplates over $24 \mathrm{~h}$, 48h, and $72 \mathrm{~h}$. MTT labeling reagent $(10 \mu \mathrm{L})$ was added for $4 \mathrm{~h}$ followed by solubilization solution $(100 \mu \mathrm{L})$ for overnight treatment. Absorptions from microplates were read in a Bio-Tek microplate reader.

Western blot analysis

The quantitative immunoblotting protocol was similar to that used previously (Luo and Miller, 1996). All analyses were repeated three times. Means of the triplicate measurements \pm SEM were graphed. Time points represented on figures were chosen based on recent publications (Burgering et al., 1995; Folkman et al., 1989; Lammers et al., 1989).

Protein extraction from cells was accomplished by the following protocol: cell medium was carefully removed and $0.5 \mathrm{ml}$ of RIPA buffer (1X PBS, 1\% NP-40, $0.5 \%$ sodium deoxycholate, $0.1 \%$ SDS; inhibitor $-10 \mathrm{mg} / \mathrm{ml}$ PMSF at $10 \mu \mathrm{L} /$ $\mathrm{ml}$ RIPA, aprotinin at $30 \mu \mathrm{L} / \mathrm{ml}$ RIPA and $100 \mathrm{mM}$ sodium orthovanadate at 10 $\mu \mathrm{L} / \mathrm{ml}$ RIPA) with inhibitors were added. A cell scraper was used to remove cells from plates and the supernatant (containing cell lysate) was extracted into a 
micro-centrifuge tube and placed on ice for $10 \mathrm{~min}$. Samples were then spun down at $10,000 \mathrm{G}$ for $10 \mathrm{~min}$ at $4^{\circ} \mathrm{C}$. The supernatant was then transferred to clean eppendorf tubes and samples were stored at $-20^{\circ} \mathrm{C}$. Protein concentration was determined using the Lowry assay with a Bio-Tek microplate reader. Protein samples (50 $\mu \mathrm{g} / \mathrm{lane})$ were loaded on SDS-polyacrylamide gels (PAGE), separated by electrophoresis and then transferred to nitrocellulose membranes. Non-specific activity was blocked by washing the membrane with $5.0 \%$ nonfat dry milk and $0.10 \%$ Tween-20 in $0.01 \mathrm{M}$ PBS (TPBS) for $1 \mathrm{~h}$ at room temperature. The membranes were incubated overnight at $4^{\circ} \mathrm{C}$ with primary antibodies. After three washes in TPBS, the membranes were incubated with a peroxidaseconjugated secondary antibody (Amersham, Piscataway, NJ ; 1:2000 in TPBS) for $1 \mathrm{~h}$. The immune complexes were detected by the enhanced chemiluminescence (ECL) method (Amersham, Piscataway, NJ). Non-specific binding was assessed on immunoblots processed without the primary or secondary antibodies. The results of such controls were consistently negative.

In order to control for inter-sample variation of the total amount of protein loaded onto the gel, the membranes were stripped of antibodies directed against target proteins and re-probed with anti-tubulin $\mathrm{Ab}$ as an internal standard. Densitometric readings of target protein contents were normalized against those of the internal standard using Optimas 6.2. The membranes were stripped by incubating in a solution containing $100 \mathrm{mM} \beta$-mercaptoethanol, 2.0\% SDS, and $62.5 \mathrm{mM}$ Tris- $\mathrm{HCl}\left(\mathrm{pH} \mathrm{6.7)}\right.$ for $30 \mathrm{~min}$ at $50^{\circ} \mathrm{C}$ or overnight at $4^{\circ} \mathrm{C}$. The membranes were then washed twice with TPBS for 15 min. Non-specific binding 
was blocked with either $5.0 \%$ milk or $2.5 \%$ BSA in PBS, and the membrane was reblotted as described above. With this method, we were able to detect small differences in protein expression (Luo et al., 1998). The relative amounts of insulin-induced protein expression in the films prepared from the immunoblots were quantified using an LKB Ultrascan XL Laser Densitometer.

Statistical analysis

Differences among treatment groups were tested using a one-way analysis of variance (ANOVA) and Tukey's (post hoc) test. Differences with $p$ values $\leq 0.05$ were considered statistically significant. Data are presented in figures as mean \pm standard error of the mean (SEM). 


\section{RESULTS AND DISCUSSION}

A major challenge in understanding vascular regulation is the lack of knowledge regarding the mechanisms that activate endothelium. More specifically, the mitogenic stimuli and intracellular signaling pathways triggering proliferation and viability are largely unknown despite their demonstrated importance in both health and disease. Mitogenesis and survival are critical in controlling new blood vessel growth (e.g. angiogenesis) and delaying vascular remodeling (e.g. apoptosis). These processes are closely regulated to prevent disease formation (Kawamura et al., 2006; Kelkar, 2003; Schramm et al., 2006). For example, during angiogenesis, mitogenic activity of endothelium promotes new capillary formation from existing capillary beds. It is involved in a variety of physiological and pathological roles, and has become a central focus for many investigators (Brey et al., 2005; Folkman, 2003; Hudlicka, 1998; Sieminski and Gooch, 2000).

Our previous in vivo studies in wounded, stretched skin indicate a role for tissue insulin in enhanced EC proliferation and survival, coincident with increases in nutrient blood flow and improved tissue viability (Shrader et al., 2007; Zhu et al., 2002; Zhu et al., 2003). We hypothesized that insulin, working through IR / IGFR, stimulates PI3-K to promote the activation and up-regulation of Akt and VEGF which augment proliferation and survival (Fig. 1). This, in turn, improves blood flow by enhancing vascularity in rapidly stretched skin. We chose an in vitro approach to evaluate insulin's role in these EC activities. Our cell culture model has the following features: (1) cultured cells allow investigation of EC 
proliferation and viability in a controlled, highly reproducible environment, (2) culture systems permit blockade studies that are lethal in animal models, (3) HUVECs express insulin receptors, allowing for the characterization of insulin signaling, and (4) these cells are easily cultured and maintained for experimentation and evaluation over a duration of several days.

Insulin induces proliferation of HUVECs through IR / IGFR and PI3-K intracellular signaling

Application of exogenous insulin over the physiological range $(0.5 \mu \mathrm{M}, 1.0$ $\mu \mathrm{M}, 1.5 \mu \mathrm{M})$ induced significant dose-dependent increases in proliferation (absorbance units) to $1.0 \mu \mathrm{M}$ insulin and $1.5 \mu \mathrm{M}$ insulin in HUVECs containing $25 \%$ serum (Fig. $2 \mathrm{~A}$ and $\mathrm{B}$ ). The $0.5 \mu \mathrm{M}$ insulin dose had no effect on $\mathrm{EC}$ mitogenesis. These responses were attenuated with LY 294002 (PI3-K blockade), and with HNMPA (IR blockade) and tyrphostin 23 (IR / IGFR blockade) (Fig. 2 A and B). Results of culture medium alone and with LY 294002, HNMPA, and tyrphostin 23 were statistically identical and therefore pooled and represented as control (Fig. 2 A and B; Fig. 6 A \& B). These results indicate that insulin, working through both IR / IGFR, stimulates endothelial cell proliferation by activating $\mathrm{PI} 3-\mathrm{K}$ effectors.

Since EC mitogenesis has been shown to be mediated through PI3-K and downstream effectors Akt and VEGF (Chau et al., 2002; Haas, 2002; Ingber, 2002; Kanda et al., 2003; Kawaguchi et al., 2001, Xiaorui, 2004), we hypothesized that insulin-induced increases in proliferation were mediated 
through PI3-K downstream effectors pAkt (Thr 308), pAkt (Ser 473), and VEGF. The optimal dose of insulin $(1.5 \mu \mathrm{M})$, determined from Fig. 2, was used to test this hypothesis. Western blots revealed activation of IR / IGFR (Fig. 3). This response was not antagonized by PI3-K blockade (Fig. 3). Although pAkt (Ser 473) played no role in insulin-induced proliferation, pAkt (Thr 308) activation and VEGF expression were confirmed and inhibited by LY 294002 (Figs. 4 and 5). These data demonstrated that insulin induces proliferation through IR / IGFRprovoked pAkt (Thr 308) and VEGF activation and up-regulation. They also support recent evidence attesting to insulin's role as a key mitogenic regulator and indicate a biologically significant role for insulin in vascular biology (Gordon et al., 2002; He et al., 2006; Kobayashi and Kamata, 2002; Linn, 2003; Pelegrinelli et al., 2001; Sundell and Knuuti, 2003; Wertheimer et al., 2000).

Insulin enhances viability of HUVECs through IR / IGFR and PI3-K intracellular signaling

Application of exogenous insulin over the physiological range $(0.5 \mu \mathrm{M}, 1.0$ $\mu \mathrm{M}, 1.5 \mu \mathrm{M})$ provoked significant dose-dependent increases in survival (absorbance units) to $1.0 \mu \mathrm{M}$ insulin and $1.5 \mu \mathrm{M}$ insulin in HUVECs containing $12.5 \%$ serum (Fig. $6 \mathrm{~A}$ and $\mathrm{B}$ ). The $0.5 \mu \mathrm{M}$ insulin dose had no effect on EC viability. These responses were attenuated with LY 294002 (PI3-K blockade) and with HNMPA (IR blockade) and tyrphostin 23 (IR / IGFR blockade) (Fig. 6 A and B). These results indicated that insulin, working through both IR / IGFR, enhances endothelial cell survival via PI3-K effectors. 
PI3-K signaling promotes cell viability (i.e. survival) through downstream effectors, predominantly by activating Akt (Chau et al., 2002; Haas, 2002; Ingber, 2002; Kanda et al., 2003; Kawaguchi et al., 2001, Xiaorui, 2004). Therefore, we hypothesized that insulin increased survival through PI3-K downstream effectors pAkt (Thr 308), pAkt (Ser 473), and VEGF. The optimal dose of insulin (1.5 $\mu \mathrm{M})$, determined from Fig. 6, was used to conduct these experiments. Western blots revealed activation of pIR / pIGFR. This response was not antagonized by PI3-K blockade (Fig. 7). Simultaneous activation of pAkt (Thr 308) and pAkt (Ser 473) also was confirmed and blocked by LY 294002 verifying a role for both phosphorylated states of Akt in insulin signaling (Fig. 8 A and B). In contrast to proliferation assay results, VEGF played no role in insulin-enhanced survival. These data demonstrated that insulin enhances EC viability through pAkt (Thr 308) and pAkt (Ser 473) up-regulation and activation.

\section{Concluding remarks}

We have presented a novel in vitro approach to study the effects of insulin on proliferation and viability of endothelial cells. These investigations characterize the mechanism(s) triggering insulin-induced intracellular signaling that promote mitogenesis and survival. This study also bridges the gap in knowledge by clarifying insulin's role in the reported benefits of mechanical stimulation (e.g. rapid stretch) in our murine model. Moreover, the data from cultured human cells confirm the validity of data obtained from this animal model. Together they provide a framework for future in vitro studies that will explicate insulin's role, if any, in endothelial cell migration and tubulogenesis. 
Fig. 1. Proposed insulin-mediated intracellular signaling pathways that stimulate endothelial cell proliferation and viability. We hypothesize insulin activates IR / IGFR promoting PI3K signaling through Akt and VEGF, enhancing HUVEC proliferation and survival. 


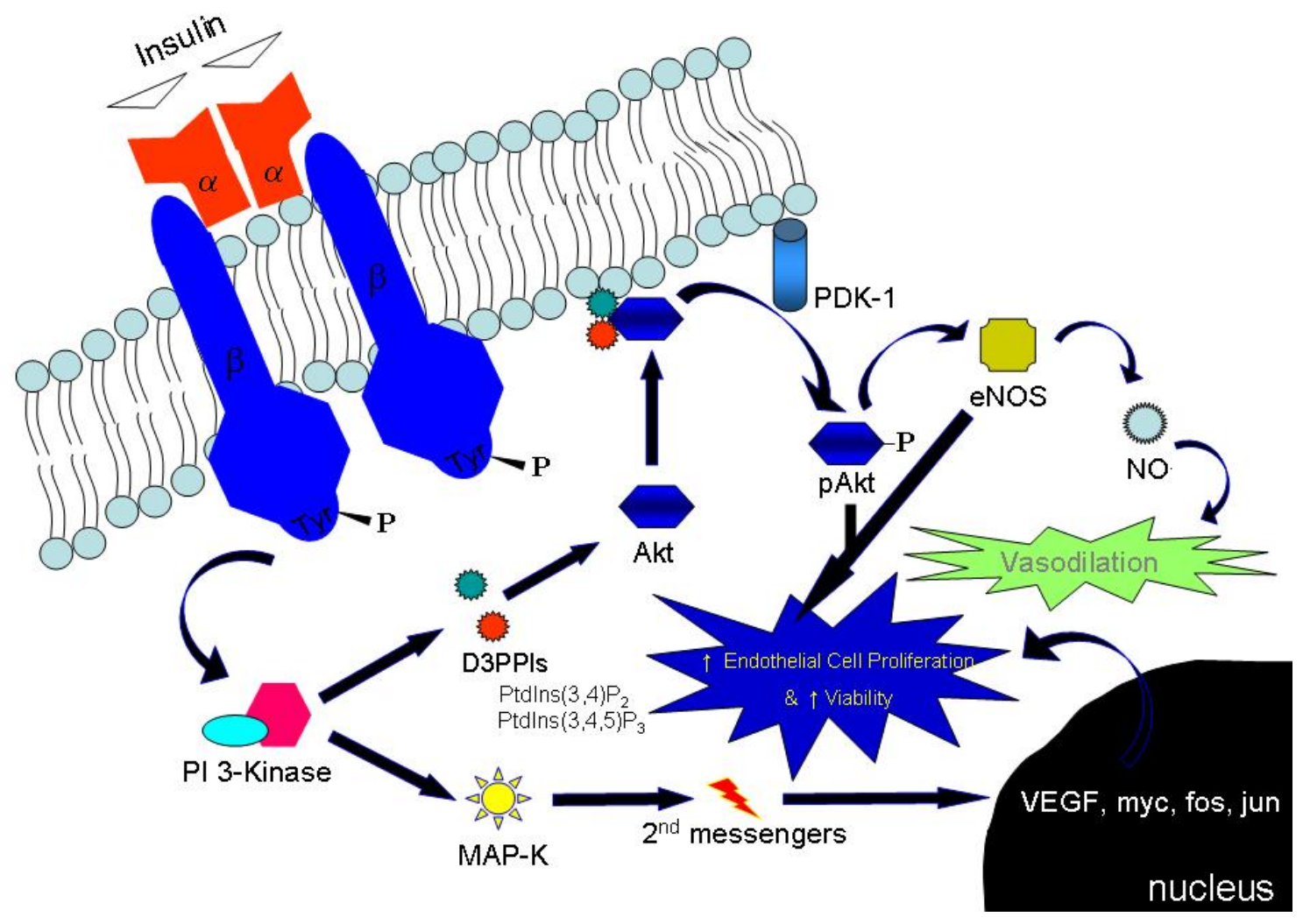


Fig. 2. A \& B. Colorimetric analyses revealed dose-dependent enhanced proliferation (measured by absorbance) of HUVECs in response to exogenous insulin under ideal culture conditions (25\% serum). Proliferation was inhibited by PI3-K blockade (LY), IR / IGFR blockade (tyrphostin 23) and by IR blockade (HNMPA). 1 = significant $(\leq 0.05)$ from control and each treatment at $24 \mathrm{~h}, 48 \mathrm{~h}$ and $72 \mathrm{~h}$. 
A

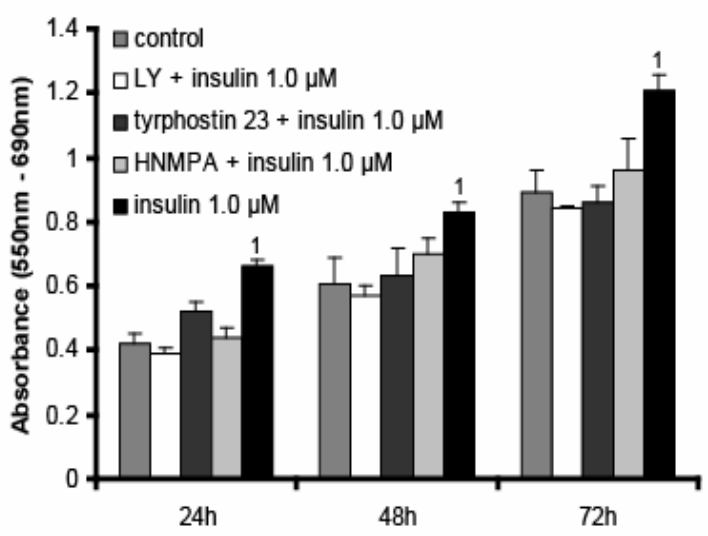

B

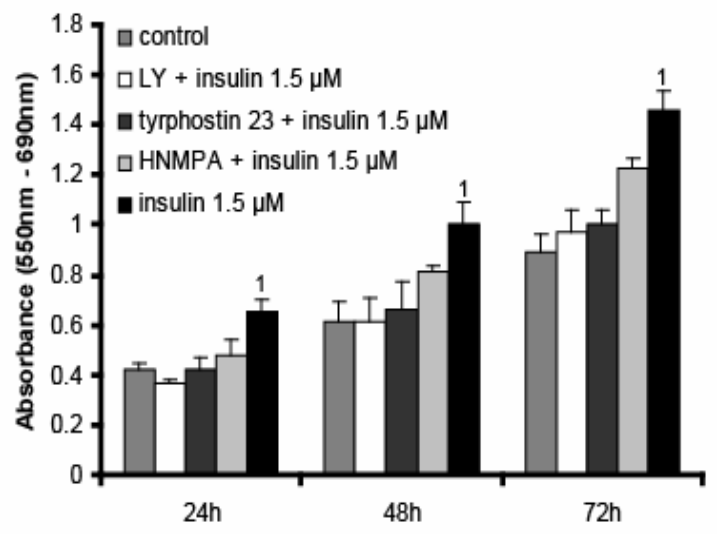


Fig. 3. Densitometry (right panel) of Western blots (left panel) revealed activation of IR / IGFR in response to exogenous insulin under ideal culture conditions (25\% serum). Receptor activation was not altered by PI3-K blockade (LY). $1=$ significant $(\leq 0.05)$ from control. 

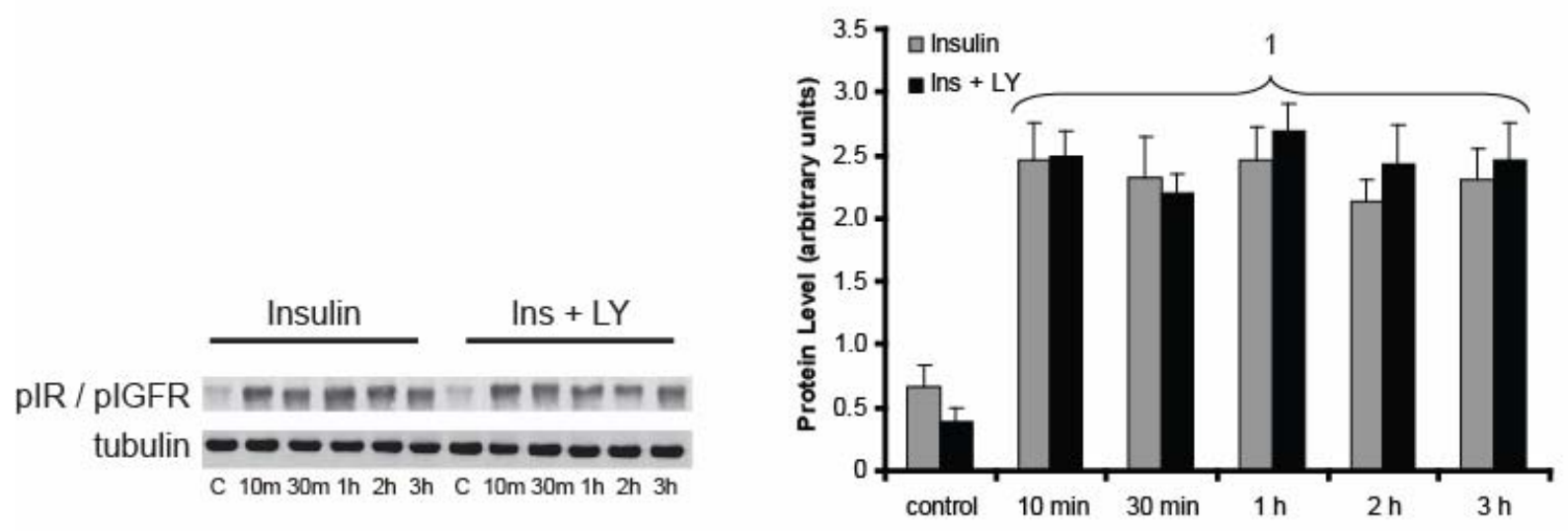
Fig. 4. Densitometry (right panel) of Western blots (left panel) revealed activation of Akt in response to exogenous insulin under ideal culture conditions $(25 \%$ serum). Activation was inhibited by PI3-K blockade (LY). $1=$ significant $(\leq 0.05)$ from control. 2 = significant $(\leq 0.05)$ from Ins $+L Y$. 


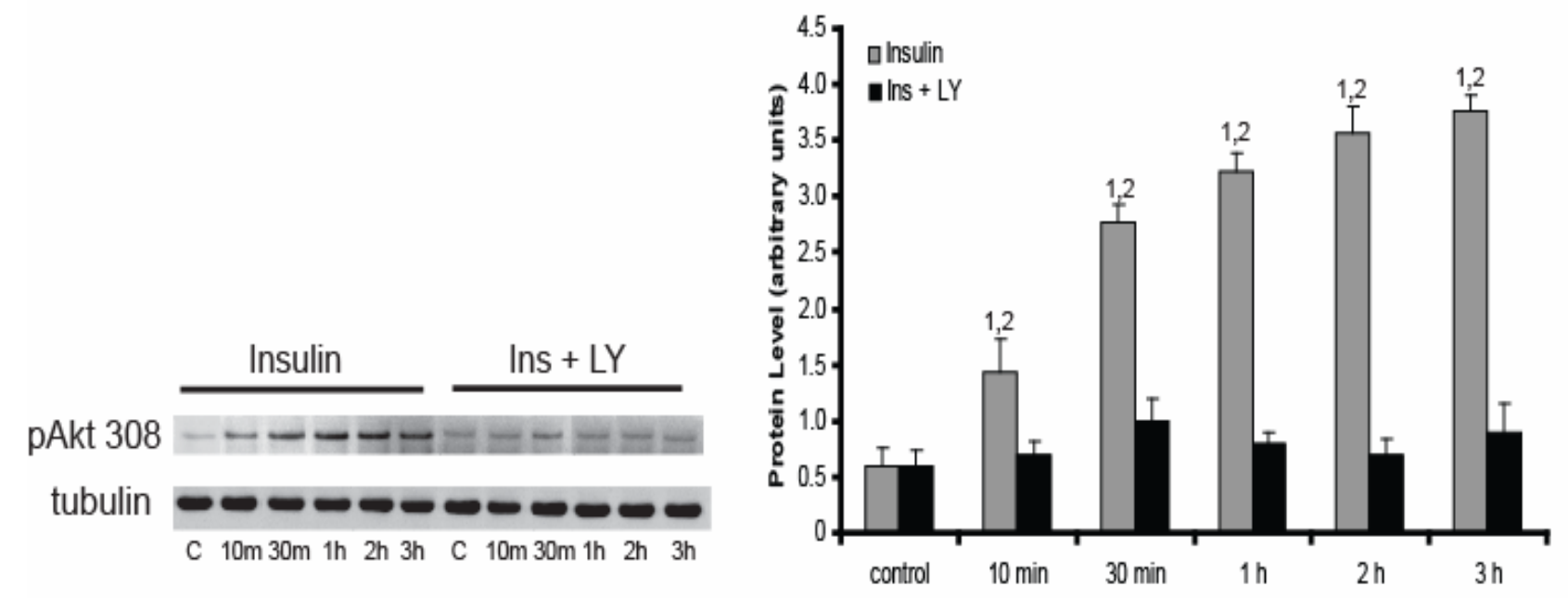


Fig. 5. Densitometry (right panel) of Western blots (left panel) revealed upregulation of VEGF in response to exogenous insulin under ideal culture conditions ( $25 \%$ serum). Up-regulation was inhibited by PI3-K blockade (LY). 1 $=$ significant $(\leq 0.05)$ from control and 10 min post-insulin treatment. $2=$ significant $(\leq 0.05)$ from Ins + LY. 


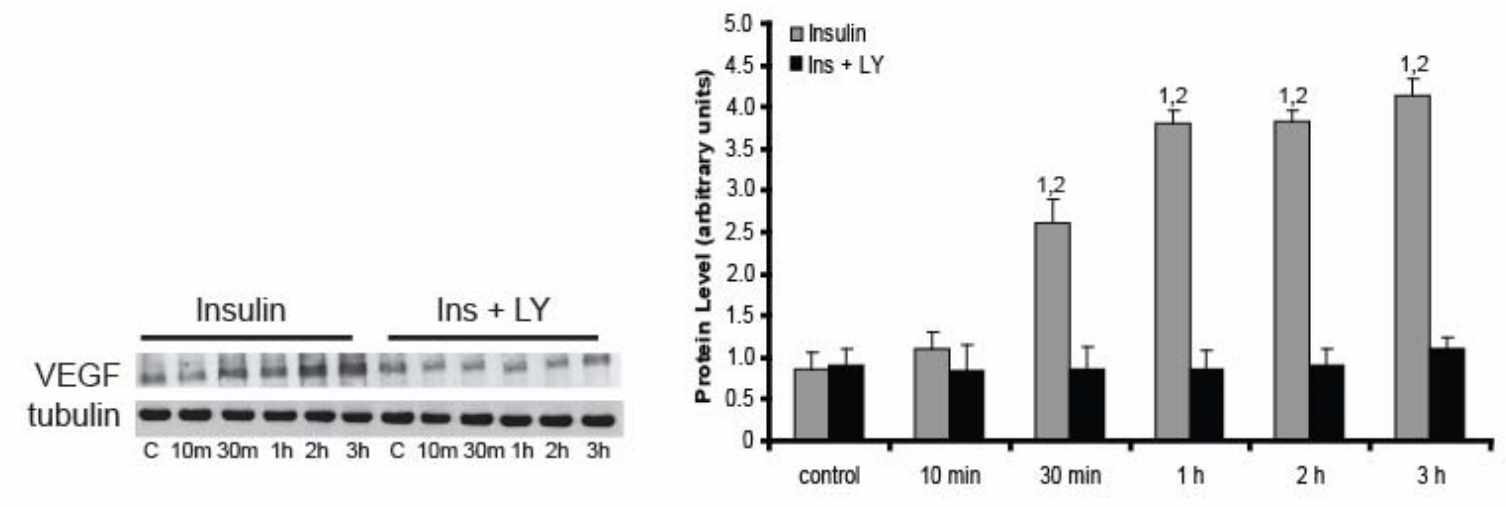


Fig. 6. A \& B. Colorimetric analyses revealed dose-dependent enhanced viability (measured by absorbance) of HUVECs in response to exogenous insulin under non-ideal culture conditions (12.5\% serum). These responses were inhibited by PI3-K blockade (LY), IR / IGFR blockade (tyrphostin 23) and by IR blockade (HNMPA). 1 = significant $(\leq 0.05)$ from control and each treatment at $24 \mathrm{~h}, 48 \mathrm{~h}$ and $72 \mathrm{~h}$. 

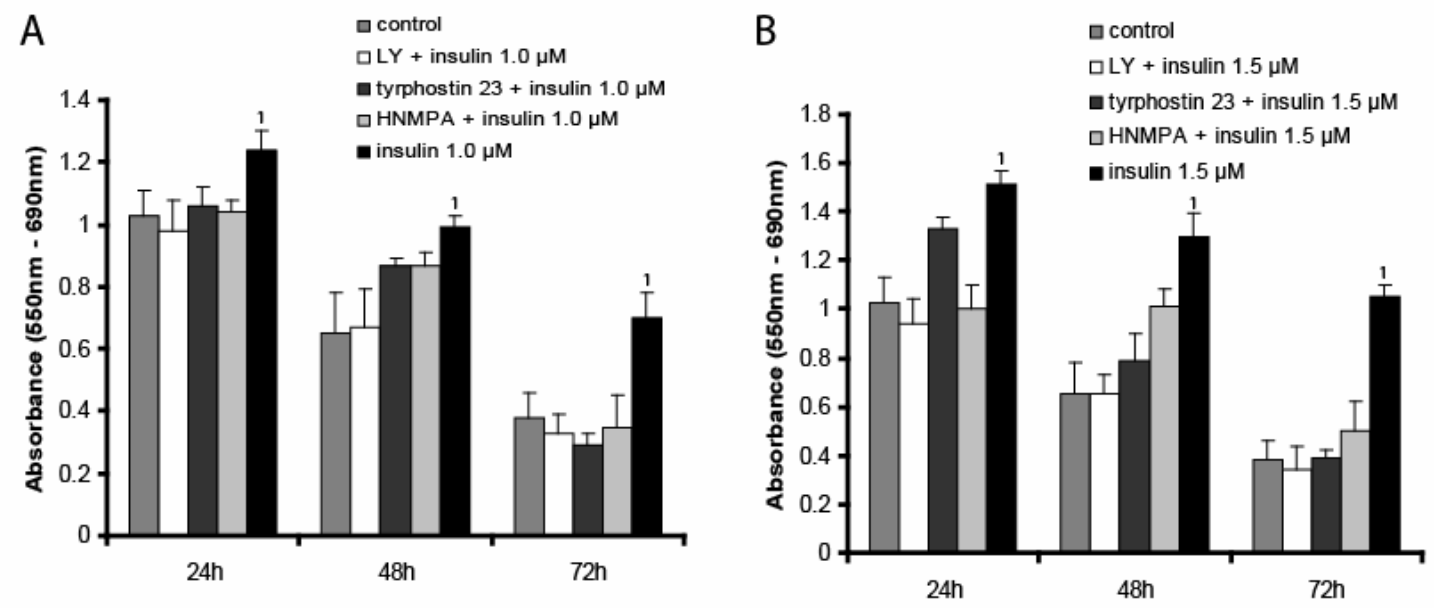
Fig. 7. Densitometry (right panel) of Western blots (left panel) revealed activation of IR / IGFR in response to exogenous insulin under non-ideal culture conditions (12.5\% serum). Receptor activation was not altered by PI3-K blockade (LY). $1=$ significant $(\leq 0.05)$ from control. 


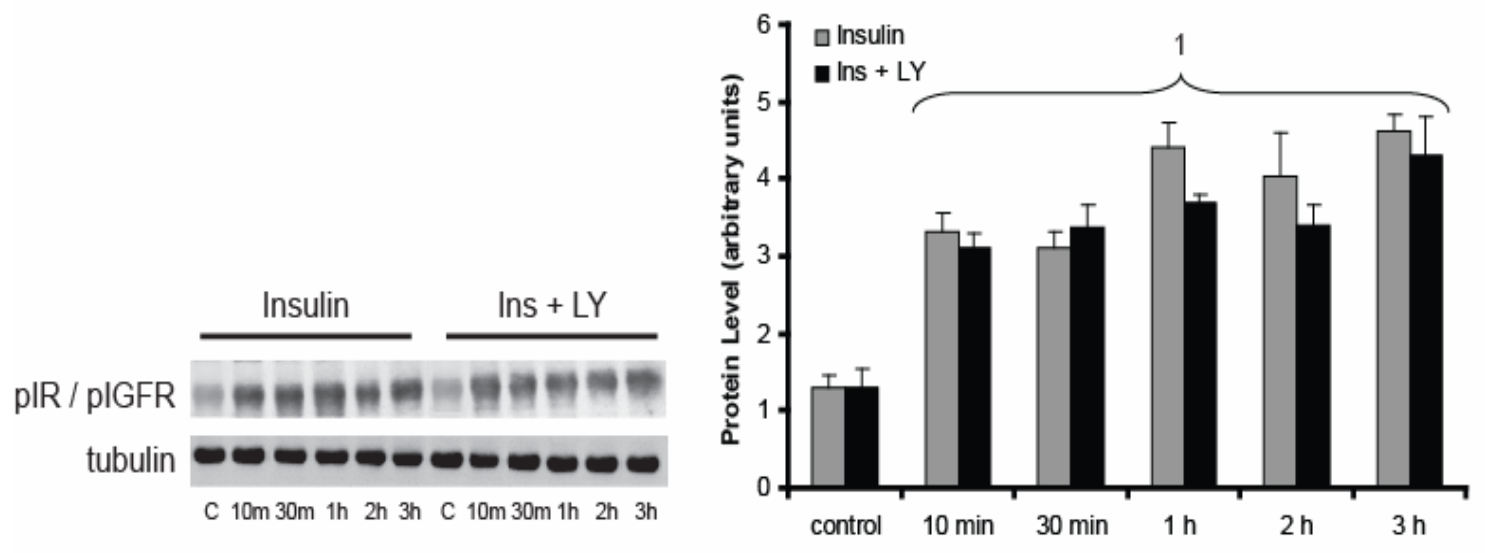


Fig. 8. A \& B. Densitometry (right panel) of Western blots (left panel) revealed activation of Akt in response to exogenous insulin under non-ideal culture conditions (12.5\% serum). Activation was inhibited by PI3-K blockade (LY). $1=$ significant $(\leq 0.05)$ from control. 2 = significant $(\leq 0.05)$ from Ins + LY at indicated post-insulin treatment time point. 

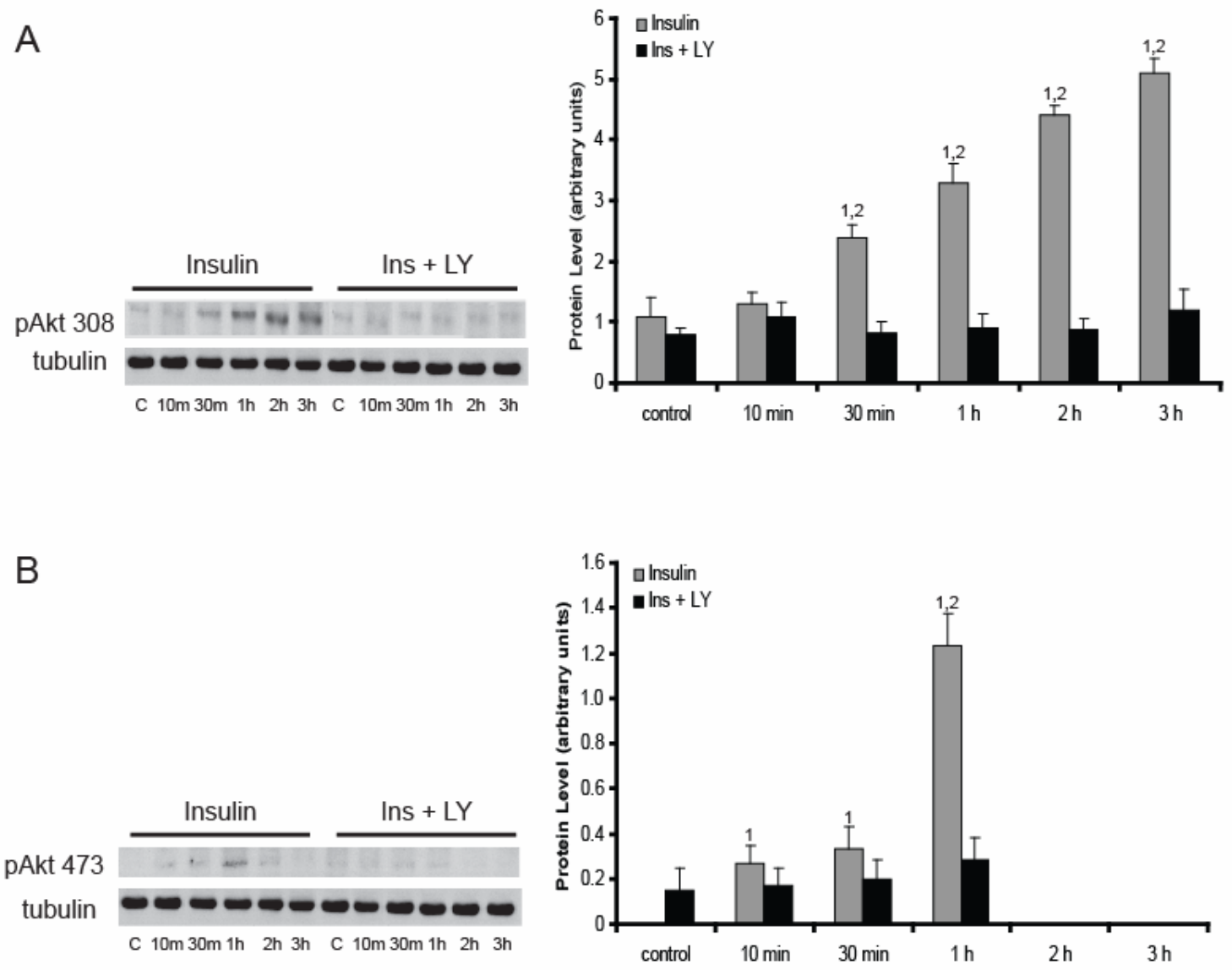


\section{REFERENCES}

1. Badr I, Brown MD, Egginton S, Hudlicka O, Milkiewicz M, Verhaeg J (2003)

Differences in local environment determine the site of physiological angiogenesis in rat skeletal muscle. Exp Physiol 88:565-568.

2. Beardsley A, Fang K, Mertz H, Castranova V, Friend S, Liu J (2004) Loss of caveolin-1 polarity impedes endothelial cell polarization and directional movement. J Biol Chem 280:3541-3547.

3. Beeson M, Sajan MP, Dizon M, Grebenev D, Gomez-Daspet J, Miura A, Kanoh Y, Powe J, Bandyopadhyay G, Standaert ML, Farese RV (2003) Activation of protein kinase C-zeta by insulin and phosphatidylinositol-3,4,5(PO4)3 is defective in muscle in type 2 diabetes and impaired glucose tolerance: amelioration by rosiglitazone and exercise. Diabetes 52:1926-1934.

4. Brewster L, Brey EM, Addis M, Xue L, Husak V, Ellinger J, Haudenschild CC, Greisler HP (2006) Improving endothelial healing with novel chimeric mitogens. Am J Surg 192:589-593.

5. Brey EM, Uriel S, Greisler HP, McIntire LV (2005) Therapeutic neovascularization: contributions from bioengineering. Tissue Eng 11:567-584.

6. Brown MD, Kent J, Kelsall CJ, Milkiewicz M, Hudlicka O (2003) Remodeling in the microcirculation of rat skeletal muscle during chronic ischemia. Microcirculation 10:179-191. 
7. Burgering BM, Coffer PJ (1995) Protein kinase B (c-Akt) in phosphatidylinositol-3-OH kinase signal transduction. Nature 376:599-602.

8. Chau CH, Chen KY, Deng HT, Kim KJ, Hosoya K, Terasaki T, Shih HM, Ann DK (2002) Coordinating Etk/Bmx activation and VEGF upregulation to promote cell survival and proliferation. Oncogene 21:8817-8829.

9. Davis GE, Saunders WB (2006) Molecular balance of capillary tube formation versus regression in wound repair: role of matrix metalloproteinases and their inhibitors. J Investig Dermatol Symp Proc 11:44-56.

10. Folkman J, Watson K, Ingber D, Hanahan D (1989) Induction of angiogenesis during the transition from hyperplasia to neoplasia. Nature 339:58-61.

11. Folkman J (2003) Fundamental concepts of the angiogenic process. Curr Mol Med 3:643-651.

12. Gordon SR (2002) Microfilament disruption in a noncycling organized tissue, the corneal endothelium, initiates mitosis. Exp Cell Res 272:127-134.

13. Haas TL (2002) Molecular control of capillary growth in skeletal muscle. Can J Appl Physiol 27:491-515.

14. He Z, Opland DM, Way KJ, Ueki K, Bodyak N, Kang PM, Izumo S, Kulkarni RN, Wang B, Liao R, Kahn CR, King GL (2006) Regulation of vascular endothelial growth factor expression and vascularization in the myocardium by 
insulin receptor and PI3K/Akt pathways in insulin resistance and ischemia. Arterioscler Thromb Vasc Biol 26:787-793.

15. Hudlicka O (1998) Is physiological angiogenesis in skeletal muscle regulated by changes in microcirculation? Microcirculation 5:5-23.

16. Ingber DE (2002) Mechanical signaling and the cellular response to extracellular matrix in angiogenesis and cardiovascular physiology. Circ Res $91: 877-887$

17. Jiang ZY, He Z, King BL, Kuroki T, Opland DM, Suzuma K, Suzuma I, Ueki K, Kulkarni RN, Kahn CR, King GL (2003) Characterization of multiple signaling pathways of insulin in the regulation of vascular endothelial growth factor expression in vascular cells and angiogenesis. J Biol Chem 278:31964-31971.

18. Kanda S, Mochizuki Y, Kanetake H (2003) Stromal cell-derived factor-1alpha induces tube-like structure formation of endothelial cells through phosphoinositide 3-kinase. J Biol Chem 278:257-262.

19. Kawaguchi M, Koshimura K, Sohmiya M, Murakami Y, Gonda T, Kato Y (2001) Effect of insulin on nitric oxide synthase-like immunostaining of arteries in various organs in Zucker diabetic fatty rats. Eur J Endocrinol 145:343-349.

20. Kawamura A, Horie T, Tsuda I, Abe Y, Yamada M, Egawa H, lida J, Sakata H, Onodera K, Tamaki T, Furui H, Kukita K, Meguro J, Yonekawa M, Tanaka S (2006) Clinical study of therapeutic angiogenesis by autologous peripheral blood 
stem cell (PBSC) transplantation in 92 patients with critically ischemic limbs. $\mathrm{J}$ Artif Organs 9:226-233.

21. Kelkar BR (2003) Induced angiogenesis for limb ischemia. Clin Orthop Relat Res234-240.

22. Kim KE, Cho CH, Kim HZ, Baluk P, McDonald DM, Koh GY (2006) In Vivo Actions of Angiopoietins on Quiescent and Remodeling Blood and Lymphatic Vessels in Mouse Airways and Skin. Arterioscler Thromb Vasc Biol.

23. Kobayashi T, Kamata K (2002) Short-term insulin treatment and aortic expressions of IGF-1 receptor and VEGF mRNA in diabetic rats. Am J Physiol Heart Circ Physiol 283:H1761-H1768.

24. Laing AJ, Dillon JP, Condon ET, Street JT, Wang JH, McGuinness AJ, Redmond HP (2007) Mobilization of endothelial precursor cells: systemic vascular response to musculoskeletal trauma. J Orthop Res 25:44-50.

25. Lammers R, Gray A, Schlessinger J, Ullrich A (1989) Differential signaling potential of insulin- and IGF-1 receptor cytoplasmic domains. EMBO J 8:13691375.

26. Layton CJ, Becker S, Osborne NN (2006) The effect of insulin and glucose levels on retinal glial cell activation and pigment epithelium-derived fibroblast growth factor-2. Mol Vis 12:43-54. 
27. Linn T, Erb D, Schneider D, Kidszun A, Elcin AE, Bretzel RG, Elcin YM (2003) Polymers for induction of revascularization in the rat fascial flap: application of vascular endothelial growth factor and pancreatic islet cells. Cell Transplant 12:769-778.

28. Luo J, Miller MW (1996) Ethanol inhibits basic fibroblast growth factormediated proliferation of C6 astrocytoma cells. J Neurochem 67:1448-1456.

29. Luo J, Lang JA, Miller MW (1998) Transforming growth factor beta1 regulates the expression of cyclooxygenase in cultured cortical astrocytes and neurons. J Neurochem 71:526-534.

30. Marino-Buslje C, Martin-Martinez M, Mizuguchi K, Siddle K, Blundell TL (1999) The insulin receptor: from protein sequence to structure. Biochem Soc Trans 27:715-726.

31. Milkiewicz M, Brown MD, Egginton S, Hudlicka O (2001) Association between shear stress, angiogenesis, and VEGF in skeletal muscles in vivo. Microcirculation 8:229-241.

32. Pelegrinelli FF, Thirone AC, Gasparetti AL, Araujo EP, Velloso LA, Saad MJ (2001) Early steps of insulin action in the skin of intact rats. J Invest Dermatol 117:971-976.

33. Schramm JC, Dinh T, Veves A (2006) Microvascular changes in the diabetic foot. Int J Low Extrem Wounds 5:149-159. 
34. Shrader C, Ressetar HG, Luo J, Cilento EV, Reilly FD (2007) Acute Stretch Promotes Endothelial Cell Proliferation in Wounded Healing Mouse Skin. Arch Derm Res (In Press).

35. Sieminski AL, Gooch KJ (2000) Biomaterial-microvasculature interactions. Biomaterials 21:2232-2241.

36. Sundell J, Knuuti J (2003) Insulin and myocardial blood flow. Cardiovasc Res 57:312-319.

37. Ullrich A, Gray A, Tam AW, Yang-Feng T, Tsubokawa M, Collins C, Henzel W, LeBon T, Kathuria S, Chen E, Jacobs S, Francke U, Ramachandran J, FujitaYamaguchi Y (1986) Insulin-like growth factor 1 receptor primary structure: comparison with insulin receptor suggests structural determinants that define function specificity. EMBO J 5:2503-2512.

38.Wertheimer E, Trebicz M, Eldar T, Gartsbein M, Nofeh-Moses S, Tennenbaum T (2000) Differential roles of insulin receptor and insulin-like growth factor-1 receptor in differentiation of murine skin keratinocytes. J Invest Dermatol 115:24-29.

39. Xiaorui Y (2004) Involvement of Insulin/Phosphoinositide 3-Kinase/Akt Signal pathway in 17-estradiol-mediated neuroprotection. J Biol Chem279.

40. Zhu X, Hall D, Ridenour G, Boo S, Jennings T, Hochberg J, Cilento E, Reilly F (2003) A mouse model for studying rapic intraoperative methods of skin closure and wound healing. Med Sci Monit 9:109-115. 
41. Zhu Y, Luo J, Barker J, Hochberg J, Cilento E, Reilly F (2002) Identification of genes induced by rapid intraoperative tissue expansion in mouse skin. Arch Dermatol Res 293:560-568. 


\section{GENERAL DISCUSSION}

Most experimental models have elucidated mechanisms of endothelial cell migration and tubulogenesis as physiologically relevant models to study angiogenesis (Joung et al., 2006; Li et al., 2005). Vital knowledge of mechanisms that promote vascular growth is critical to treat human disease. Recent data demonstrate the importance of mechanical-chemical signaling that is transmitted throughout the endothelial cell and through extracellular matrix (ECM) adhesions on the surface of endothelium (Chau et al., 2002; Haas, 2002; Ingber, 2002; Joung et al., 2006; Shiu et al., 2005).

We have developed a novel in vivo approach utilizing acute mechanical stretch to investigate endothelial cell proliferation as a marker vascular growth in healing mouse skin (Badr et al., 2003; Brown et al., 2003; Munoz-Chapuli et al., 2002). This model has the following features: (1) the modulus of elasticity approximates the skin of the human face, (2) flowmetry demonstrates surgically created flaps are well perfused, (3) mechanical manipulation (acute stretch) drastically improves flap viability as assessed by decreases up to $75 \%$ in marginal tissue necrosis, (4) wounding alone (unstretched skin) enhances proliferation and protein kinase B expression, and (5) the dorsal distally based skin flap is a reliable model for studying wound closure.

These in vivo studies indicated a role for tissue insulin in enhanced EC proliferation and survival, coincident with increases in nutrient blood flow and improved tissue viability (Shrader et al., 2007; Zhu et al., 2002; Zhu et al., 2003). Therefore, our laboratory developed a novel in vitro approach using HUVECs to 
study the effects of insulin on proliferation and viability. Our cell culture model has the following features: (1) it allows investigation of EC proliferation and viability in a controlled, highly reproducible environment, (2) culture systems permit blockade studies that are lethal in animal models, (3) HUVECs express insulin receptors, allowing for the characterization of insulin signaling, and (4) these cells are easily cultured and maintained for experimentation and evaluation over a duration of several days.

In vitro investigations characterized the mechanism(s) triggering insulininduced intracellular signaling that promote mitogenesis and survival. The gap in knowledge was bridged by clarifying insulin's role in the reported benefits of mechanical stimulation (e.g. rapid stretch) in our murine model. Moreover, the data from cultured human cells confirmed the validity of data obtained from the animal model. Together they provided a framework for future in vitro studies that will explicate insulin's role, if any, in endothelial cell migration and tubulogenesis. Our important findings are described as follows:

- Mechanical stimulation enhances local flap perfusion and remote extracorporeal wound healing that is coincident with endothelial cell proliferation

Acute stretching of a surgically created skin flap in our SKH1 hairless mouse model improves viability and healing. As previously reported, increases up to $50 \%$ in blood flow and decreases of $75 \%$ in tissue necrosis were detected at post-operative day 5 (Zhu et al., 2003). After careful consideration of these results and a review of the literature, we chose to look at post-operative day 6 
and beyond to determine the optimal time point for maximal increases in flap perfusion. We discovered mechanical stimulation using acute stretch results in a maximal 3-fold increase in flap perfusion at post-operative day 7 . This observation was coincident with improved flap viability and healing.

Our laboratory became interested in the effects, if any, of acute stretch beyond the local area of application. This was accomplished by creating an unstretched wound on the animal in a location remote (extracorporal) to the stretched dorsal flap. Extracorporeal wounding of skin overlying the sternum exhibited a significant improvement in healing with complete remission prior to that seen in unstretched, wounded animals. This finding provided evidence that there are beneficial systemic effects of acute stretch beyond the localized site of application.

The next major challenge was determining the mechanism of stretchresponsive increases in flap perfusion. We hypothesized stretch-induced temporal increases in blood flow, optimal at post-operative day 7 , were a result of new vascular growth (arteriogenesis and angiogenesis). Endothelial cell proliferation was selected as a marker for these experiments (Badr et al., 2003; Brown et al., 2003; Munoz-Chapuli et al., 2002). Immunolabeling of endothelium specific factor VIII with proliferating cellular nuclear antigen (PCNA) was performed. These double-labeled immunohistochemical preparations revealed a 6-fold increase in endothelial cell proliferation at post-operative day 6 in acutely stretched skin. The results were confirmed by Western blot analysis of PCNA. 
These data support our hypothesis that acute stretch enhances endothelial cell mitogenesis by promoting increase vascularity in healing wounded skin.

- Mechanical stretch enhances up-regulation and activation of tissue insulin and angiogenic factors

Although advantages of skin stretching have been demonstrated both clinically and experimentally, the cellular and molecular mechanisms underlying these benefits are unknown (Neuman, 1957; Sasaki, 1987; Siegert et al., 1993). We have previously reported the up-regulation of tissue insulin mRNA in stretched skin (Zhu et al., 2002). It was unclear if this increased transcription was biologically significant. We hypothesized that acute stretch-induced endothelial cell proliferation was tissue insulin mediated through phosphoinositide-3 kinase (PI3-K) effectors, i.e., protein kinase B (Akt) and vascular endothelial growth factor (VEGF).

Using Western blot analysis, we confirmed the up-regulation of tissue insulin in response to acute stretch. Stretch also promoted activation of insulin receptor (pIR) and insulin growth factor receptor (pIGFR). Despite only a 40\% homology in insulin and insulin growth factor, both receptor types respond to insulin activation and are associated with mitogenic insulin signaling (Layton et al., 2006; Marino-Buslje et al., 1999). Our preliminary studies (unpublished observation) demonstrated that stretch does not alter endothelial expression of these receptors $(p \geq 0.05)$. However, stretch did significantly impact the activation of IR / IGFR. Immunolabeling with factor VIII and PCNA confirmed the presence and activation of these receptors on proliferating endothelium. The 
relatively large increases in receptor activity in immunolabeled tissue sections compared to Western blots indicate that endothelial cells are the predominant cell type expressing the activated insulin receptors. These data demonstrate that tissue insulin and its receptors are stretch-responsive and are located on mitotic endothelial cells. Moreover, these results support recent evidence demonstrating insulin's role as a key mitogenic regulator and indicate a biologically significant role for insulin in the observed benefits of acute stretch (Gordon, 2002; Kobayashi and Kamata, 2002; Linn et al., 2003; Pelegrinelli et al., 2001; Sundell and Knuuti, 2003; Wertheimer et al., 2000).

Angiogenesis has been shown to be mediated through PI3-K and downstream effectors Akt and VEGF (Chau et al., 2002; Haas, 2002; Ingber, 2002; Kanda et al., 2003; Kawaguchi et al., 2001; Xiaorui, 2004). We demonstrated that acute stretch up-regulates VEGF, VEGF receptor 2 (flk-1), and Akt, while enhancing activation (pAkt) of Akt. Therefore, acute stretch, unlike wounding alone, works through both VEGF and Akt. This could be the result of acute stretch-induced mechanical-chemical signaling that is transmitted throughout the endothelial cell and through extracellular matrix (ECM) adhesions (Chau et al., 2002; Haas, 2002; Ingber, 2002; Joung et al., 2006; Shiu et al., 2005). These results are coincident with the up-regulation of tissue insulin and receptor activation. These intracellular signaling events may serve as the link between stretch-induced insulin release and endothelial cell proliferation.

- Mechanical induction of protein expression and activation provides temporal support for insulin-mediated endothelial cell proliferation 
We hypothesized that acute stretch-induced endothelial cell proliferation is tissue insulin mediated through PI3-K effectors, i.e., Akt (pAkt) and VEGF. The temporal relationships among proteins up-regulated / activated by acute stretch provides further evidence that insulin activates it's receptors (pIR/pIGFR) and stimulates endothelial cell proliferation (indicated by PCNA) through PI3-K by Akt (pAkt), VEGF and flk-1 signaling in our in vivo mouse model.

- Insulin induces proliferation of HUVECs through IR / IGFR and PI3-K intracellular signaling Application of exogenous insulin over the physiological range induced significant dose-dependent increases in proliferation. These responses were attenuated with LY 294002 (PI3-K blockade), and with HNMPA (IR blockade) and tyrphostin 23 (IR / IGFR blockade). These results indicated that insulin, working through both IR / IGFR, stimulate endothelial cell proliferation by activating PI3-K effectors.

Since EC mitogenesis has been shown to be mediated through PI3-K and downstream effectors Akt and VEGF (Chau et al., 2002; Haas, 2002; Ingber, 2002; Kanda et al., 2003; Kawaguchi et al., 2001, Xiaorui, 2004), we hypothesized that insulin-induced increases in proliferation were mediated through PI3-K downstream effectors pAkt (Thr 308), pAkt (Ser 473), and VEGF. The optimal dose of insulin $(1.5 \mu \mathrm{M})$ was used to test this hypothesis. Western blots revealed activation of IR / IGFR. This response was not antagonized by PI3-K blockade. Although pAkt (Ser 473) played no role in insulin-induced proliferation, pAkt (Thr 308) activation and VEGF expression were confirmed and 
inhibited by LY 294002. These data demonstrated that insulin induces proliferation through IR / IGFR-provoked pAkt (Thr 308) and VEGF activation and up-regulation. They also support recent evidence attesting to insulin's role as a key mitogenic regulator and indicate a biologically significant role for insulin in vascular biology (Gordon et al., 2002; He et al., 2006; Kobayashi and Kamata, 2002; Linn, 2003; Pelegrinelli et al., 2001; Sundell and Knuuti, 2003; Wertheimer et al., 2000).

- Insulin enhances survival of HUVECs through IR / IGFR and PI3-K intracellular signaling

Application of exogenous insulin over the physiological range provoked significant dose-dependent increases in survival. These responses were attenuated with LY 294002 (PI3-K blockade) and with HNMPA (IR blockade) and tyrphostin 23 (IR / IGFR blockade). These results indicated that insulin, working through both IR / IGFR, enhances endothelial cell survival via PI3-K effectors.

PI3-K signaling promotes cell viability (i.e. survival) through downstream effectors, predominantly by activating Akt (Chau et al., 2002; Haas, 2002; Ingber, 2002; Kanda et al., 2003; Kawaguchi et al., 2001, Xiaorui, 2004). Therefore, we hypothesized that insulin increased survival through PI3-K downstream effectors pAkt (Thr 308), pAkt (Ser 473), and VEGF. The optimal dose of insulin (1.5 $\mu \mathrm{M})$, was used to conduct these experiments. Western blots revealed activation of pIR / pIGFR. This response was not antagonized by PI3-K blockade.

Simultaneous activation of pAkt (Thr 308) and pAkt (Ser 473) also was confirmed and blocked by LY 294002 verifying a role for both phosphorylated states of Akt 
in insulin signaling. In contrast to proliferation assay results, VEGF played no role in insulin-enhanced survival. These data demonstrated that insulin enhances EC viability through pAkt (Thr 308) and pAkt (Ser 473) up-regulation and activation. 


\section{References for Literature Review and General Discussion}

Adams,T.E., V.C.Epa, T.P.Garrett, and C.W.Ward. 2000. Structure and function of the type 1 insulin-like growth factor receptor. Cell Mol. Life Sci. 57:10501093.

Akita,S., T.Daian, H.Ishihara, T.Fujii, and K.Akino. 2004. Leukemia inhibitory factor-transfected embryonic fibroblasts and vascular endothelial growth factor successfully improve the skin substitute wound healing by increasing angiogenesis and matrix production. J. Dermatol. Sci. 36:1123.

Asayama,K., F.Nyfeler, D.English, S.J.Pilkis, and I.M.Burr. 1984. Alloxaninduced free radical production in isolated cells. Selective effect on islet cells. Diabetes 33:1008-1011.

Austad, E. D., Thomas, S. B. and Pasyk, K. A. 1986. Tissue expansion. Dividend or loan? Plast. Reconstr. Surg. 78:63-67.

Balestrini,J.L. and K.L.Billiar. 2005. Equibiaxial cyclic stretch stimulates fibroblasts to rapidly remodel fibrin. J. Biomech.

Bartell, T. H. and Mustoe, T. A. 1989. Animal models of human tissue expansion. Plast. Reconstr. Surg. 83:681-686.

Baserga,R. 1999. The IGF-I receptor in cancer research. Exp. Cell Res. 253:1-6.

Baserga,R. 2000. The contradictions of the insulin-like growth factor 1 receptor. Oncogene 19:5574-5581.

Bates,S.H., R.N.Kulkarni, M.Seifert, and M.G.Myers, Jr. 2005. Roles for leptin receptor/STAT3-dependent and -independent signals in the regulation of glucose homeostasis. Cell Metab 1:169-178.

Beeson,M., M.P.Sajan, M.Dizon, D.Grebenev, J.Gomez-Daspet, A.Miura, Y.Kanoh, J.Powe, G.Bandyopadhyay, M.L.Standaert, and R.V.Farese. 2003. Activation of protein kinase C-zeta by insulin and phosphatidylinositol-3,4,5-(PO4)3 is defective in muscle in type 2 diabetes and impaired glucose tolerance: amelioration by rosiglitazone and exercise. Diabetes 52:1926-1934.

Bermont,L., F.Lamielle, S.Fauconnet, H.Esumi, A.Weisz, and G.L.Adessi. 2000. Regulation of vascular endothelial growth factor expression by insulin-like growth factor-I in endometrial adenocarcinoma cells. Int. J. Cancer 85:117-123.

Bhushan,M., H.S.Young, P.E.Brenchley, and C.E.Griffiths. 2002. Recent advances in cutaneous angiogenesis. Br. J. Dermatol. 147:418-425. 
Bielenberg,D.R., C.D.Bucana, R.Sanchez, C.K.Donawho, M.L.Kripke, and I.J.Fidler. 1998. Molecular regulation of UVB-induced cutaneous angiogenesis. J. Invest Dermatol. 111:864-872.

Bravo,R. and H.donald-Bravo. 1987. Existence of two populations of cyclin/proliferating cell nuclear antigen during the cell cycle: association with DNA replication sites. J. Cell Biol. 105:1549-1554.

Brognard,J., A.S.Clark, Y.Ni, and P.A.Dennis. 2001. Akt/protein kinase B is constitutively active in non-small cell lung cancer cells and promotes cellular survival and resistance to chemotherapy and radiation. Cancer Res. 61:3986-3997.

Brown,D.L., C.D.Kane, S.D.Chernausek, and D.G.Greenhalgh. 1997. Differential expression and localization of insulin-like growth factors I and II in cutaneous wounds of diabetic and nondiabetic mice. Am. J. Pathol. 151:715-724.

Burgering,B.M. and P.J.Coffer. 1995. Protein kinase B (c-Akt) in phosphatidylinositol-3-OH kinase signal transduction. Nature 376:599-602.

Burri, P.H. 2004. Intussusceptive angiogenesis: its emergence, its characteristics, and its significance. Dev. Dyn. 231:474-488.

Byrne,A.M., D.J.Bouchier-Hayes, and J.H.Harmey. 2005. Angiogenic and cell survival functions of vascular endothelial growth factor (VEGF). J. Cell Mol. Med. 9:777-794.

Cantley,L.C. and B.G.Neel. 1999. New insights into tumor suppression: PTEN suppresses tumor formation by restraining the phosphoinositide 3kinase/AKT pathway. Proc. Natl. Acad. Sci. U. S. A 96:4240-4245.

Chai,J., M.K.Jones, and A.S.Tarnawski. 2004. Serum response factor is a critical requirement for VEGF signaling in endothelial cells and VEGFinduced angiogenesis. FASEB J. 18:1264-1266.

Chang,E., J.Yang, U.Nagavarapu, and G.S.Herron. 2002. Aging and survival of cutaneous microvasculature. J. Invest Dermatol. 118:752-758.

Chau,C.H., K.Y.Chen, H.T.Deng, K.J.Kim, K.Hosoya, T.Terasaki, H.M.Shih, and D.K.Ann. 2002. Coordinating Etk/Bmx activation and VEGF upregulation to promote cell survival and proliferation. Oncogene 21:88178829 .

Conway,E.M., D.Collen, and P.Carmeliet. 2001. Molecular mechanisms of blood vessel growth. Cardiovasc. Res. 49:507-521. 
Datta,K., T.F.Franke, T.O.Chan, A.Makris, S.I.Yang, D.R.Kaplan, D.K.Morrison, E.A.Golemis, and P.N.Tsichlis. 1995. AH/PH domainmediated interaction between Akt molecules and its potential role in Akt regulation. Mol. Cell Biol. 15:2304-2310.

Denizot,F. and R.Lang. 1986. Rapid colorimetric assay for cell growth and survival. Modifications to the tetrazolium dye procedure giving improved sensitivity and reliability. J. Immunol. Methods 89:271-277.

Detillieux,K.A., F.Sheikh, E.Kardami, and P.A.Cattini. 2003. Biological activities of fibroblast growth factor-2 in the adult myocardium. Cardiovasc. Res. 57:8-19.

Dickson,A.J. 1998. Apoptosis regulation and its applications to biotechnology. Trends Biotechnol. 16:339-342.

Ding, Y.H., X.D.Luan, J.Li, J.A.Rafols, M.Guthinkonda, F.G.Diaz. 2004. Exercise-induced overexpression of angiogenic factors and reduction of ischemia/reperfusion injury in stroke. Curr. Neurovasc. Res. 1:411-20.

Duraisamy,Y., M.Slevin, N.Smith, J.Bailey, J.Zweit, C.Smith, N.Ahmed, and J.Gaffney. 2001. Effect of glycation on basic fibroblast growth factor induced angiogenesis and activation of associated signal transduction pathways in vascular endothelial cells: possible relevance to wound healing in diabetes. Angiogenesis. 4:277-288.

Dvorak,H.F. 2005. Angiogenesis: update 2005. J. Thromb. Haemost. 3:18351842.

Ehlert, T. K., and J. R. Thomas. 1991. Rapid intraoperative tissue expansion for closure of facial defects. Arch. Otolaryngol. Head Neck Surg. 117:10431049.

Feldschuh,J. and Y.Enson. 1977. Prediction of the normal blood volume. Relation of blood volume to body habitus. Circulation 56:605-612.

Ferrara,N. 2002. Role of vascular endothelial growth factor in physiologic and pathologic angiogenesis: therapeutic implications. Semin. Oncol. 29:1014.

Franke,T.F., S.I.Yang, T.O.Chan, K.Datta, A.Kazlauskas, D.K.Morrison, D.R.Kaplan, and P.N.Tsichlis. 1995. The protein kinase encoded by the Akt proto-oncogene is a target of the PDGF-activated phosphatidylinositol 3-kinase. Cell 81:727-736.

Frantz,S., K.A.Vincent, O.Feron, and R.A.Kelly. 2005. Innate immunity and angiogenesis. Circ. Res. 96:15-26. 
Freeman,J., D.B.Kellock, C.C.Yu, J.Crocker, D.A.Levison, and P.A.Hall. 1993. Proliferating cell nuclear antigen (PCNA) and nucleolar organiser regions in Hodgkin's disease: correlation with morphology. J. Clin. Pathol. 46:446-449.

Fuchs,J., N.Groth, T.Herrling, and G.Zimmer. 1997. Electron paramagnetic resonance studies on nitroxide radical 2,2,5,5-tetramethyl-4-piperidin-1oxyl (TEMPO) redox reactions in human skin. Free Radic. Biol. Med. 22:967-976.

Gavin, T.P., C.B.Robinson, R.C.Yeager, J.A.England, L.W.Nifong, R.C.Hickner. 2004. Angiogenic growth factor response to acute systemic exercise in human skeletal muscle. J. App. Physiol. 96:19-24.

Garcia PB, Nieto CS, Ortega JMR. 1991. Morphological changes in the vascularization of delayed flaps in rabbits. Br. J. Plast. Surg. 44:285-90.

Gartner,M.H., J.D.Benson, and M.D.Caldwell. 1992. Insulin-like growth factors I and II expression in the healing wound. J. Surg. Res. 52:389-394.

Gerlier,D. and N.Thomasset. 1986. Use of MTT colorimetric assay to measure cell activation. J. Immunol. Methods 94:57-63.

Gibson, T. 1977. The physical properties of skin. Reconstructive Plastic Surgery (J. Converse, ed.) p. 69-77.

Gitay-Goren,H., T.Cohen, S.Tessler, S.Soker, S.Gengrinovitch, P.Rockwell, M.Klagsbrun, B.Z.Levi, and G.Neufeld. 1996. Selective binding of VEGF121 to one of the three vascular endothelial growth factor receptors of vascular endothelial cells. J. Biol. Chem. 271:5519-5523.

Gordon,S.R. 2002. Microfilament disruption in a noncycling organized tissue, the corneal endothelium, initiates mitosis. Exp. Cell Res. 272:127-134.

Goto, F., K.Goto, K.Weindel, J.Folkman. 1993. Synergistic effects of vascular endothelial growth factor and basic fibroblast growth factor on the proliferation and cord formation of bovine capillary endothelial cells within collagen gels. Lab. Inves. 69:508-517.

Greenbaum, S. S., and C. H. Greenbaum. 1990. Intraoperative tissue expansion using a foley catheter following excision of a basal cell carcinoma. $J$. Dermatol. Surg. Oncol. 16:45-48.

Greenbaum, S. S. 1993. Intraoperative tissue expansion with the foley catheter. J. Dermatol. Surg. Oncol. 19:1079-1083. 
Grzeszkiewicz,T.M., D.J.Kirschling, N.Chen, and L.F.Lau. 2001. CYR61 stimulates human skin fibroblast migration through Integrin alpha vbeta 5 and enhances mitogenesis through integrin alpha vbeta 3 , independent of its carboxyl-terminal domain. J. Biol. Chem. 276:21943-21950.

Grzeszkiewicz,T.M., V.Lindner, N.Chen, S.C.Lam, and L.F.Lau. 2002. The angiogenic factor cysteine-rich 61 (CYR61, CCN1) supports vascular smooth muscle cell adhesion and stimulates chemotaxis through integrin alpha(6)beta(1) and cell surface heparan sulfate proteoglycans. Endocrinology 143:1441-1450.

Guida, R. A., Cohen, J. I., Cook, T. A., Swanson, N. A., and R. Burgeson. 1993. Assessment of survival and microscopic changes in porcine skin flaps undergoing immediate intraoperative tissue expansion. Otolaryngol. Head Neck Surg. 109:926-932.

Haas,T.L., M.Milkiewicz, S.J.Davis, A.L.Zhou, S.Eggington, M.D.Brown, J.A.Madri, O.Hudlicka. 2000. Matrix metalloproteinases activity is required for activity-induced angiogenesis in rat skeletal muscle. Am. J. Physiol. Heart Circ. Physiol. 279:H1540-H1547.

Haas,T.L. 2002. Molecular control of capillary growth in skeletal muscle. Can. J. Appl. Physiol 27:491-515.

Hamed,G., C.S.Heffess, B.M.Shmookler, and B.M.Wenig. 1995. Amyloid goiter. A clinicopathologic study of 14 cases and review of the literature. Am. J. Clin. Pathol. 104:306-312.

Hammersen,F., B.Endrich, and K.Messmer. 1985. The fine structure of tumor blood vessels. I. Participation of non-endothelial cells in tumor angiogenesis. Int. J. Microcirc. Clin. Exp. 4:31-43.

Hansen,M.B., S.E.Nielsen, and K.Berg. 1989. Re-examination and further development of a precise and rapid dye method for measuring cell growth/cell kill. J. Immunol. Methods 119:203-210.

Hayward,C.P., E.M.Cramer, Z.Song, S.Zheng, R.Fung, J.M.Masse, R.H.Stead, and T.J.Podor. 1998. Studies of multimerin in human endothelial cells. Blood 91:1304-1317.

Hernandez-Sanchez,C., V.Blakesley, T.Kalebic, L.Helman, and D.LeRoith. 1995. The role of the tyrosine kinase domain of the insulin-like growth factor-I receptor in intracellular signaling, cellular proliferation, and tumorigenesis. J. Biol. Chem. 270:29176-29181.

Herve,M.A., H.Buteau-Lozano, S.Mourah, F.Calvo, and M.Perrot-Applanat. 2005. VEGF189 stimulates endothelial cells proliferation and migration in 
vitro and up-regulates the expression of Flk-1/KDR mRNA. Exp. Cell Res. 309:24-31.

Hinton,D.R., S.He, and P.F.Lopez. 1998. Apoptosis in surgically excised choroidal neovascular membranes in age-related macular degeneration. Arch. Ophthalmol. 116:203-209.

Hoang,M.V., M.C.Whelan, and D.R.Senger. 2004. Rho activity critically and selectively regulates endothelial cell organization during angiogenesis. Proc. Natl. Acad. Sci. U. S. A 101:1874-1879.

Hochberg,J., M.Raman, E.Cilento, K.Kemp, M.Barrett, R.Thomas, and F.Reilly. 1994. Development and evaluation of an in vivo mouse model for studying myocutaneous flap microcirculation and viability before and after suturing or stapling. Int. J. Microcirc. Clin. Exp. 14:67-72.

Hoeben,A., B.Landuyt, M.S.Highley, H.Wildiers, A.T.Van Oosterom, and E.A.De Bruijn. 2004. Vascular endothelial growth factor and angiogenesis. Pharmacol. Rev. 56:549-580.

Hong,R. and D.Chakravarti. 2003. The human proliferating Cell nuclear antigen regulates transcriptional coactivator p300 activity and promotes transcriptional repression. J. Biol. Chem. 278:44505-44513.

Hoyer,L.W. 1981. The factor VIII complex: structure and function. Blood 58:1-13.

Ilan,N., S.Mahooti, and J.A.Madri. 1998. Distinct signal transduction pathways are utilized during the tube formation and survival phases of in vitro angiogenesis. J. Cell Sci. 111 ( Pt 24):3621-3631.

Ingber,D.E. 2002. Mechanical signaling and the cellular response to extracellular matrix in angiogenesis and cardiovascular physiology. Circ. Res. 91:877887.

Johnson, T. M., L. Lowe, M. D. Brown, M. J. Sullivan, and B. R. Nelson. 1993. Histology and physiology of tissue expansion. J. Dermatol. Surg. Oncol. 19:1074-1078.

Joung,I.S., M.N.Iwamoto, Y.T.Shiu, and C.T.Quam. 2006. Cyclic strain modulates tubulogenesis of endothelial cells in a 3D tissue culture model. Microvasc. Res. 71:1-11.

Kanda,S., Y.Mochizuki, and H.Kanetake. 2003. Stromal cell-derived factor1 alpha induces tube-like structure formation of endothelial cells through phosphoinositide 3-kinase. J. Biol. Chem. 278:257-262.

Kawaguchi,M., K.Koshimura, M.Sohmiya, Y.Murakami, T.Gonda, and Y.Kato. 2001. Effect of insulin on nitric oxide synthase-like 
immunostaining of arteries in various organs in Zucker diabetic fatty rats. Eur. J. Endocrinol. 145:343-349.

Kim,Y.B., K.Kotani, T.P.Ciaraldi, R.R.Henry, and B.B.Kahn. 2003. Insulinstimulated protein kinase $C$ lambda/zeta activity is reduced in skeletal muscle of humans with obesity and type 2 diabetes: reversal with weight reduction. Diabetes 52:1935-1942.

Kindblom,L.G. 1982. Factor VIII related antigen and mast cells. Acta Pathol. Microbiol. Immunol. Scand. [A] 90:437-439.

Ko,J., J.Ross, H.Awad, H.Hurwitz, and B.Klitzman. 2005. The effects of ZD6474, an inhibitor of VEGF signaling, on cutaneous wound healing in mice. J. Surg. Res. 129:251-259.

Kobayashi,T. and K.Kamata. 2002. Short-term insulin treatment and aortic expressions of IGF-1 receptor and VEGF mRNA in diabetic rats. Am. J. Physiol Heart Circ. Physiol 283:H1761-H1768.

Kroll,J. and J.Waltenberger. 2000. Regulation of the endothelial function and angiogenesis by vascular endothelial growth factor-A (VEGF-A). $Z$. Kardiol. 89:206-218.

Kraus, R.M., H.W.Stallings, R.C.Yeager, T.P.Gavin. 2004. Circulating plasma VEGF response to exercise in sedentary and endurance-trained men. $J$. App. Physiol. 96:1445-1450.

Kuebler,W.M., U.Uhlig, T.Goldmann, G.Schael, A.Kerem, K.Exner, C.Martin, E.Vollmer, and S.Uhlig. 2003. Stretch activates nitric oxide production in pulmonary vascular endothelial cells in situ. Am. J. Respir. Crit Care Med. 168:1391-1398.

Kunz-Schughart,L.A., J.A.Schroeder, M.Wondrak, R.F.van, K.Lehle, F.Hofstaedter, and D.N.Wheatley. 2006. Potential of fibroblasts to regulate the formation of three-dimensional vessel-like structures from endothelial cells in vitro. Am. J. Physiol Cell Physiol 290:C1385-C1398.

Lam, A.C., Nguyen, Q.H., Tahery, D.P., Cohen, B.H., Sasaki, G. H., and Moy,

R.L. 1994. Decrease in skin-closing tension intraoperatively with suture tension reel, balloon expansion, and undermining. J. Dermatol. Surg. Oncol. 20:368371.

Layton C.J., Becker S., Osborne N.N. 2006. The effect of insulin and glucose level on retinal glial cell activation and pigment epithelium-derived fibroblast growth factor-2. Mol Vis 12:43-54.

Li,S., N.F.Huang, and S.Hsu. 2005. Mechanotransduction in endothelial cell migration. J. Cell Biochem. 96:1110-1126. 
Li,S. 2005. Analysis of endothelial cell migration under flow. Methods Mol. Biol. 294:107-121.

Lloyd, P.G., B.M.Prior, H.T.Yang, R.L.Terjung. 2003. Angiogenic growth factor expression in rat skeletal muscle in response to training. Am. J. Physiol. Heart Circ. Physiol. 284:1668-1678.

Luo,J., J.R.West, and N.J.Pantazis. 1996. Ethanol exposure reduces the density of the low-affinity nerve growth factor receptor (p75) on pheochromocytoma (PC12) cells. Brain Res. 737:34-44.

Luo,J., J.R.West, and N.J.Pantazis. 1996. Ethanol exposure reduces the density of the low-affinity nerve growth factor receptor (p75) on pheochromocytoma (PC12) cells. Brain Res. 737:34-44.

Luo,J. and M.W.Miller. 1997. Basic fibroblast growth factor- and platelet-derived growth factor-mediated cell proliferation in B104 neuroblastoma cells: effect of ethanol on cell cycle kinetics. Brain Res. 770:139-150.

Lynch,S.E., R.B.Colvin, and H.N.Antoniades. 1989. Growth factors in wound healing. Single and synergistic effects on partial thickness porcine skin wounds. J. Clin. Invest 84:640-646.

Machida,B.K., M.Liu-Shindo, G.H.Sasaki, D.H.Rice, and P.Chandrasoma. 1991. Immediate versus chronic tissue expansion. Ann. Plast. Surg. 26:227-231.

Mackay, D. R., Saggers, G. C., Kotwal, and Manders, E.K. 1990. Stretching skin: undermining is more important than intraoperative expansion. Plast. Reconstr. Surg. 86:722-730.

Marek,D.J., G.E.Copeland, M.Zlowodzki, and P.A.Cole. 2005. The application of dermatotraction for primary skin closure. Am. J. Surg. 190:123-126.

Marino-Buslje C., Martin-Martinez M., Mizuguchi K., Siddle K., Blundell T.L. 1999. The insulin receptor: from protein sequence to structure. Biochem Soc Trans 27:715-726.

McGuire, M. F. Studies of the Excisional Wound. I. 1980. Biomechanical effects of undermining and wound orientation on closing tension and work. Plast. Reconstr. Surg. 66:419-427.

Miller,D.W., S.Vosseler, N.Mirancea, D.J.Hicklin, P.Bohlen, H.E.Volcker, F.G.Holz, and N.E.Fusenig. 2005. Rapid vessel regression, protease inhibition, and stromal normalization upon short-term vascular endothelial growth factor receptor 2 inhibition in skin carcinoma heterotransplants. Am. J. Pathol. 167:1389-1403. 
Milton S.H. 1969. The effects of delay on the survival of experimental pedicled skin flaps. Br. J. Plast. Surg. 22:244-52.

Milton S.H. 1970. Pedicled skin flaps: the fallacy of the length:width ratio. $\mathrm{Br}$. J. Surg. 57:502-8.

Montagna, W. 1971. Cutaneous comparative biology. Arch. Der. 104:577-591.

Morris,A.E. and J.Schmid. 2000. Effects of insulin and LongR(3) on serum-free Chinese hamster ovary cell cultures expressing two recombinant proteins. Biotechnol. Prog. 16:693-697.

Mosmann,T. 1983. Rapid colorimetric assay for cellular growth and survival: application to proliferation and cytotoxicity assays. J. Immunol. Methods 65:55-63.

Munoz-Chapuli,R., M.Gonzalez-Iriarte, R.Carmona, G.Atencia, D.Macias, and J.M.Perez-Pomares. 2002. Cellular precursors of the coronary arteries. Tex. Heart Inst. J. 29:243-249.

Murohara,T. and T.Asahara. 2002. Nitric oxide and angiogenesis in cardiovascular disease. Antioxid. Redox. Signal. 4:825-831.

Murthy,S.S., A.Tosolini, T.Taguchi, and J.R.Testa. 2000. Mapping of AKT3, encoding a member of the Akt/protein kinase B family, to human and rodent chromosomes by fluorescence in situ hybridization. Cytogenet. Cell Genet. 88:38-40.

Nakatani,K., H.Sakaue, D.A.Thompson, R.J.Weigel, and R.A.Roth. 1999. Identification of a human Akt3 (protein kinase B gamma) which contains the regulatory serine phosphorylation site. Biochem. Biophys. Res. Commun. 257:906-910.

Nakatsu,M.N., R.C.Sainson, J.N.Aoto, K.L.Taylor, M.Aitkenhead, S.Perezdel-Pulgar, P.M.Carpenter, and C.C.Hughes. 2003. Angiogenic sprouting and capillary lumen formation modeled by human umbilical vein endothelial cells (HUVEC) in fibrin gels: the role of fibroblasts and Angiopoietin-1. Microvasc. Res. 66:102-112.

Neuman,C.A. 1957. The expansion of an area of skin by progressive distension of subcutaneous balloon. Plastic Reconstructive Surgery:124-130.

Odedra,R. and J.B.Weiss. 1987. A synergistic effect on microvessel cell proliferation between basic fibroblast growth factor (FGFb) and endothelial cell stimulating angiogenesis factor (ESAF). Biochem. Biophys. Res. Commun. 143:947-953. 
Oh,S.H., W.Y.Kim, J.H.Kim, M.N.Younes, A.K.El-Naggar, J.N.Myers, M.Kies, P.Cohen, F.Khuri, W.K.Hong, and H.Y.Lee. 2006. Identification of insulin-like growth factor binding protein-3 as a farnesyl transferase inhibitor SCH66336-induced negative regulator of angiogenesis in head and neck squamous cell carcinoma. Clin. Cancer Res. 12:653-661.

Olsen,L., J.A.Sherratt, P.K.Maini, and F.Arnold. 1997. A mathematical model for the capillary endothelial cell-extracellular matrix interactions in woundhealing angiogenesis. IMA J. Math. Appl. Med. Biol. 14:261-281.

Pai,R., I.L.Szabo, B.A.Soreghan, S.Atay, H.Kawanaka, and A.S.Tarnawski. 2001. PGE(2) stimulates VEGF expression in endothelial cells via ERK2/JNK1 signaling pathways. Biochem. Biophys. Res. Commun. 286:923-928.

Pasyk, K. A., Austad, E. E., McClutchey, K.D. and Cherry, G. W. 1982. Electron Microscopic Evaluation of pig skin and soft tissues expanded with a selfinflating silicone implant. Plast. Reconstr. Surg. 70:37-45.

Partovian,C. and M.Simons. 2004. Regulation of protein kinase B/Akt activity and Ser473 phosphorylation by protein kinase Calpha in endothelial cells. Cell Signal. 16:951-957.

Pelegrinelli,F.F., A.C.Thirone, A.L.Gasparetti, E.P.Araujo, L.A.Velloso, and M.J.Saad. 2001. Early steps of insulin action in the skin of intact rats. J. Invest Dermatol. 117:971-976.

Perona,R. 2006. Cell signalling: growth factors and tyrosine kinase receptors. Clin. Transl. Oncol. 8:77-82.

Piotrowicz,R.S., P.A.Maher, and E.G.Levin. 1999. Dual activities of 22-24 kDA basic fibroblast growth factor: inhibition of migration and stimulation of proliferation. J. Cell Physiol 178:144-153.

Poulaki,V., C.S.Mitsiades, C.McMullan, D.Sykoutri, G.Fanourakis, V.Kotoula, S.Tseleni-Balafouta, D.A.Koutras, and N.Mitsiades. 2003. Regulation of vascular endothelial growth factor expression by insulin-like growth factor I in thyroid carcinomas. J. Clin. Endocrinol. Metab 88:5392-5398.

Powers,C.J., S.W.McLeskey, and A.Wellstein. 2000. Fibroblast growth factors, their receptors and signaling. Endocr. Relat Cancer 7:165-197.

Prior, B.M., H.T.Yang, R.L.Terjung. 2004. What makes vessels grow with exercise training? J. App. Physiol. 97:1119-1128.

Radovan, C. 1979. Development of adjacent flaps using a temporary expander. Plast. Reconstr. Forum 2:62. 
Roesel,J.F. and L.B.Nanney. 1995. Assessment of differential cytokine effects on angiogenesis using an in vivo model of cutaneous wound repair. $J$. Surg. Res. 58:449-459.

Rommel,C., B.A.Clarke, S.Zimmermann, L.Nunez, R.Rossman, K.Reid, K.Moelling, G.D.Yancopoulos, and D.J.Glass. 1999. Differentiation stage-specific inhibition of the Raf-MEK-ERK pathway by Akt. Science 286:1738-1741.

Sakai,S., Y.Endo, N.Ozawa, T.Sugawara, A.Kusaka, T.Sayo, H.Tagami, and S.Inoue. 2003. Characteristics of the epidermis and stratum corneum of hairless mice with experimentally induced diabetes mellitus. J. Invest Dermatol. 120:79-85.

Sasaki,G.H. 1987. Intraoperative sustained limited expansion (ISLE) as an immediate reconstructive technique. Clin. Plast. Surg. 14:563-573.

Scheidegger,K.J., B.Cenni, D.Picard, and P.Delafontaine. 2000. Estradiol decreases IGF-1 and IGF-1 receptor expression in rat aortic smooth muscle cells. Mechanisms for its atheroprotective effects. J. Biol. Chem. 275:38921-38928.

Schumacher,R., M.A.Soos, J.Schlessinger, D.Brandenburg, K.Siddle, and A.Ullrich. 1993. Signaling-competent receptor chimeras allow mapping of major insulin receptor binding domain determinants. J. Biol. Chem. 268:1087-1094.

Senger,D.R., C.A.Perruzzi, M.Streit, V.E.Koteliansky, A.R.de Fougerolles, and M.Detmar. 2002. The alpha(1)beta(1) and alpha(2)beta(1) integrins provide critical support for vascular endothelial growth factor signaling, endothelial cell migration, and tumor angiogenesis. Am. J. Pathol. 160:195-204.

Shapiro, A. L., M. Hochman, J. R. Thomas, and G. Brantham. 1996. Effects of intraoperative tissue expansion and skin flaps on wound closing tensions. Arch. Otolaryngol. Head Neck Surg. 122:1107-1111.

Shiu,Y.T., J.A.Weiss, J.B.Hoying, M.N.Iwamoto, I.S.Joung, and C.T.Quam. 2005. The role of mechanical stresses in angiogenesis. Crit Rev. Biomed. Eng 33:431-510.

Shrader C., H.G.Ressetar, J.Luo, E.V.Cilento, F.D.Reilly. 2007. Acute stretch promotes endothelial cell proliferation in wounded healing mouse skin. Arch Derm Res (In Press). 
Shukla,A., A.R.Dunn, M.A.Moses, and K.J.Van Vliet. 2004. Endothelial cells as mechanical transducers: enzymatic activity and network formation under cyclic strain. Mech. Chem. Biosyst. 1:279-290.

Siegert,R., H.Weerda, S.Hoffmann, and C.Mohadjer. 1993. Clinical and experimental evaluation of intermittent intraoperative short-term expansion. Plast. Reconstr. Surg. 92:248-254.

Skalak,T.C. 2005. Angiogenesis and microvascular remodeling: a brief history and future roadmap. Microcirculation 12:47-58.

Slevin,M., S.Kumar, and J.Gaffney. 2002. Angiogenic oligosaccharides of hyaluronan induce multiple signaling pathways affecting vascular endothelial cell mitogenic and wound healing responses. J. Biol. Chem. 277:41046-41059.

Soos,M.A., C.E.Field, R.Lammers, A.Ullrich, B.Zhang, R.A.Roth, A.S.Andersen, T.Kjeldsen, and K.Siddle. 1992. A panel of monoclonal antibodies for the type I insulin-like growth factor receptor. Epitope mapping, effects on ligand binding, and biological activity. J. Biol. Chem. 267:12955-12963.

Soos,M.A., C.E.Field, and K.Siddle. 1993. Purified hybrid insulin/insulin-like growth factor-I receptors bind insulin-like growth factor-I, but not insulin, with high affinity. Biochem. J. 290 ( Pt 2):419-426.

Soos,M.A., B.T.Nave, and K.Siddle. 1993. Immunological studies of type I IGF receptors and insulin receptors: characterisation of hybrid and atypical receptor subtypes. Adv. Exp. Med. Biol. 343:145-157.

Stephan,C.C. and T.A.Brock. 1996. Vascular endothelial growth factor, a multifunctional polypeptide. P. R. Health Sci. J. 15:169-178.

Sundell,J. and J.Knuuti. 2003. Insulin and myocardial blood flow. Cardiovasc. Res. 57:312-319.

Susuki S, Isshiki N, Ogawa Y, Goto M, Hayashi O. 1986. The minimal requirement of circulation for survival of undelayed and delayed flaps in rats. Plast.Reconstr. Surg. 78:221-6.

Tada,H., O.Shiho, K.Kuroshima, M.Koyama, and K.Tsukamoto. 1986. An improved colorimetric assay for interleukin 2. J. Immunol. Methods 93:157-165.

Takahashi,H., M.Numasaki, M.T.Lotze, and H.Sasaki. 2005. Interleukin-17 enhances bFGF-, HGF- and VEGF-induced growth of vascular endothelial cells. Immunol. Lett. 98:189-193. 
Takasaki,Y., D.Fishwild, and E.M.Tan. 1984. Characterization of proliferating cell nuclear antigen recognized by autoantibodies in lupus sera. J. Exp. Med. 159:981-992.

Taub,D.D. and J.J.Oppenheim. 1994. Chemokines, inflammation and the immune system. Ther. Immunol. 1:229-246.

Tavarez-Pagan,J.J., C.M.Oliveira, and D.K.Banerjee. 2004. Insulin upregulates a Glc3Man9GlcNAc2-PP-Dol pool in capillary endothelial cells not essential for angiogenesis. Glycoconj. J. 20:179-188.

Thurston, G. 2003. Role of angiopoietins and tie receptor tyrosine kinases in angiogenesis and lymphangiogenesis. Cell Tissue Res. 314:61-68.

Trabucchi,E., E.Radaelli, M.Marazzi, D.Foschi, M.Musazzi, A.M.Veronesi, and W.Montorsi. 1988. The role of mast cells in wound healing. Int. J. Tissue React. 10:367-372.

Turinsky,J. and A.mrau-Abney. 1999. Akt kinases and 2-deoxyglucose uptake in rat skeletal muscles in vivo: study with insulin and exercise. Am. J. Physiol 276:R277-R282.

Ullrich A., Gray A., Tam A.W., Yang-Feng T., Tsubokawa M., Collins C., Henzel W., LeBon T., Kathuria S., Chen E., Jacobs S., Francke U., Ramachandran J., Fujita-Yamaguchi Y. 1986. Insulin-like growth factor 1 receptor primary structure: comparison with insulin receptor suggests structural determinants that define function specificity. EMBO J 5:25032512.

Unger,R.E., K.Peters, Q.Huang, A.Funk, D.Paul, and C.J.Kirkpatrick. 2005. Vascularization and gene regulation of human endothelial cells growing on porous polyethersulfone (PES) hollow fiber membranes. Biomaterials 26:3461-3469.

Vander Kolk,C.A., J.J.McCann, K.R.Knight, and B.M.O'Brien. 1987. Some further characteristics of expanded tissue. Clin. Plast. Surg. 14:447-453.

Von Offenberg,S.N., P.M.Cummins, E.J.Cotter, P.A.Fitzpatrick, Y.A.Birney, E.M.Redmond, and P.A.Cahill. 2005. Cyclic strain-mediated regulation of vascular endothelial cell migration and tube formation. Biochem. Biophys. Res. Commun. 329:573-582.

Wada,H., M.Matsuo, A.Uenaka, N.Shimbara, K.Shimizu, and E.Nakayama. 1995. Rejection antigen peptides on BALB/c RL male 1 leukemia recognized by cytotoxic $T$ lymphocytes: derivation from the normally untranslated 5 ' region of the c-akt proto-oncogene activated by long terminal repeat. Cancer Res. 55:4780-4783. 
Waseem,N.H. and D.P.Lane. 1990. Monoclonal antibody analysis of the proliferating cell nuclear antigen (PCNA). Structural conservation and the detection of a nucleolar form. J. Cell Sci. 96 ( Pt 1):121-129.

Wechsler,H.L. and E.R.Fisher. 1978. Pathologic investigation of cutaneous stretch. Int. J. Dermatol. 17:726-731.

Weihua,Z., R.Tsan, A.J.Schroit, and I.J.Fidler. 2005. Apoptotic cells initiate endothelial cell sprouting via electrostatic signaling. Cancer Res. 65:11529-11535.

Wenig,B.M., S.L.Abbondanzo, and C.S.Heffess. 1994. Epithelioid angiosarcoma of the adrenal glands. A clinicopathologic study of nine cases with a discussion of the implications of finding "epithelial-specific" markers. Am. J. Surg. Pathol. 18:62-73.

Wertheimer,E., M.Trebicz, T.Eldar, M.Gartsbein, S.Nofeh-Moses, and T.Tennenbaum. 2000. Differential roles of insulin receptor and insulin-like growth factor-1 receptor in differentiation of murine skin keratinocytes. J. Invest Dermatol. 115:24-29.

West,M.J., L.Slomianka, and H.J.Gundersen. 1991. Unbiased stereological estimation of the total number of neurons in thesubdivisions of the rat hippocampus using the optical fractionator. Anat. Rec. 231:482-497.

White,M.F., S.Takayama, and C.R.Kahn. 1985. Differences in the sites of phosphorylation of the insulin receptor in vivo and in vitro. J. Biol. Chem. 260:9470-9478.

White,M.F., S.E.Shoelson, H.Keutmann, and C.R.Kahn. 1988. A cascade of tyrosine autophosphorylation in the beta-subunit activates the phosphotransferase of the insulin receptor. J. Biol. Chem. 263:2969-2980.

Wiedlocha,A. and V.Sorensen. 2004. Signaling, internalization, and intracellular activity of fibroblast growth factor. Curr. Top. Microbiol. Immunol. 286:4579.

Woods,A.L., P.A.Hall, N.A.Shepherd, A.M.Hanby, N.H.Waseem, D.P.Lane, and D.A.Levison. 1991. The assessment of proliferating cell nuclear antigen (PCNA) immunostaining in primary gastrointestinal lymphomas and its relationship to histological grade, $\mathrm{S}+\mathrm{G} 2+\mathrm{M}$ phase fraction (flow cytometric analysis) and prognosis. Histopathology 19:21-27.

Xiaorui,Y. 2004. Involvement of Insulin/Phosphoinositide 3-Kinase/Akt Signal pathway in 17-estradiol-mediated neuroprotection. J. Biol. Chem.:279.

Zhu,X., D.Hall, G.Ridenour, S.Boo, T.Jennings, J.Hochberg, E.Cilento, and F.D.Reilly. 2003. A mouse model for studying rapid intraoperative 
methods of skin closure and wound healing. Med. Sci. Monit. 9:BR109BR115.

Zhu,Y., J.Luo, J.Barker, J.Hochberg, E.Cilento, and F.Reilly. 2002. Identification of genes induced by rapid intraoperative tissue expansion in mouse skin. Arch. Dermatol. Res. 293:560-568.

Zimmermann,S. and K.Moelling. 1999. Phosphorylation and regulation of Raf by Akt (protein kinase B). Science 286:1741-1744. 


\section{Carl D. Shrader Jr.}

Business Address: Department of Neurobiology and Anatomy

P.O. Box 9128, Robert C. Byrd Health Sciences Center

West Virginia University

Morgantown, WV 26505-9128

Phone: (304) 293-2212

Fax: (304) 293-8159

e-mail: cshrader@hsc.wvu.edu

\section{Professional Position}

2002-Present

Graduate Research Assistant

Department of Neurobiology and Anatomy

West Virginia University, Morgantown, WV

\section{Education}

WV Wesleyan College, $\quad$ B.S. $\quad$ Chemistry 1999

Buckhannon, WV

West Virginia University, Ph.D. Anatomy in progress Morgantown, WV

\section{Research Interests}

- Mechanisms promoting wound healing

- Insulin-induced mitogenic signal transduction

- Regulation of endothelial cell activity

- Expression and action of angiogenic mediators

- Mechanotransduction

\section{Participation in Scientific Meetings}

FASEB, Experimental Biology Annual Meeting, Washington, D.C., 2004 FASEB, Experimental Biology Annual Meeting, San Diego, CA, 2005 FASEB, Experimental Biology Annual Meeting, San Francisco, 2006 FASEB, Experimental Biology Annual Meeting, Washington, D.C., 2007 


\section{Honors and Awards}

Medical Scientist Scholars Recipient 1999

Summa Cum Laude, WVWC 1999

ACS Outstanding Senior Chemist 1999

Beta Beta Beta 1997

Nicholas Hyma Scholar $\quad 1997$

Alpha Lambda Delta 1996

WVWC Academic Scholar 1995

\section{Membership}

Microcirculatory Society (since 2005)

\section{Publications}

Manuscripts

1. Shrader, C., H. G. Ressetar, J. Luo, E. V. Cilento, and F. D. Reilly. Acute Stretch promotes endothelial cell proliferation in wounded healing mouse skin. Arch. Derm. Res. (submitted).

2. Shrader, C., K. M. Bailey, G. W. Konat, E. V. Cilento, and F. D. Reilly. Insulin induces enhanced proliferation and viability of human umbilical vein endothelial cells (HUVECs). Microvasc. Res. (submitted).

\section{$\underline{\text { Abstracts }}$}

1. Shrader, C., J. Luo, E. Cilento, and F. Reilly. Insulin 1 - a stretch-responsive gene-specific protein in the skin. FASEB J., 18(4): A260(197.31), 2004.

2. Shrader, C., J. Luo, H. Ressetar, E. Cilento, and F. Reilly. Acute stretch triggers mitogenesis in healing mouse skin. FASEB J., 19(4): A1270(693.5), 2005.

3. Shrader, C., M. Prescott, J. Luo, E. Cilento, and F. Reilly. Acute stretch Enhances expression of Akt and VEGF in healing mouse skin. FASEB J., 20(4): A709(461.2), 2006.

4. Shrader, C., H. Ressetar, J. Luo, E. Cilento, and F. Reilly. Stretch responsive tissue insulin-induced angiogenesis in wounded healing mouse skin. FASEB J., 21(5): A527(601.6), 2007. 